$$
\text { MAURÍCIO MIRIAN }
$$

Avaliação comparativa do grau de esforço e condição cardíaca em cavalos árabes e mestiços árabes submetidos a treinamento de resistência, avaliados através de teste de esforço máximo em esteira

São Paulo 


\section{Avaliação comparativa do grau de esforço e condição cardíaca em cavalos árabes e mestiços árabes submetidos a treinamento de resistência, avaliados através de teste de esforço máximo em esteira.}

Tese apresentada ao Programa de Pós-Graduação em Clínica Veterinária da Faculdade de Medicina Veterinária e Zootecnia da Universidade de São Paulo para obtenção do título de Doutor em Ciências

Departamento:

Clínica Médica

Área de Concentração:

Clínica Veterinária

Orientador:

Prof. Dr. Wilson Roberto Fernandes 
Autorizo a reprodução parcial ou total desta obra, para fins acadêmicos, desde que citada a fonte.

DADOS INTERNACIONAIS DE CATALOGAÇÃO-NA-PUBLICAÇÃO

(Biblioteca Virginie Buff D’Ápice da Faculdade de Medicina Veterinária e Zootecnia da Universidade de São Paulo)

Mirian, Maurício

Avaliação comparativa do grau de esforço e condição cardíaca em cavalos árabes e mestiços árabes submetidos a treinamento de resistência, avaliados através de teste de esforço máximo em esteira / Maurício Mirian. -- 2014

103 f. : il.

Tese (Doutorado) - Universidade de São Paulo. Faculdade de Medicina Veterinária e Zootecnia. Departamento de Clínica Médica, São Paulo, 2014.

Programa de Pós-Graduação: Clínica Veterinária.

Área de concentração: Clínica Veterinária.

Orientador: Prof. Dr. Wilson Roberto Fernandes.

1. Equinos. 2. Teste de esforço. 3. Adaptação cardíaca. 4. Treinamento. 5. Exercício. I. Título. 


\section{FACULDADE DE MEDICINA VETERINÁRIA E ZOOTECNIA}

\section{Comissão de Ética no Uso de Animais
CERTIFICADO}

Certificamos que o Projeto intitulado "Avaliação comparativa do grau de esforço e condição cardíaca em cavalos árabes e mestiços árabes submetidos a treinamento de resistência, avaliados através de teste de esforço máximo em esteira", protocolado sob o $\mathrm{n}^{\circ} 1741 / 2009$, utilizando 20 (vinte) cavalos, sob a responsabilidade do Prof. Dr. Wilson Roberto Fernandes, está de acordo com os princípios éticos de experimentação animal da Comissão de Bioética da Faculdade de Medicina Veterinária e Zootecnia da Universidade de São Paulo e foi aprovado em reunião de 19 de agosto de 2009.

São Paulo, 18 de março de 2014

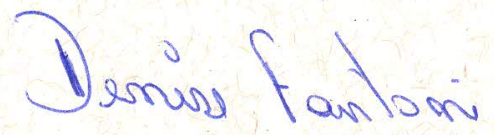

Profa Dra Denise Tabacchi Fantoni

Presidente da Comissão de Bioética FMVZ/USP 


\section{FOLHA DE AVALIAÇÃO}

Nome: MIRIAN, Maurício

Título: Avaliação comparativa do grau de esforço e condição cardíaca em cavalos árabes e mestiços árabes submetidos a treinamento de resistência, avaliados através de teste de esforço máximo em esteira.

Tese apresentada ao Programa de Pós-Graduação em Clínica Veterinária da Faculdade de Medicina Veterinária e Zootecnia da Universidade de São Paulo para obtenção do título de Doutor em Ciências

Data:

\section{Banca Examinadora}

$\operatorname{Prof(a).~Dr(a).~}$

Instituição: Julgamento:

$\operatorname{Prof}(\mathrm{a}) . \operatorname{Dr}(\mathrm{a})$.

Instituição: Julgamento:

Prof(a). Dr(a).

Instituição: Julgamento:

$\operatorname{Prof(a).~Dr(a).~}$

Instituição: Julgamento:

Prof(a). Dr(a).

Instituição: Julgamento: 
“Haverá um dia em que o homem conhecerá o íntimo do animal, neste dia, um crime contra um animal será considerado um crime contra a humanidade" 


\section{AGRADECIMENTOS}

Primeiro queria agradecer a DEUS, NOSSA SENHORA APARECIDA, SÃO JUDAS e SÃO FRANCISCO DE ASSIS, por me guiarem e iluminarem meu caminho nessa vida;

A minha esposa Angela por me apoiar sempre em todas as minhas decisões me dando força e sendo meu porto seguro todos os dias;

A Giulia minha filha tão esperada e amada que hoje é a razão do meu viver;

Agradecer também aos meus pais Mauro e Alexandra e irmão Marcio, minha avó Dona Ada, meu sogro Paulo e minhas sogras Marcia e Cida, meus cunhados Karina e Marcelo por me apoiarem e me incentivarem na conclusão dessa dissertação.

Ao professor Wilson, que me orientou e me deu condições de crescer como profissional e como pessoa me aguentando no mestrado, no doutorado com todas as intercorrências que passamos, umas por nossas culpas e outras por forças maiores mas que no final superamos e aqui estamos,

Não posso me esquecer de agradecer do fundo do meu coração aqueles que me ajudaram e que sem eles seria quase que impossível à conclusão da parte prática desse trabalho: Thiago, Carolina, Patrícia, Sandro, Maria Letícia, Paulo (Todos pós graduandos orientados também do prof. Wilson), Marilene, Caio, Fernanda, Cristina (Pós Graduandos do departamento de cirurgia), as alunas de iniciação científica Carolina e Renata, ao Júlio, todos os 
funcionários do hospital, a todos os residentes e estagiários que passaram pelo hospital nesse período todo sem vocês jamais teria conseguido ter feito a esteira funcionar e coletar todos os dados para essa tese;

Ao Dr. Gerson e ao Dr. Guilherme que disponibilizaram alguns de seus animais que iriam entrar em treinamento para que pudessem vir para São Paulo e serem avaliados na esteira, alterando a rotina de treinos totalmente por 7 dias a cada 3 meses.

A todas as meninas dos laboratórios. A Sabrina e Clara por terem paciência em me ensinar a pipetar e ajudar a resolver os problemas burocráticos para compra de Kits de reagentes, fornecedores, a Malu e Mau por me aguentarem no Laboratório de Hematologia com varias amostras atrapalhando toda a rotina, a Marli no laboratório de Bioquímica mais uma vez atrapalhando a rotina e enchendo de amostrar o aparelho de hemogasometria tão temperamental que em algumas ocasiões se negava a processar as amostras.

A todos os professores do Hospital que me ensinaram muito nesses quatro anos de convivência quase que diária. Luiz, André, Carla, Raquel, Stefano, Denise, Aline, muito obrigado por me ajudarem a sair um veterinário melhor do que quando entrei, mas a muitos anos-luz atrás do que vocês são.

Marquinhos muito obrigado por toda ajuda nesse quatro anos de tese,Passamos por poucas e boas até mesmo quando a esteira "resolveu se suicidar" se afogando em lama....... cara se não fosse por você nem meu projeto nem o hospital andaria direito. Rosendo, Gerva sem vocês estaria perdido também. 
Espero não ter me esquecido de citar o nome de ninguém, mas se esqueci me desculpem. Vocês também foram muito importantes para a realização dessa tese.

Do fundo do Coração

MUITO OBRIGADO!! 


\section{RESUMO}

MIRIAN, M. Avaliação comparativa do grau de esforço e condição cardíaca em cavalos árabes e mestiços árabes submetidos a treinamento de resistência, avaliados através de teste de esforço máximo em esteira. [Comparative assessment of the degree of effort and heart condition in Arab horses and crossbred Arab subjected to resistance training, evaluated by maximal exercise test on treadmill]. 2014. 103 f. Tese (Doutorado em Ciências) Faculdade de Medicina Veterinária e Zootecnia, Universidade de São Paulo, São Paulo, 2014

As modalidades esportivas equestres exigem cada vez mais cavalos com alto desempenho. Portanto o conhecimento das principais adaptações dos sistemas envolvidos na melhora do desempenho (muscular, pulmonar e cardiocirculatório) se faz necessário. Há diversos estudos na literatura sobre a adaptação do sistema muscular e respiratório em equinos, porém os poucos estudos existentes que envolvam o sistema cardiocirculatório durante o exercício referem-se apenas a alterações de ritmo. O número de trabalhos científios é ainda mais escasso quando se pesquisa a interação do treinamento físico com o sistema cardiocirculatório. O presente estudo tem por objetivo caracterizar as principais alterações cardiocirculatórias decorrentes da prática de atividade física contínua em intensidade leve a moderada por um período de 90 dias de treinamento aeróbico. Para isso foram avaliados nove equinos, da raça Árabe e Cruzados Árabes, machos ou fêmeas, adultos, em início das atividades de treinamento para prática de enduro, sendo cinco treinados a campo e quatro treinados em esteira de velocidade a $60 \%$ da frequência cardíaca máxima por 90 dias. Podemos concluir no presente estudo que o treinamento aeróbico num período de 90 dias já é suficiente para promover hipertrofia da parede livre do ventrículo esquerdo melhorando a força de contração cardíaca. Essa, por sua vez, permite o aumento do volume ejetado pelo ventrículo esquerdo tendo como consequência um melhor fornecimento de oxigênio e nutrientes para a musculatura que está sendo utilizada para a atividade física levando a melhora dos parâmetros de desempenho (lactato, limiar de lactato, FC, V200, $\mathrm{PCO}_{2}$ ). No mesmo período se observa a diminuição da FC tanto de repouso como durante a prática de atividade física e diminuição do DC, PAS e PAM. Os resultados sugerem que assim como observado em ratos e em atletas a diminuição da PAS se dá pela diminuição do DC por ação do cronotropismo negativo.

Palavras-chave: Equinos. Teste de esforço. Adaptação cardíaca. Treinamento. Exercício. 


\begin{abstract}
MIRIAN, M. Comparative assessment of the degree of effort and heart condition in arab horses and crossbred arab subjected to resistance training, evaluated by maximal exercise test on treadmill [Avaliação comparativa do grau de esforço e condição cardíaca em cavalos árabes e mestiços árabes submetidos a treinamento de resistência, avaliados através de teste de esforço máximo em esteira]. 2014. 103 f. Tese (Doutorado Ciências) - Faculdade de Medicina Veterinária e Zootecnia, Universidade de São Paulo, São Paulo, 2014

Equestrian sports are increasingly demanding high performance horses. Therefore the knowledge of the main adaptations of the systems involved in the improvement of performance (muscle, lung and cardiocirculatory) is required. There are several studies in the literature on the adaptation of muscle and respiratory system in horses, but the few studies involving the cardio-circulatory system during exercise refers only to arrhythmic events. The number of studies is even sparse when researching the interaction of physical training with the cardiocirculatory system. The present study aims to characterize the main cardiovascular changes resulting from the practice of continuous physical activity in mild to moderate for a period of 90 days of aerobic training intensity. Nine horses were evaluated, arab and crusader arab breed, male or female, adult, in the beginning of training activities for practicing endurance, five trained to field and four trained treadmill speed at $60 \%$ of maximum heart rate for 90 days. We can conclude in this study that aerobic training within 90 days is enough to promote hypertrophy of the free wall of the left ventricle to improve the strength of cardiac contraction. This improvement increases the volume ejected by the left ventricle resulting in a better supply of oxygen and nutrients to the muscles being used for physical activity leading to improvement in performance parameters (lactate, lactate threshold, FC, V200, PCO2). In the same period we observe a decrease in heart rate both at rest and during physical activity and decreased DC, SBP and MBP. The results suggest that as observed in rats and athletes decreased SBP occurs by decreasing the DC for the negative chronotropic action.
\end{abstract}

Key-words: Equine. Effort test. Cardiac adaptation. Training. Excercise. 


\section{LISTA DE ABREVIATURAS E SIGLAS}

\begin{tabular}{|c|c|}
\hline Aod & Diâmetro da raiz aórtica \\
\hline bpm & Batimentos por Minuto \\
\hline CK & Creatinina Fosfoquinase \\
\hline $\mathrm{cm}$ & Centímetros \\
\hline $\mathrm{DC}$ & Débito cardíaco \\
\hline DIVD & Diâmetro Interno do Ventrículo Direito \\
\hline DIVE & Diâmetro Interno do Ventrículo Esquerdo \\
\hline $\mathrm{dl}$ & Decilitros \\
\hline FE & fração de ejeção \\
\hline $\mathrm{FC}$ & Freqüência cardíaca \\
\hline FCmáx & Freqüência cardíaca máxima \\
\hline FS & Fração de encurtamento do ventrículo esquerdo \\
\hline $\mathrm{G}$ & Gauge \\
\hline g & Gramas \\
\hline h & Horas \\
\hline $\mathrm{H}^{+}$ & Hidrogênio molecular \\
\hline Hto & Hematócrito \\
\hline $\mathrm{Kg}$ & Quilograma \\
\hline $\mathrm{Km}$ & Quilômetros \\
\hline 1 & Litros \\
\hline LDH & Lactato desidrogenase \\
\hline $\mathrm{m}$ & Metros \\
\hline $\mathrm{Mg}$ & Miligramas \\
\hline $\min$ & Minutos \\
\hline $\mathrm{ml}$ & Mililitros \\
\hline Mmol & Milimol \\
\hline PAD & Pressão Arterial Diastólica \\
\hline PAM & Pressão Arterial Média \\
\hline PAS & Pressão Arterial Sistólica \\
\hline
\end{tabular}




$\begin{array}{ll}\mathrm{pH} & \text { Concentração de íons hidrogênio de uma solução } \\ \mathrm{Pi} & \text { Fosforo inorgânico } \\ \text { PLVE } & \text { Parede livre do ventrículo esquerdo } \\ \mathrm{PV} & \text { Peso vivo } \\ \mathrm{RVP} & \text { Resistencia Vascular Periférica } \\ \text { TPC } & \text { Tempo de Preenchimento Capilar } \\ \mathrm{s} & \text { Segundos } \\ \text { SIV } & \text { Septo intraventricular } \\ \text { T0 } & \text { Teste Inicial } \\ \text { T1 } & \text { Teste após } 90 \text { dias de treinamento } \\ \text { V } & \text { Volume do ventrículo esquerdo } \\ \text { V200 } & \text { Velocidade do teste que o animal atinge 200 batimentos } \\ \text { VHCM } & \text { cardíacos por minuto } \\ \text { VO2 } & \text { Hemoglobina corpuscular médio } \\ \text { VO } & \text { Consumo de Oxigênio }\end{array}$




\section{LISTA DE SIMBOLOS}

$\begin{array}{ll}\% & \text { Porcentagem } \\ + & \text { Adição } \\ \circledR & \text { Marca Registrada } \\ \leq & \text { Menor ou Igual } \\ = & \text { Igual } \\ \mathrm{X} & \text { Multiplicação } \\ \pm & \text { Mais ou menos } \\ \text { / } & \text { Por }\end{array}$




\section{LISTA DE TABELAS}

Tabela 1- Valores da frequência cardíaca obtidos no teste progressivo escalonado de esforço máximo inicial - São Paulo - 2013 41

Tabela 2- Valores da frequência cardíaca obtidos no teste progressivo escalonado de esforço máximo após 90 dias de treinamento aeróbico - São Paulo - 2013 42

Tabela 3- Valores do V200 obtido no teste inicial e após 90 dias de treinamento, obtidos com todos os animais agrupados e subdivididos em relação ao tipo de treinamento São Paulo - 2013 45

Tabela 4- Valores da pressão arterial sistólica obtidos no teste progressivo escalonado de esforço máximo inicial - São Paulo - 2013 46

Tabela 5- Valores da pressão arterial sistólica obtidos no teste progressivo escalonado de esforço máximo após 90 dias de treinamento - São Paulo - 2013

Tabela 6- Valores da PAD obtidos no teste progressivo escalonado de esforço máximo inicial - São Paulo - 2013 50

Tabela 7- Valores da PAD obtidos no teste progressivo escalonado de esforço máximo após 90 dias de treinamento aeróbico - São Paulo - 2013 
Tabela 8- Valores da PAM obtidos no teste progressivo escalonado de esforço máximo inicial - São Paulo - 2013 54

Tabela 9- Valores da PAM obtidos no teste progressivo escalonado de esforço máximo após 90 dias de treinamento aeróbico - São Paulo - 2013 55

Tabela 10 - Valores da concentração de lactato sanguíneo obtidos no teste progressivo escalonado de esforço máximo inicial - São Paulo - 2013 58

Tabela 11 - Valores da concentração de lactato sanguíneo obtidos no teste progressivo escalonado de esforço máximo após 90 dias de treinamento aeróbico - São Paulo 2013 59

Tabela 12 - Valores da concentração de hidrogênio sanguíneo (pH) obtidos no teste progressivo escalonado de esforço máximo inicial - São Paulo - 2013 62

Tabela 13 - Valores da concentração hidrogênio sanguíneo $(\mathrm{pH})$ obtidos no teste progressivo escalonado de esforço máximo após 90 dias de treinamento aeróbico - São Paulo 2013. 63

Tabela 14 - Valores da concentração de oxigênio sanguíneo $\left(\mathrm{PO}_{2}\right)$ obtidos no teste progressivo escalonado de esforço máximo inicial - São Paulo - 2013 66 
Tabela 15 - Valores da concentração oxigênio sanguíneo $\left(\mathrm{PO}_{2}\right)$ obtidos no teste progressivo escalonado de esforço máximo após 90 dias de treinamento aeróbico São Paulo 2013

Tabela 16 - Valores da concentração de gás carbônico sanguíneo $\left(\mathrm{PCO}_{2}\right)$ obtidos no teste progressivo escalonado de esforço máximo inicial - São Paulo - 2013 70

Tabela 17 - Valores da concentração gás carbônico sanguíneo $\left(\mathrm{PCO}_{2}\right)$ obtidos no teste progressivo escalonado de esforço máximo após 90 dias de treinamento aeróbico São Paulo - 2013 71

Tabela 18 - Valores da porcentagem da concentração de oxigênio sanguíneo $\left(\mathrm{SO}_{2} \%\right)$ obtidos no teste progressivo escalonado de esforço máximo inicial - São Paulo - 2013 .... 74

Tabela 19 - Valores da porcentagem da concentração de oxigênio sanguíneo $\left(\mathrm{SO}_{2} \%\right)$ obtidos no teste progressivo escalonado de esforço máximo após 90 dias de treinamento aeróbico - São Paulo - 2013 75

Tabela 20 - Valores de FC; volume final circulante (VFC ml), débito cardíaco (DC 1/mim) e fração de ejeção (FE\%) obtidos nos testes iniciais e após 90 dias de treinamento São Paulo -2013 
Tabela 21 - Valores de diâmetro interno de átrio esquerdo (AE), diâmetro interno da artéria aorta (Ao), relação átrio esquerdo e aorta (relação AE/Ao), diâmetro interno de ventrículo direito em diástole (VDd), espessura do septo ventricular em diástole (SIVd) obtidos nos testes iniciais e após 90 dias de treinamento - São Paulo - 2013

Tabela 22 - Valores de diâmetro interno de ventrículo esquerdo em diástole (DVEd), espessura da parede livre do ventrículo esquerdo em diástole (PLVEd), espessura de septo ventricular em sístole (SIVs), diâmetro interno de ventrículo esquerdo em sístole (DVEs), espessura de parede livre do ventrículo esquerdo em sístole (PLVEs), obtidos nos testes iniciais e após 90 dias de treinamento - São Paulo - 2013 80

Tabela 23 - Valores de volume final diastólico do ventrículo esquerdo (VFSVE), volume final sistólico do ventrículo esquerdo (VFDVE), fração de espessamento do septo ventricular (EFSIV), fração de encurtamento do ventrículo esquerdo (RFDVE) e fração de espessamento da parede livre do ventrículo esquerdo (EFPLVE), obtidos nos testes iniciais e após 90 dias de treinamento - São Paulo - 2013 80 


\section{LISTA DE ILUSTRAÇÕES}

Gráfico 1- Valores da frequência cardíaca obtidos no teste progressivo escalonado de esforço máximo inicial e após 90 dias de treinamento 42

Gráfico 2- Valores da frequência cardíaca obtidos no teste progressivo escalonado de esforço máximo inicial e após 90 dias de treinamento a campo

Gráfico 3- Valores da frequência cardíaca obtidos no teste progressivo escalonado de esforço máximo inicial e após 90 dias de treinamento na esteira controlado 43

Gráfico 4- Gráfico comparativo dos valores da frequência cardíaca obtidas no teste inicial dos subgrupos treinados a campo e na esteira.

Gráfico 5- Gráfico comparativo dos valores da frequência cardíaca obtidas no teste após 90 dias de treinamento dos subgrupos treinados a campo e na esteira

Gráfico 6- Valores do V200 obtido no teste inicial e após 90 dias de treinamento, obtidos com todos os animais agrupados e subdivididos em relação ao tipo de treinamento.... 45

Gráfico 7- Valores da pressão arterial sistólica obtidos no teste progressivo escalonado de esforço máximo inicial e após 90 dias de treinamento.

Gráfico 8- Valores da PAS obtidos no teste progressivo escalonado de esforço máximo inicial e após 90 dias de treinamento a campo 
Gráfico 9 - Valores da PAS obtidos no teste progressivo escalonado de esforço máximo inicial e após 90 dias de treinamento na esteira controlado.

Gráfico 10 - Gráfico comparativo dos valores da PAS obtidas no teste inicial dos subgrupos treinados a campo e na esteira

Gráfico 11 - Gráfico comparativo dos valores da PAS obtidas no teste após 90 dias de treinamento dos subgrupos treinados a campo e na esteira 49

Gráfico 12 - Valores da PAD obtidos no teste progressivo escalonado de esforço máximo inicial e após 90 dias de treinamento

Gráfico 13 - Valores da PAD obtidos no teste progressivo escalonado de esforço máximo inicial e após 90 dias de treinamento a campo 52

Gráfico 14 - Valores da PAD obtidos no teste progressivo escalonado de esforço máximo inicial e após 90 dias de treinamento na esteira controlado. .52

Gráfico 15 - Gráfico comparativo dos valores da PAD obtidas no teste inicial dos subgrupos treinados a campo e na esteira

Gráfico 16 - Gráfico comparativo dos valores da PAD obtidas no teste após 90 dias de treinamento dos subgrupos treinados a campo e na esteira 53

Gráfico 17 - Valores da PAM obtidos no teste progressivo escalonado de esforço máximo inicial e após 90 dias de treinamento 
Gráfico 18 - Valores da PAM obtidos no teste progressivo escalonado de esforço máximo inicial e após 90 dias de treinamento a campo

Gráfico 19 - Valores da PAM obtidos no teste progressivo escalonado de esforço máximo inicial e após 90 dias de treinamento na esteira controlado. 56

Gráfico 20 - Gráfico comparativo dos valores da PAM obtidas no teste inicial dos subgrupos treinados a campo e na esteira 57

Gráfico 21 - Gráfico comparativo dos valores da PAM obtidas no teste após 90 dias de treinamento dos subgrupos treinados a campo e na esteira 57

Gráfico 22 - Valores da concentração de lactato sanguíneo obtidos no teste progressivo escalonado de esforço máximo inicial e após 90 dias de treinamento 59

Gráfico 23 - Valores da concentração de lactato sanguíneo obtidos no teste progressivo escalonado de esforço máximo inicial e após 90 dias de treinamento a campo ....60

Gráfico 24 - Valores da concentração de lactato sanguíneo obtidos no teste progressivo escalonado de esforço máximo inicial e após 90 dias de treinamento na esteira controlado 60

Gráfico 25 - Gráfico comparativo dos valores da concentração de lactato sanguíneo obtido no teste inicial dos subgrupos treinados a campo e na esteira 61 
Gráfico 26 - Gráfico comparativo dos valores da concentração de lactato sanguíneo obtido no teste após 90 dias de treinamento dos subgrupos treinados a campo e na esteira 61

Gráfico 27 - Valores da concentração de hidrogênio sanguíneo (pH) obtidos no teste progressivo escalonado de esforço máximo inicial e após 90 dias de treinamento .... 63

Gráfico 28 - Valores da concentração hidrogênio sanguíneo $(\mathrm{pH})$ obtidos no teste progressivo escalonado de esforço máximo inicial e após 90 dias de treinamento a campo ....64 64

Gráfico 29 - Valores da concentração de hidrogênio sanguíneo (pH) obtidos no teste progressivo escalonado de esforço máximo inicial e após 90 dias de treinamento na esteira controlado 64

Gráfico 30 - Gráfico comparativo dos valores da concentração de hidrogênio sanguíneo $(\mathrm{pH})$ obtidas no teste inicial dos subgrupos treinados a campo e na esteira 65

Gráfico 31 - Gráfico comparativo dos valores da concentração de hidrogênio sanguíneo $(\mathrm{pH})$ obtidas no teste após 90 dias de treinamento dos subgrupos treinados a campo e na esteira 65

Gráfico 32 - Valores da concentração de oxigênio sanguíneo $\left(\mathrm{PO}_{2}\right)$ obtidos no teste progressivo escalonado de esforço máximo inicial e após 90 dias de treinamento ....6 67

Gráfico 33 - Valores da concentração oxigênio sanguíneo $\left(\mathrm{PO}_{2}\right)$ obtidos no teste progressivo escalonado de esforço máximo inicial e após 90 dias de treinamento a campo ....68 
Gráfico 34 - Valores da concentração de oxigênio sanguíneo $\left(\mathrm{PO}_{2}\right)$ obtidos no teste progressivo escalonado de esforço máximo inicial e após 90 dias de treinamento na esteira controlado 68

Gráfico 35 - Gráfico comparativo dos valores da concentração de oxigênio sanguíneo $\left(\mathrm{PO}_{2}\right)$ obtidas no teste inicial dos subgrupos treinados a campo e na esteira .....

Gráfico 36 - Gráfico comparativo dos valores da concentração de oxigênio sanguíneo $\left(\mathrm{PO}_{2}\right)$ obtidas no teste após 90 dias de treinamento dos subgrupos treinados a campo e na esteira. 69

Gráfico 37 - Valores da concentração de gás carbônico sanguíneo $\left(\mathrm{PCO}_{2}\right)$ obtidos no teste progressivo escalonado de esforço máximo inicial e após 90 dias de treinamento .... 71

Gráfico 38 - Valores da concentração gás carbônico sanguíneo $\left(\mathrm{PCO}_{2}\right)$ obtidos no teste progressivo escalonado de esforço máximo inicial e após 90 dias de treinamento a campo. 72

Gráfico 39 -Valores da concentração de gás carbônico sanguíneo $\left(\mathrm{PCO}_{2}\right)$ obtidos no teste progressivo escalonado de esforço máximo inicial e após 90 dias de treinamento na esteira controlado. 72

Gráfico 40 - Gráfico comparativo dos valores da concentração de gás carbônico sanguíneo $\left(\mathrm{PCO}_{2}\right)$ obtidas no teste inicial dos subgrupos treinados a campo e na esteira...... 73 
Gráfico 41 - Gráfico comparativo dos valores da concentração de gás carbônico sanguíneo $\left(\mathrm{PCO}_{2}\right)$ obtidas no teste após 90 dias de treinamento dos subgrupos treinados a campo e na esteira

Gráfico 42 - Valores da porcentagem da concentração de oxigênio sanguíneo $\left(\mathrm{SO}_{2} \%\right)$ obtidos no teste progressivo escalonado de esforço máximo inicial e após 90 dias de treinamento . 75

Gráfico 43 - Valores da porcentagem da concentração de oxigênio sanguíneo $\left(\mathrm{SO}_{2} \%\right)$ obtidos no teste progressivo escalonado de esforço máximo inicial e após 90 dias de treinamento a campo 76

Gráfico 44 - Valores da porcentagem da concentração de oxigênio sanguíneo $\left(\mathrm{SO}_{2} \%\right)$ obtidos no teste progressivo escalonado de esforço máximo inicial e após 90 dias de treinamento na esteira controlado 76

Gráfico 45 - Gráfico comparativo dos valores da porcentagem da concentração de oxigênio sanguíneo $\left(\mathrm{SO}_{2} \%\right)$ obtidas no teste inicial dos subgrupos treinados a campo e na esteira. 77

Gráfico 46 - Gráfico comparativo dos valores da porcentagem da concentração de oxigênio sanguíneo $\left(\mathrm{SO}_{2} \%\right)$ obtidas no teste após 90 dias de treinamento dos subgrupos treinados a campo e na esteira 77

Gráfico 47 - Valores de Frequência Cardíaca (FC) obtidos nos testes iniciais e após 90 dias de treinamento 
Gráfico 48 - Valores de Volume Final Circulante (VFC ml) obtidos nos testes iniciais e após 90 dias de treinamento

Gráfico 49 - Valores do Débito Cardíaco (DC 1/min) obtidos nos testes iniciais e após 90 dias de treinamento 82

Gráfico 50 - Valores da Fração de Ejeção (FE\%) obtidos nos testes iniciais e após 90 dias de treinamento 82

Gráfico 51 - Valores do Diâmetro interno do Átrio Esquerdo (AE) obtidos nos testes iniciais e após 90 dias de treinamento.

Gráfico 52 - Valores do Diâmetro interno da artéria Aorta (Ao) obtidos nos testes iniciais e após 90 dias de treinamento. 83

Gráfico 53 - Valores da relação do Diâmetro interno do Átrio Esquerdo (AE) / Diâmetro interno do Átrio Esquerdo (AE) obtidos nos testes iniciais e após 90 dias de treinamento 84

Gráfico 54 - Valores do diâmetro interno de ventrículo direito em diástole (VDd), espessura do septo ventricular em diástole (SIVd), diâmetro interno de ventrículo esquerdo em diástole (DVEd), espessura da parede livre do ventrículo esquerdo em diástole (PLVEd) obtidos nos testes iniciais e após 90 dias de treinamento 84

Gráfico 55 - Valores da espessura de septo ventricular em sístole (SIVs), diâmetro interno de ventrículo esquerdo em sístole (DVEs), espessura de parede livre do ventrículo esquerdo em sístole (PLVEs), obtidos nos testes iniciais e após 90 dias de treinamento 85 
Gráfico 56 - Valores do volume final diastólico do ventrículo esquerdo (VFSVE), volume final sistólico do ventrículo esquerdo (VFDVE), obtidos nos testes iniciais e após 90 dias de treinamento

Gráfico 57 - Valores da fração de espessamento do septo ventricular (EFSIV), fração de encurtamento do ventrículo esquerdo (RFDVE) e fração de espessamento da parede livre do ventrículo esquerdo (EFPLVE), obtidos nos testes iniciais e após 90 dias de treinamento 86

Gráfico 58 - Valores de Frequência Cardíaca (FC) obtidos nos testes iniciais e após 90 dias de treinamento nos grupos treinados a campo e na esteira.

Gráfico 59 - Valores de Volume Final Circulante (VFC ml) obtidos nos testes iniciais e após 90 dias de treinamento nos grupos treinados a campo e na esteira

Gráfico 60 - Valores do Débito Cardíaco (DC 1/min) obtidos nos testes iniciais e após 90 dias de treinamento nos grupos treinados a campo e na esteira 87

Gráfico 61 - Valores da Fração de Ejeção (FE\%) obtidos nos testes iniciais e após 90 dias de treinamento nos grupos treinados a campo e na esteira. 88

Gráfico 62 - Valores do Diâmetro interno do Átrio Esquerdo (AE) obtidos nos testes iniciais e após 90 dias de treinamento nos grupos treinados a campo e na esteira .88

Gráfico 63 - Valores do Diâmetro interno da artéria Aorta (Ao) obtidos nos testes iniciais e após 90 dias de treinamento nos grupos treinados a campo e na esteira 89 
Gráfico 64 - Valores da relação do Diâmetro interno do Átrio Esquerdo (AE) / Diâmetro interno do Átrio Esquerdo (AE) obtidos nos testes iniciais e após 90 dias de treinamento nos grupos treinados a campo e na esteira.

Gráfico 65 - Valores do diâmetro interno de ventrículo direito em diástole (VDd), espessura do septo ventricular em diástole (SIVd), diâmetro interno de ventrículo esquerdo em diástole (DVEd), espessura da parede livre do ventrículo esquerdo em diástole (PLVEd) obtidos nos testes iniciais e após 90 dias de treinamento nos grupos treinados a campo e na esteira 90

Gráfico 66 - Valores da espessura de septo ventricular em sístole (SIVs), diâmetro interno de ventrículo esquerdo em sístole (DVEs), espessura de parede livre do ventrículo esquerdo em sístole (PLVEs), obtidos nos testes iniciais e após 90 dias de treinamento nos grupos treinados a campo e na esteira. 90

Gráfico 67 - Valores do volume final diastólico do ventrículo esquerdo (VFSVE), volume final sistólico do ventrículo esquerdo (VFDVE), obtidos nos testes iniciais e após 90 dias de treinamento nos grupos treinados a campo e na esteira 91

Gráfico 68 - Valores da fração de espessamento do septo ventricular (EFSIV), fração de encurtamento do ventrículo esquerdo (RFDVE) e fração de espessamento da parede livre do ventrículo esquerdo (EFPLVE), obtidos nos testes iniciais e após 90 dias de treinamento nos grupos treinados a campo e na esteira 91

Quadro 1. Valores de referencia de normalidade para exame ecocardiográfico para cavalos da raça Árabe ou cruza Árabe (Michima, 2003) 39 


\section{SUMÁRIO}

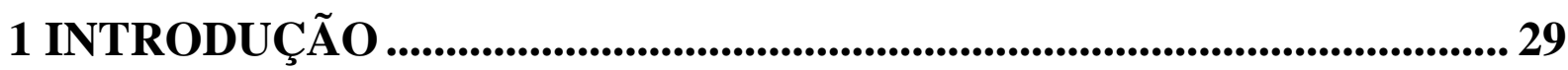

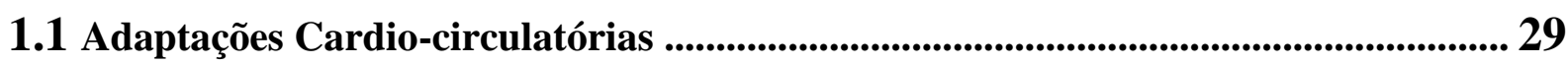

1.2 Provas de esforço ............................................................................................................................... 31

1.3 Enduro equestre....................................................................................................................... 33

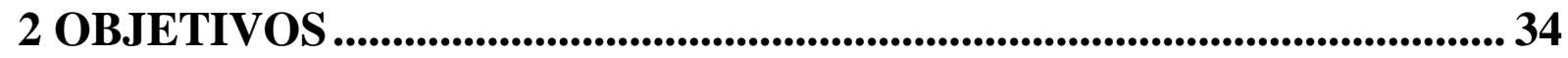

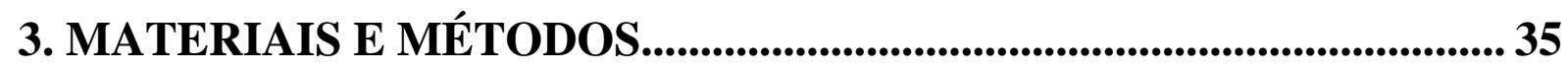

3.1 Treinamento Físico .....................................................................................................35

3.2 Avaliação Física …………………....................................................................................................37

3.3 Crase Sangüínea ..........................................................................................................38

3.4 Avaliação Cardíaca .......................................................................................................................39

3.4.1 Ecocardiograma …………………................................................................................ 39

3.4.2 Pressã o arterial ........................................................................................................... 40

3.5 Análise Estatística...............................................................................................................................40

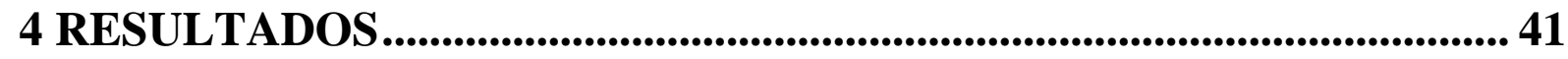

4.1 Frequência Cardíaca ...............................................................................................................41

4.2 Pressão arterial sistólica................................................................................................................... 46

4.3 Pressão arterial diastólica .............................................................................................................50

4.4 Pressão arterial média......................................................................................................................54

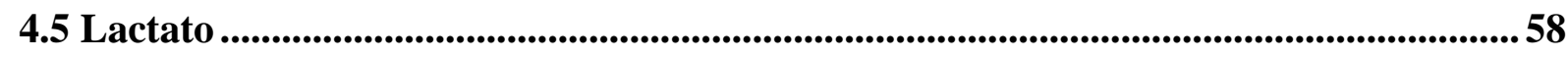

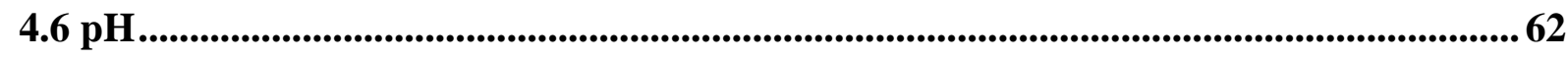


4.7 $\mathrm{PO}_{2}$

4.8 $\mathrm{PCO}_{2}$

4.9 $\mathrm{SO}_{2} \%$ 74

4.10 Ecocardiograma de repouso 78

5 DISCUSSÃO 92

6 CONCLUSÃO .99

REFERÊNCIA 


\section{INTRODUÇÃO}

Para a prática de atividades esportivas necessita-se cada vez mais de um cavalo de alto desempenho e com seus sistemas músculo-esquelético, respiratório e cardiovascular íntegros, funcionando como verdadeiras engrenagens acopladas a fim de fornecer todo aporte para realização das atividades físicas, e o entendimento dessa interação e interdependência é de extrema importância para a avaliação do potencial atlético de cada animal, bem como para estudo quanto da queda de rendimento dos cavalos, e também para a prescrição de treinos específicos para correção e/ou melhora de limitações individuais.

O exercício repetitivo provoca inúmeras alterações celulares e teciduais no organismo como um todo, porém, a alteração mais importante determinada pelo treinamento ocorre pelo aumento da produção de proteínas, tanto estruturais como funcionais. Acredita-se que esse aumento seja decorrente do acúmulo de metabólitos e de produtos residuais que aumentariam a transcrição do DNA específico para as proteínas, incluindo o aumento das enzimas que controlam a produção destes metabólitos. Isso faz com que ocorra aumento ao máximo da produção e eliminação desses metabólitos, ou seja, um aumento funcional dos tecidos com aumento dos órgãos (HINCHCLIFF; GOER, 2007).

\subsection{Adaptações Cardio-circulatórias}

São vários os efeitos cardiovasculares provocados pelo treinamento físico vigoroso praticado durante longos períodos, observados experimentalmente e em atletas competitivos, altamente treinados (SCHEUR et al., 1974; RASKOFF et al., 1976; BLOMQVIST; SALTIN, 1983). Verifica-se maior eficiência mecânica da musculatura esquelética, aumento da capilarização, das atividades enzimáticas, aumento da capacidade funcional pulmonar e melhor relação ventilação/perfusão. Essas alterações cardiovasculares resultam de complexas interações de mecanismos centrais e periféricos, operando em níveis estruturais, eletrofisiológicos, bioquímicos, metabólicos e neurogênicos (MARON, 2001). Elas dependem também da intensidade e duração do treinamento, do tipo de atividade atlética e de fatores genéticos. 
Um programa de treinamento aeróbico realizado regularmente tem potencial para provocar importantes alterações autonômicas e hemodinâmicas que podem influenciar diretamente o sistema cardiovascular. Entre essas adaptações, as reduções da frequência cardíaca de repouso e da pressão arterial sistólica são especialmente importantes no tratamento de homens hipertensos de grau leve a moderado, possibilitando a redução da dosagem de medicação bem como em alguns casos ter a pressão arterial controlada apenas com a prática da atividade física (RONDON; BRUM, 2003).

A hipertrofia ventricular esquerda é também uma adaptação a este treinamento físico, tanto em humanos quanto em cavalos, que se desenvolve como processo compensatório ou adaptativo a um estímulo hemodinâmico, representado pela sobrecarga de pressão e/ou volume. A teoria que melhor explica os padrões de hipertrofia considera que a resposta ventricular se processa no sentido de manter o estresse parietal ventricular relativamente constante e o volume sistólico adequado (EVANS, 1994; EVANS, 1999; POOLE; ERICKON, 2004; GHORAYEB et al., 2005; OLIVEIRA et al.,2006).

A resposta cardiovascular depende, entre outros fatores, do tipo de exercício executado, se estático ou dinâmico. Nos exercícios dinâmicos, motivo do estudo, ocorre aumento do débito cardíaco pelo aumento da frequência cardíaca e do volume sistólico. A frequência cardíaca aumenta linearmente com o consumo de oxigênio durante o exercício, enquanto que diminui em repouso após um período de treinamento devido a um controle autonômico. O volume de ejeção sistólico aumenta em resposta à descarga adrenérgica que ocorre durante o exercício. Ocorre uma redistribuição de fluxo sanguíneo, o que leva, concomitantemente, a um aumento deste fluxo para a musculatura esquelética, em detrimento de outras regiões, por aumento sistêmico de catecolaminas circulantes durante o exercício (NETO et al., 1999).

A bradicardia durante exercício submáximo é resultante da ação do tônus parassimpático e aumento do retorno venoso (EVANS, 1999). O retorno venoso é o volume de sangue ejetado por batimento do ventrículo direito para o esquerdo que em condição de repouso é de aproximadamente $1000 \mathrm{ml}(2-2,5 \mathrm{ml} / \mathrm{kg})$ elevando-se para $1700 \mathrm{ml}(3-4 \mathrm{ml} / \mathrm{kg})$ durante exercício máximo (POOLE; ERICKON, 2004).

À medida que ocorre aumento na intensidade do exercício físico, existe um acréscimo na demanda de oxigênio corporal que pode exceder a capacidade do sistema cardiorrespiratório de ofertar oxigênio para o metabolismo aeróbio. Nestas condições ocorre a glicólise até a etapa de formação do piruvato e este, na ausência de oxigênio, ao invés de 
entrar no ciclo de Krebs e dar continuidade a glicólise aeróbica, é deslocado para a direita através da ação da enzima marca-passo LDH (Lactato desidrogenase) formando ácido láctico (lactato).

Por esse motivo a concentração de lactato pode ser utilizada para determinar a via metabólica pra a obtenção de energia nas fibras musculares, pois ocorre o aumento e acúmulo da concentração deste subproduto do metabolismo anaeróbico em resposta a um exercício intenso, sendo este aumento proporcional ao aumento do esforço exigido e da frequência cardíaca para a realização de tal atividade (ROSE; HODGSON, 1994).

Estudos realizados em ratos espontaneamente hipertensos, os quais foram submetidos à sessão de exercício físico realizado na intensidade correspondente a $55 \%$ do consumo de oxigênio pico, observou-se uma redução importante na pressão arterial no período pósexercício por até 90 minutos após o término da atividade, fato este observado também em ratos normotensos e em pacientes humanos hipertensos (FORJAZ et al., 1998).

Diversos pesquisadores comprovam que o efeito do exercício na pressão arterial depende do tipo de exercício, da duração e da intensidade do mesmo, sendo que no geral exercícios dinâmicos de baixa a moderada intensidade possuem maiores efeitos na queda da pressão (TIPTON, 1991; MARCEAU, et al., 1993; VÉRAS-SILVA et al., 1997), sendo recomendado a prática de atividades físicas com sessões de 30 a 45 minutos de duração (SBH, 1998; ACSM`S, 2000).

A intensidade do exercício é fator crucial para a obtenção dos efeitos benéficos da prática de atividade física na diminuição dos valores de pressão arterial. Véras-Silva et al. (1997) demonstraram que treinamento em baixa intensidade $\left(50 \% \mathrm{VO}_{2}\right)$ provocou diminuição significativa da pressão sistólica, diastólica e média, quando comparada a treinamentos em alta intensidade $\left(80 \% \mathrm{VO}_{2}\right)$ em camundongos.

\subsection{Provas de esforço}

Provas de esforço em cavalos atletas podem ser realizadas tanto em esteiras rolantes como a campo, com vantagens e desvantagens nos dois métodos. A avaliação realizada a campo apresenta a vantagem de se pode realizar testes com velocidades, andamentos, superfícies e ambiente similares aos de competição. Entretanto na avaliação a campo, a 
influência do jóquei ou ginete, pode se tornar dificuldades quando se tenta padronizar um teste na pratica (EVANS, 2004).

Já os testes realizados em esteira de alta velocidade possibilitam melhor controle das condições físicas dos cavalos, além de permitir padronização das condições ambientais, à possibilidade de repetição das velocidades estabelecidas no protocolo e da duração de cada estágio. O teste na esteira possibilita também ao pesquisador uma facilidade de acesso ao cavalo para que se façam coletas de sangue durante o exercício. Contudo, para se realizar o teste na esteira de velocidade tem-se a necessidade de se adaptar o animal à esteira. (EVANS, 2004).

Existem alguns estudos, em seres humanos, comparando treinamento aeróbio em esteira, com treinamento de corrida ao ar livre, para verificar se há diferença nas respostas hemodinâmicas em função do ambiente. Crouter, et al., (2001) estudaram um grupo de 15 voluntários universitários corredores de cross-country que praticavam exercícios regularmente, isto é, cerca de 5 vezes por semana. Foram avaliados parâmetros respiratórios, frequiência cardíaca e consumo de oxigênio através de espirometria e radiotelemetria além de dois tipos de testes: 1) corrida em esteira até a fadiga e 2) corrida em pista coberta de $200 \mathrm{~m}$ onde os atletas foram instruídos para cumprir a distância de uma milha (1609 m) no menor tempo possível. As repostas fisiológicas encontradas foram semelhantes nos dois grupos com exceção da dosagem de ácido láctico que foi maior no teste em pista de corrida.

Em outro estudo, Ceci; Hassmen (1991) avaliaram o esforço subjetivo percebido pelos indivíduos ao praticarem o mesmo tipo de exercício, em duas condições distintas. Foram avaliados 12 indivíduos em duas condições de treinamento: treinamento ao ar livre e treinamento em esteira, sendo utilizada para análise do esforço subjetivo uma escala de avaliação da percepção do exercício com 15 níveis de intensidade, onde 1 seria exercício muito fácil e 15 exercício muito exaustivo.

Os mesmos indivíduos treinaram em ambas as condições e foram controlados, para que treinassem na mesma intensidade de exercício físico. Foram relacionados os índices 11,13 e 15 dessa escala com a velocidade, frequência cardíaca e dosagem sanguínea de lactato durante a corrida em esteira e em ambiente aberto, em dois momentos com intervalo de 30 dias.

Os valores dos parâmetros fisiológicos se mostraram superiores nos indivíduos que correram ao ar livre, quando comparados aos que treinaram em esteira. Porém, quando comparados nos dois momentos do teste eles ficaram praticamente iguais para todos os 
índices de esforço, indicando mesmo esforço físico, mas de uma maneira mais agradável para a realização do exercício no grupo que treinou ao ar livre.

Por esse motivo tem-se a necessidade de compreender os eventos mais relevantes sobre a fisiologia animal durante o exercício, para que se possa tirar o maior proveito dos potenciais genético e de treinamento individual (MARQUES, 2002).

\subsection{Enduro equestre}

Enduro equestre é uma competição onde a velocidade e a resistência do cavalo é posta a prova, aliados à destreza e conhecimentos do cavaleiro. A distância mínima para uma competição é de $40 \mathrm{~km}$ podendo chegar até $160 \mathrm{~km}$ dependendo do tipo de competição. Essa quilometragem é dividida em diversas etapas chamadas de anéis que correspondem a $40 \mathrm{~km}$ do percurso. No início da prova e ao final dos anéis, todos os animais são submetidos a uma avaliação por um médico veterinário da organização da prova, num período máximo de 30 minutos após o término do anel, onde esses cavalos passam por exames clínicos e são avaliados se estão aptos ou não a prosseguir na prova. Vence a prova quem percorrer a distância determinada no menor tempo possível e com o animal nas melhores condições físicas.

Como cada vez mais as modalidades esportivas equestres exigem cavalos com alto desempenho, conhecer as principais adaptações dos sistemas envolvidos na melhora do desempenho (muscular, pulmonar e cardiocirculatório) se faz necessário. Há diversos estudos na literatura sobre a adaptação do sistema muscular e respiratório em equinos, porém com relação ao sistema cardiocirculatório, apenas estudos visando identificar os principais eventos arrítmicos ocorridos durante o exercício são encontrados. Quando se pesquisa a interação do treinamento físico com o sistema cardiocirculatório, menor é este numero de trabalhos. 


\section{OBJETIVOS}

O presente estudo tem por objetivo caracterizar as principais alterações cardiocirculatórias decorrentes da prática de atividade física contínua em intensidade leve a moderada por um período de 90 dias de treinamento aeróbico.

Tem por objetivo também comparar os efeitos obtidos com o tipo de treinamento em que os animais foram submetidos:

$\checkmark \quad$ Treinamento a campo - com protocolo proposto pelos treinadores dos centros equestres

$\checkmark \quad$ Treinamento em esteira - com métodos de controle constante e protocolo baseado em frequência cardíaca. 


\section{MATERIAIS E MÉTODOS}

Animais:

Foram avaliados nove equinos, da raça Árabe e Cruzados Árabes, machos ou fêmeas, adultos, em início das atividades de treinamento para prática de enduro.

Todos os animais passaram por exame clinico detalhado visando avaliar as condições de higidez dos mesmos. A avaliação dos animais seguiu o protocolo padrão pré-estabelecido, conforme descrito:

Avaliação física - consistiu na aferição das frequências cardíaca, respiratória e movimentação cecal através de auscultação cardíaca, pulmonar e movimentação da válvula ileocecal, mensuração da temperatura retal, pesquisa do reflexo da tosse, inspeção das mucosas e tempo de preenchimento capilar (TPC) e exame de locomotor.

Exames complementares - hemograma, bioquímica sérica (CK, LDH, Lactato, Glicemia), ecocardiograma e eletrocardiograma em repouso.

\subsection{Treinamento Físico}

Os 9 animais serão distribuídos em dois grupos de treinamentos distintos, a saber:

Grupo 1 - Treinado à campo (5 animais)

Grupo 2 - Treinado em esteira de alta velocidade (4 animais)

Os animais treinados à campo foram cedidos pelos proprietários para as avaliações realizadas na esteira, porém o treinamento não pode ser influenciado pelos pesquisadores, sendo seguido o protocolo de treinamento já estipulado pelos treinadores dos centros equestres.

Já os animais que foram treinados exclusivamente na esteira de velocidade, o protocolo de treinamento foi delineado a partir dos resultados obtidos no teste de esforço 
inicial no qual foi determinado o limiar de lactato e frequência cardíaca máxima através da utilização de Polar®. As velocidades iniciais para a prática da atividade física tomando por base a manutenção de $60 \%$ da frequência cardíaca máxima ou pico, obtida no teste inicial foram determinadas individualmente para cada animal com o intuito de se obter um esforço relativo semelhante para todos.

O protocolo delineado para esses animais consistiu em 12 semanas (90 dias) de atividade física exclusivamente aeróbica utilizando-se $60 \%$ da FC máxima obtida no teste de esforço inicial se seguindo os protocolos a baixo:

\section{Protocolo 1 - 3 semanas}

10 min passo inclinação $4 \%$

5 trote (FC entre 120 e 140 bpm) inclinação $4 \%$

5 passo inclinação $4 \%$

5 trote (FC entre 120 e 140 bpm) inclinação $4 \%$

5 passo inclinação $0 \%$

\section{Protocolo 2 - 3 semanas}

5 min passo inclinação $4 \%$

10 trote (FC entre 120 e 140 bpm) inclinação $4 \%$

5 passo inclinação $4 \%$

5 trote (FC entre 120 e 140 bpm) inclinação $4 \%$

5 passo inclinação $0 \%$

\section{Protocolo 3 - 3 semanas}

5 min passo inclinação $4 \%$

20 trote (FC entre 120 e 140 bpm) inclinação $4 \%$

5 passo inclinação $0 \%$

\section{Protocolo 4 - 3 semanas}

5 min passo inclinação $4 \%$

30 trote (FC entre 140 e 160 bpm) inclinação $4 \%$

5 min passo inclinação $0 \%$ 
A frequência da prática da atividade física se deu três vezes na semana nas primeiras seis semanas e posteriormente aumentou-se a frequência para quatro vezes na semana nas seis semanas finais.

Os valores de inclinação descritos nos protocolos são apenas as inclinações iniciais. Conforme o passar do treino e a melhora do condicionamento dos animais, foi necessário aumentar a velocidade e a inclinação da esteira para conseguir atingir a frequência de 120 bpm e mantê-la no intervalo estabelecido, sem alterar a andadura no animal (trote).

\subsection{Avaliação Física}

Ambos os grupos foram submetidos ao teste de esforço máximo em esteira rolante, seguindo o protocolo de velocidade descrito a baixo. Esta avaliação foi repetida em todos os animais, com intervalo de 90 dias.

O teste de esforço progressivo máximo foi realizado seguindo o seguinte protocolo de incremento de velocidade: inicio a 2,5 m/seg (passo) e incremento de $0,83 \mathrm{~m} / \mathrm{seg}$ a cada 3 minutos nos primeiros quatro estágios até ser atingida a velocidade de $5 \mathrm{~m} / \mathrm{seg}$ (canter ou galope curto); a partir daí, o incremento da velocidade foi de $1,67 \mathrm{~m} / \mathrm{seg}$ até o $7^{\circ}$ estágio atingindo a velocidade de $10 \mathrm{~m} / \mathrm{seg}$ (galope); e um ultimo estágio, com incremento de 2,5 $\mathrm{m} / \mathrm{seg}$ para atingir uma velocidade final de $12,5 \mathrm{~m} / \mathrm{seg}$, com seis graus de inclinação para compensar a resistência do solo, forçando os animais avaliados a atingirem o esforço máximo.

Foi considerado esforço máximo quando o animal não conseguia mais manter a velocidade independente de estímulos, sua frequência cardíaca não aumentava mais independente do estímulo para aumento de sua velocidade. 


\subsection{Crase Sanguínea}

Foi feito colheita de sangue através da cateterização da veia jugular com cateter $16 \mathrm{G} \mathrm{x}$ 2 e plug de vedação fixado na pele com fio de Nylon 2,0 e posteriormente colado com cola de secagem rápida e heparinizado, o que possibilitou a colheita de sangue venoso para análise sanguínea dos seguintes parâmetros: lactato sérico, hemoglobina circulante, além de hematócrito (Hto) e hemoglobina corpuscular média (VHCM),

Todas as colheitas foram realizadas com seringas acopladas em extensor de equipo descartáveis e todo o conjunto heparinizado. O sangue coletado foi acondicionado em tubos siliconizados e heparinizados para hemograma, e tubos siliconizados com fluoreto de sódio para determinação do lactato.

As amostras foram processadas no Laboratório de Hematologia e Bioquímica do departamento de clínica médica da Faculdade de Medicina Veterinária e Zootecnia da Universidade de São Paulo, utilizando-se o método de UV enzimático proposto por WESTGARD; LAHMEYER E BIRNBAUM (1972) com a utilização de kit comercial Lactato Kovalent (ART 1100075K), produzido pela Kovalent do Brasil Ltda.

As amostras de sangue total utilizadas para determinação do número de hemácias circulantes, concentração sérica de hemoglobina e hematócrito foram processadas no contador automático BC-2800 VET utilizando-se kit específico para o equipamento. 


\subsection{Avaliação Cardíaca}

\subsubsection{Ecocardiograma}

Foi realizado a cada 3 meses em repouso, um dia antes do teste de esforço, utilizandose o equipamento 180 plus da SonoSite ${ }^{\circledR}$ e seguindo o padrão das medidas ecocardiográficas determinadas para a raça por Michima (2003), que avaliou e padronizou a técnica de ecocardiograma para cavalos árabes e mestiços árabes que realizem provas de enduro demonstrado no quadro 1.

Mensuração do diâmetro interno do ventrículo direito (DIVD), septo intraventricular (SIV), diâmetro interno do ventrículo esquerdo (DIVE), parede livre do ventrículo esquerdo (PLVE), diâmetro da raiz aórtica (Aod), fração de encurtamento do ventrículo esquerdo (FS), fração de ejeção (EF) e volume do ventrículo esquerdo (V) de preferência pelo modo $M$, nos cortes transversais de ventrículo esquerdo e das valvas mitral e aórtica, pela janela cardíaca direita devido à maior facilidade para obtenção de boas imagens. Foram considerados como padrão os seguintes valores:

Quadro 1. Valores de referencia de normalidade para exame ecocardiográfico para cavalos da raça Árabe ou cruza Árabe (MICHIMA, 2003).

\begin{tabular}{|l|r|r|}
\hline & \multicolumn{1}{l|}{ SISTOLE } & \multicolumn{1}{l|}{ DIASTOLE } \\
\hline \hline DIVD $(\mathrm{cm})$ & 2,04 & 1,61 \\
SIV $(\mathrm{cm})$ & 2,68 & 4,17 \\
DIVE $(\mathrm{cm})$ & 9,72 & 5,94 \\
PLVE $(\mathrm{cm})$ & 2,69 & 4,23 \\
E-septo $(\mathrm{cm})$ & & 1.96 \\
Aod $(\mathrm{cm})$ & 7,21 & \\
FS\% & & 39,06 \\
EF\% & & 66,38 \\
V $\left(\mathrm{cm}^{3}\right)$ & 534,24 & 181,75 \\
\hline
\end{tabular}




\subsubsection{Pressão arterial}

$+$

Para a mensuração da pressão arterial foi canulado a artéria facial com cateter $20 \mathrm{G}$ após bloqueio anestésico com injeção intradérmica de $0,3 \mathrm{ml}$ de anestésico local (cloridrato de lidocaína 2\%) e fixado com cola de secagem rápida conforme técnica descrita por Rose e Hodgson (1994). Foram utilizados extensores de equipo preenchidos com solução heparinizada e acoplados ao monitor multiparâmetros da marca GE modelo Dash 3000 quer permitiu a aferição da pressão sistólica, diastólica e média.

Esta mesma via de acesso serviu para a coleta de sangue arterial e análise da hemogasometria arterial realizada em aparelho Roche® modelo Cobas b 121.

\subsection{Análise Estatística}

Foi realizado Analise de Variância de Amostras repetidas (ANOVA) de duas vias com nível de significância de 5\% ( $\leq 00,05)$, com intervalo de confiança de $95 \%$ de Bonferroni, comparando a intensidade e testes (inicial e após 90 dias), e Análise de Variância de Amostras (ANOVA) de três vias com nível de significância de 5\% ( $\mathrm{p} \leq 0,05)$, com intervalo de confiança de $95 \%$ de Bonferroni, comparando intensidade, tipo de treino (campo ou esteira) e teste (inicial e após 90 dias)

Para as variáveis cardíacas do eletrocardiograma e ecocardiograma de repouso foi utilizado o teste de Analise de Variância de Amostras repetidas (ANOVA) de uma via com nível de significância de 5\% ( $\mathrm{p} \leq 0,05)$, com intervalo de confiança de 95\% de Bonferroni. 


\section{RESULTADOS}

\subsection{Frequência Cardíaca}

Os valores da frequência cardíaca obtidos nos testes iniciais e após 90 dias de treinamento com todos os animais estão demonstrados nas tabelas 1 e 2 e gráfico 1 .

Tabela 1 - Valores da frequência cardíaca obtidos no teste progressivo escalonado de esforço máximo inicial São Paulo - 2013

\begin{tabular}{ccccccccccc}
\hline & ANIMAIS & MO & M1 & M2 & M3 & M4 & M5 & M6 & M7 & M8 \\
\cline { 2 - 10 } & 1 & 40 & & & 148 & 178 & 190 & 210 & 230 & \\
& 2 & & 64 & 80 & 129 & 115 & 178 & & & \\
Inicial & 4 & & & & & & & & & \\
T0 & 5 & 38 & 76 & 126 & 130 & 161 & 191 & 224 & & \\
& 6 & 36 & 124 & 152 & 185 & 207 & 190 & 210 & 220 & \\
& 7 & 40 & 78 & 111 & 121 & 146 & 161 & & & \\
& 8 & 34 & 67 & 129 & 128 & 165 & & 207 & & \\
& 9 & 81 & 109 & 136 & 162 & 180 & 156 & 208 & 225 & \\
& 9 & & & 135 & 135 & 146 & 192 & 225 & & \\
& media & 49 & 91 & 122 & 142 & 162 & 180 & 214 & 225 &
\end{tabular}


Tabela 2 - Valores da frequência cardíaca obtidos no teste progressivo escalonado de esforço máximo após 90 dias de treinamento aeróbico - São Paulo - 2013

\begin{tabular}{ccccccccccc}
\hline & ANIMAIS & MO & M1 & M2 & M3 & M4 & M5 & M6 & M7 & M8 \\
\cline { 2 - 10 } & 1 & 34 & 91 & 139 & 163 & 177 & 204 & 224 & 239 & \\
50 dias & 2 & 35 & 94 & 136 & 161 & 180 & 193 & 210 & 236 & \\
T1 & 5 & 42 & 117 & 122 & 154 & 147 & 166 & 204 & & \\
& 5 & 56 & 119 & 118 & 134 & 143 & 163 & 172 & 187 & \\
& 6 & 55 & 103 & 147 & 133 & 133 & 123 & 159 & 192 & \\
& 7 & 45 & 130 & 141 & 152 & 160 & 177 & 211 & & \\
& 8 & 30 & 99 & 109 & 122 & 134 & 150 & 178 & 200 & \\
& 9 & 30 & 103 & 108 & 141 & 160 & 171 & 220 & 221 & \\
\hline
\end{tabular}

Gráfico 1 - Valores da frequência cardíaca obtidos no teste progressivo escalonado de esforço máximo inicial e após 90 dias de treinamento

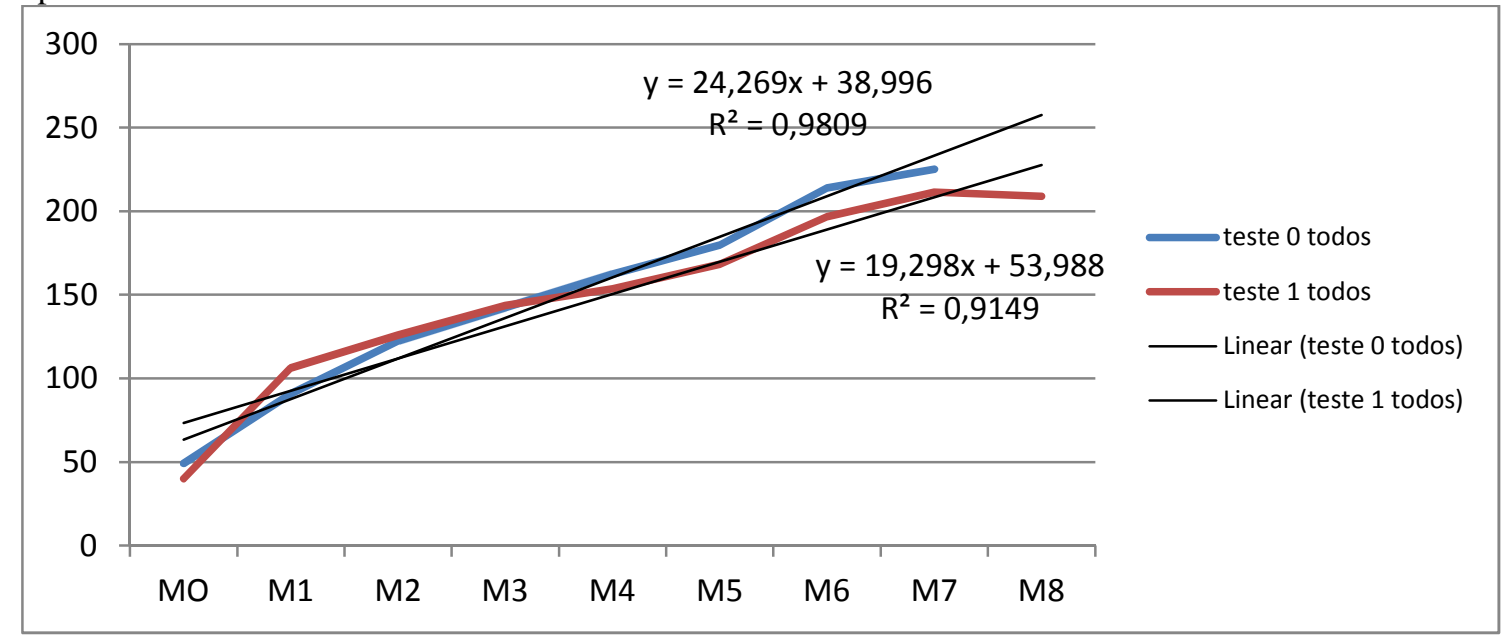

Quando reagrupados em relação ao tipo de treinamento, os resultados estão demonstrados nos gráficos 2 a 5 . 
Gráfico 2 - Valores da frequência cardíaca obtidos no teste progressivo escalonado de esforço máximo inicial e após 90 dias de treinamento a campo

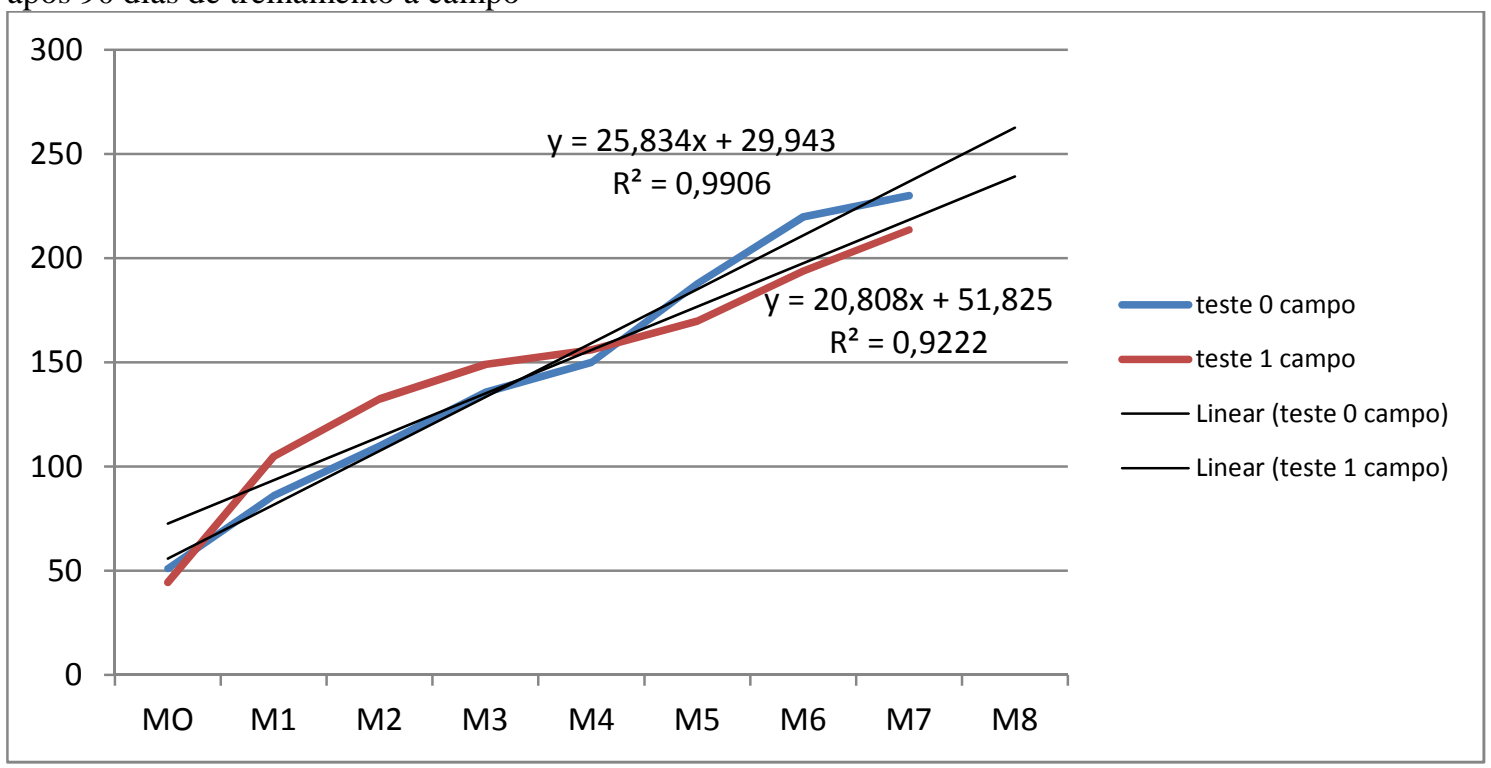

Gráfico 3 - Valores da frequência cardíaca obtidos no teste progressivo escalonado de esforço máximo inicial e após 90 dias de treinamento na esteira controlado

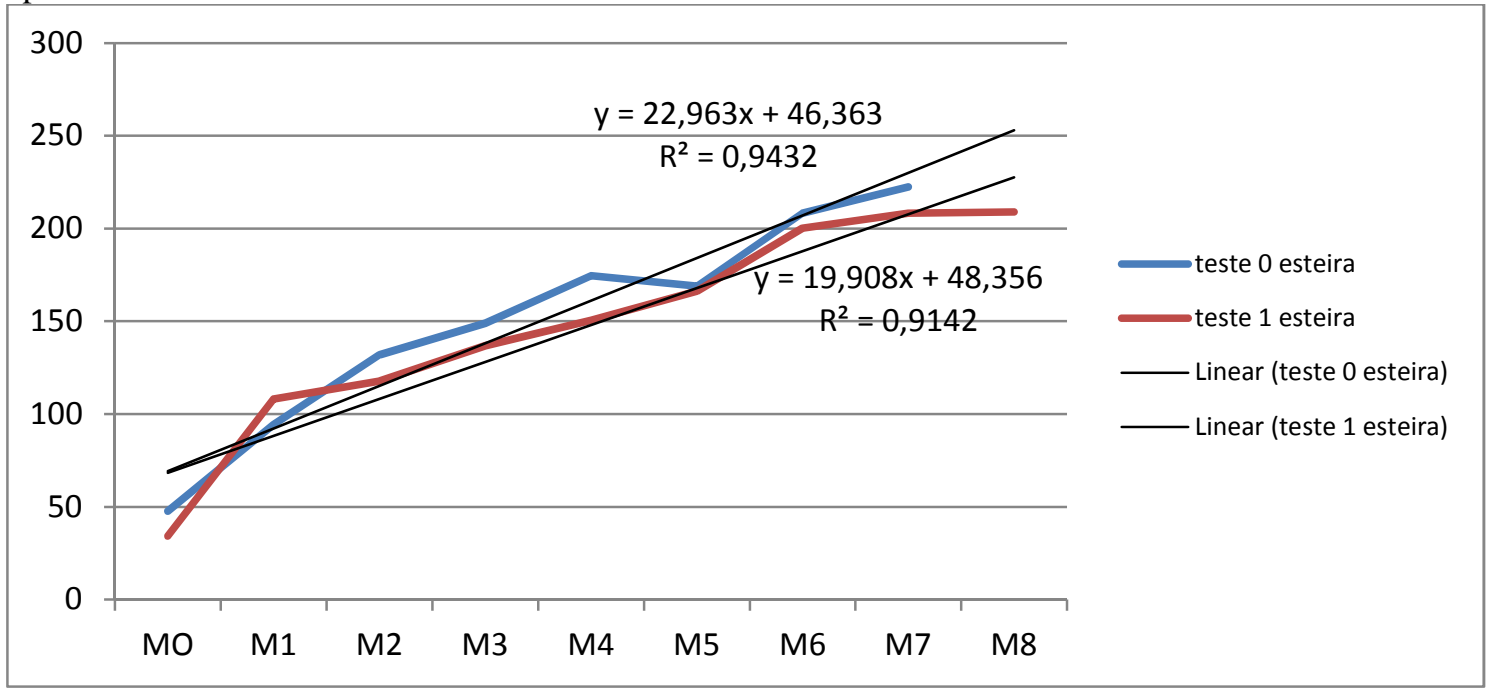


Gráfico 4 - Gráfico comparativo dos valores da frequência cardíaca obtidas no teste inicial dos subgrupos treinados a campo e na esteira

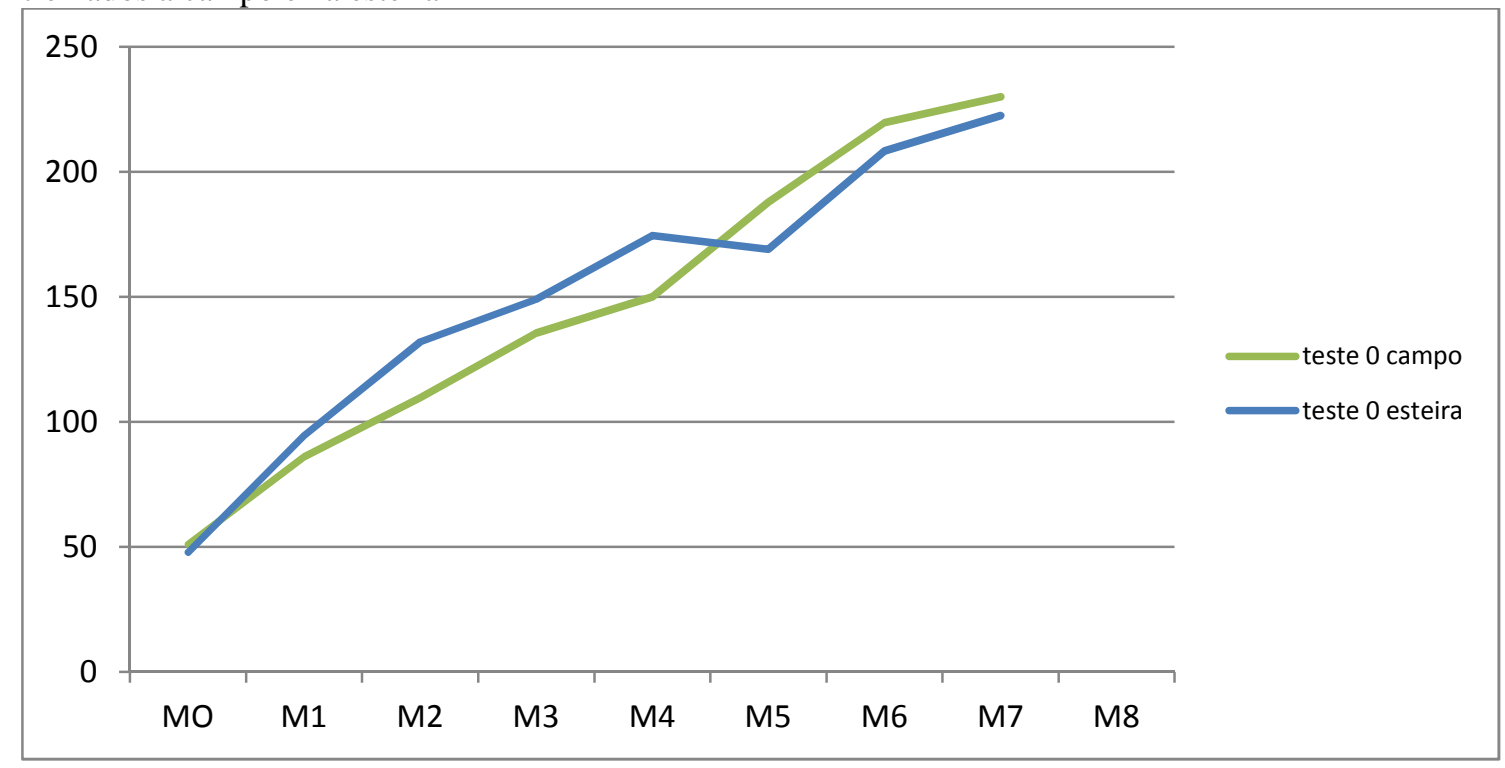

Gráfico 5 - Gráfico comparativo dos valores da frequência cardíaca obtidas no teste após 90 dias de treinamento dos subgrupos treinados a campo e na esteira

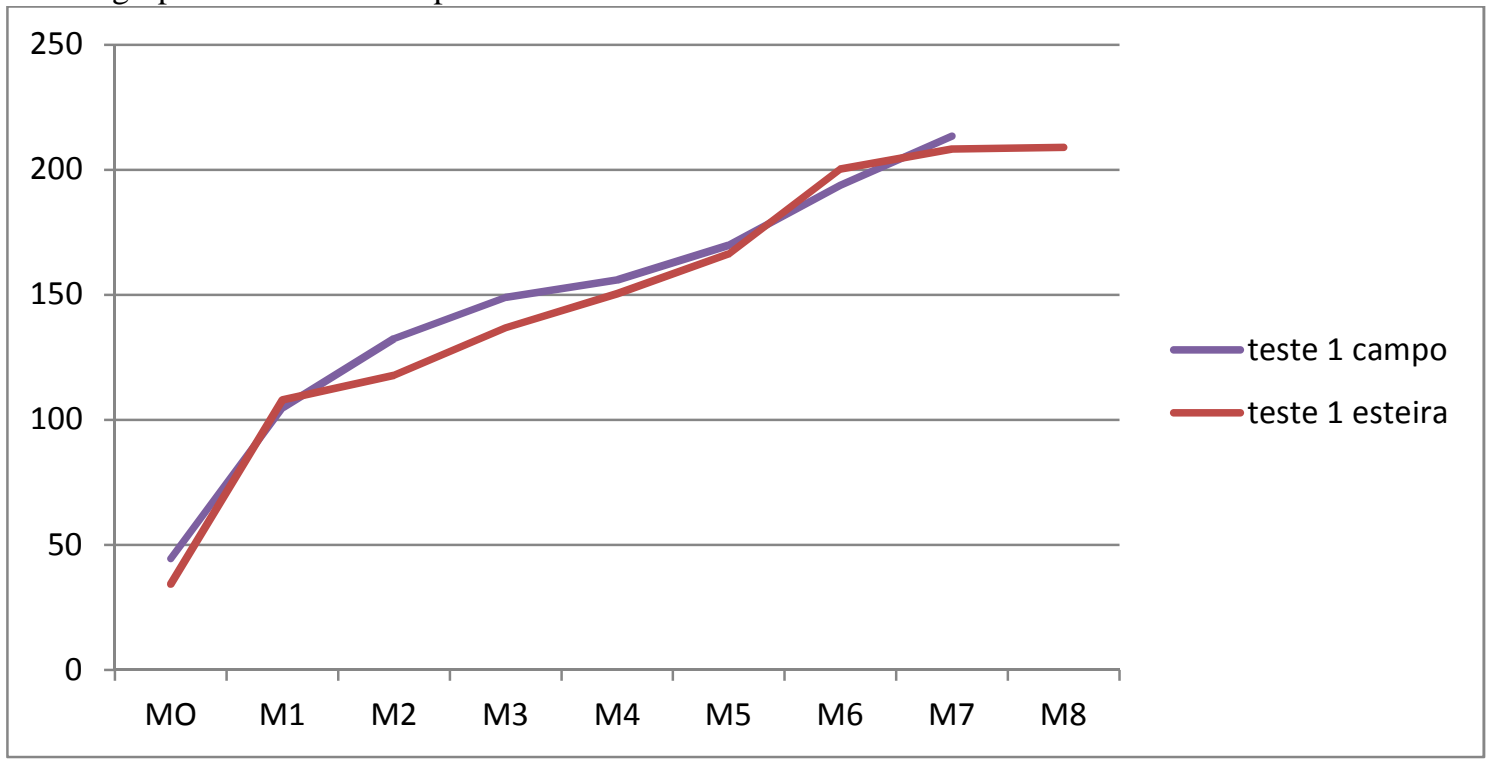


Os valores do V200 obtidos nos testes foram calculados a partir das equações de regressão linear obtidas e demonstradas nos gráficos sendo os valores expressos na tabela 3 e no gráfico 6.

Tabela 3 - Valores do V200 obtido no teste inicial e após 90 dias de treinamento, obtidos com todos os animais agrupados e subdivididos em relação ao tipo de treinamento - São Paulo - 2013

\begin{tabular}{ccccccc} 
& $\begin{array}{c}\text { teste } 0 \\
\text { todos }\end{array}$ & $\begin{array}{c}\text { teste } 1 \\
\text { todos }\end{array}$ & $\begin{array}{c}\text { teste } 0 \\
\text { campo }\end{array}$ & $\begin{array}{c}\text { teste } 1 \\
\text { campo }\end{array}$ & $\begin{array}{c}\text { teste } 0 \\
\text { esteira }\end{array}$ & $\begin{array}{c}\text { teste } 1 \\
\text { esteira }\end{array}$ \\
\hline $\mathrm{V} 200 \mathrm{~m} / \mathrm{s}$ & 6,63 & 7,56 & 6,58 & 7,12 & 6,69 & 7,61 \\
\hline
\end{tabular}

Gráfico 6 - Valores do V200 obtido no teste inicial e após 90 dias de treinamento, obtidos com todos os animais agrupados e subdivididos em relação ao tipo de treinamento

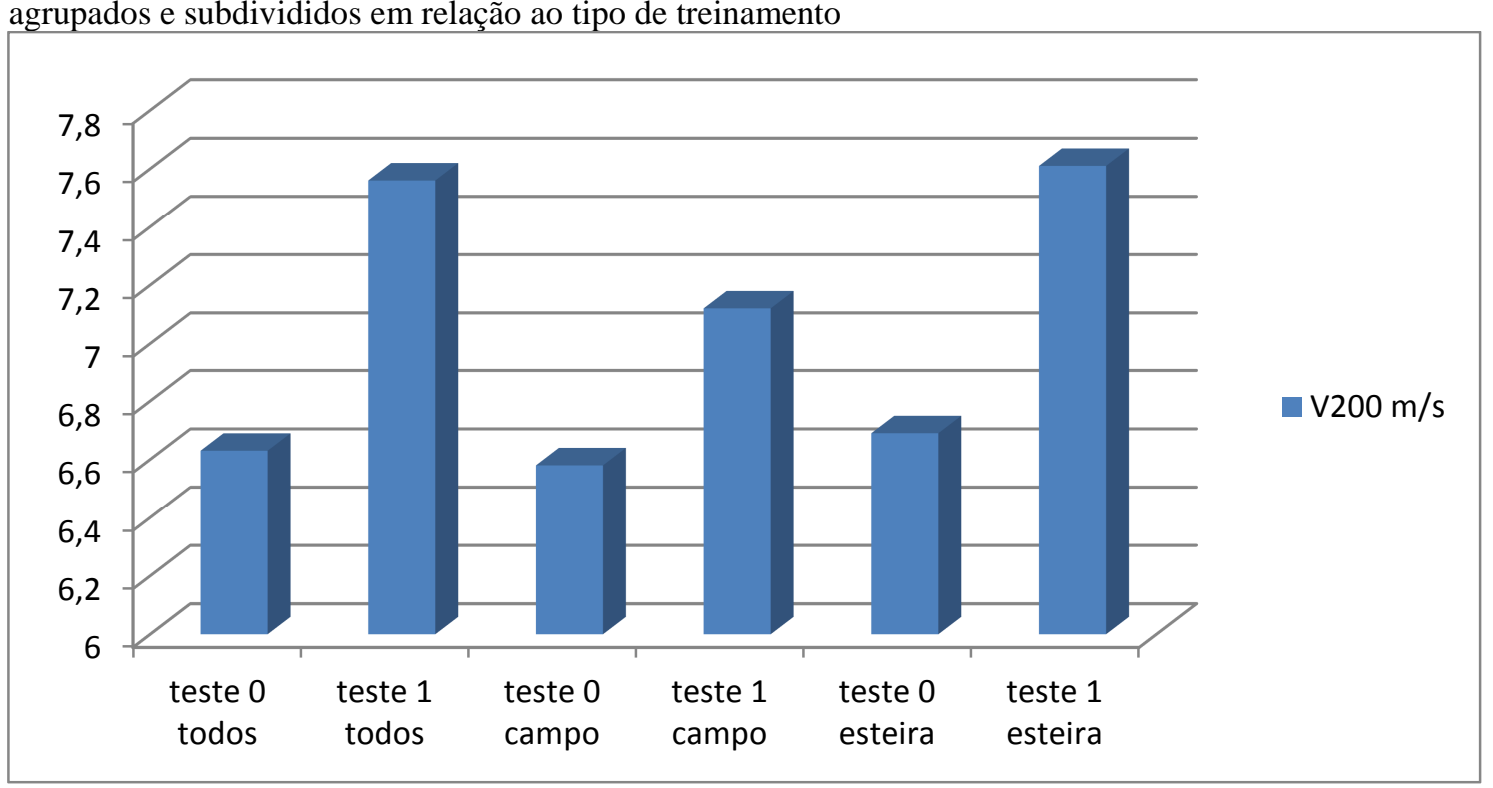




\subsection{Pressão arterial sistólica}

Os valores da PAS obtidos nos testes iniciais e após 90 dias de treinamento com todos os animais estão demonstrados nas tabelas 4 e 5 e gráfico 7.

Tabela 4 - Valores da pressão arterial sistólica obtidos no teste progressivo escalonado de esforço máximo inicial - São Paulo - 2013

\begin{tabular}{|c|c|c|c|c|c|c|c|c|c|c|}
\hline \multirow{11}{*}{$\begin{array}{c}\text { Inicial } \\
\text { T0 }\end{array}$} & ANIMAIS & $\mathrm{MO}$ & M1 & M2 & M3 & M4 & M5 & M6 & M7 & M8 \\
\hline & 1 & 125,00 & 154,00 & 137,00 & 156,00 & 160,00 & 187,00 & 232,00 & 235,00 & \\
\hline & 2 & & 112,00 & 135,00 & 157,00 & 155,00 & 130,00 & & & \\
\hline & 3 & 110,00 & 149,00 & 152,00 & 170,00 & 160,00 & 177,00 & 229,00 & & \\
\hline & 4 & 164,00 & 196,00 & 173,00 & 182,00 & 191,00 & 219,00 & 241,00 & & \\
\hline & 5 & 100,00 & 110,00 & 134,00 & 141,00 & 187,00 & 212,00 & 234,00 & & \\
\hline & 6 & 73,00 & 73,00 & 86,00 & 128,00 & 130,00 & 100,00 & 114,00 & 146,00 & \\
\hline & 7 & 120,00 & 138,00 & 169,00 & 189,00 & 190,00 & 214,00 & 245,00 & & \\
\hline & 8 & 84,00 & 92,00 & 121,00 & 135,00 & 135,00 & 163,00 & & & \\
\hline & 9 & 71,00 & 87,00 & 154,00 & 161,00 & 141,00 & 150,00 & 133,00 & 157,00 & \\
\hline & média & 106 & 123 & 140 & 158 & 161 & 172 & 216 & 191 & \\
\hline
\end{tabular}


Tabela 5 - Valores da pressão arterial sistólica obtidos no teste progressivo escalonado de esforço máximo após 90 dias de treinamento - São Paulo - 2013

\begin{tabular}{ccccccccccc}
\hline & ANIMAIS & MO & M1 & M2 & M3 & M4 & M5 & M6 & M7 & M8 \\
\cline { 2 - 11 } & 2 & 110 & 144 & 112 & 140 & 156 & 181 & 213 & 170 & \\
90 dias & 4 & 119 & 93 & 123 & 131 & 96 & 134 & 126 & 100 & \\
T1 & 5 & 84 & 95 & 98 & 117 & 114 & 110 & 164 & 170 & \\
& 6 & 91 & 95 & 130 & 135 & 142 & 171 & 190 & 202 & 218 \\
& 7 & 106 & 109 & 107 & 123 & 144 & 145 & 143 & & \\
& 8 & 126 & 142 & 150 & 162 & 195 & 204 & 234 & 240 & \\
& 9 & 90 & 145 & 155 & 164 & 187 & 175 & 210 & 235 & \\
\hline
\end{tabular}

Gráfico 7 - Valores da pressão arterial sistólica obtidos no teste progressivo escalonado de esforço máximo inicial e após 90 dias de treinamento

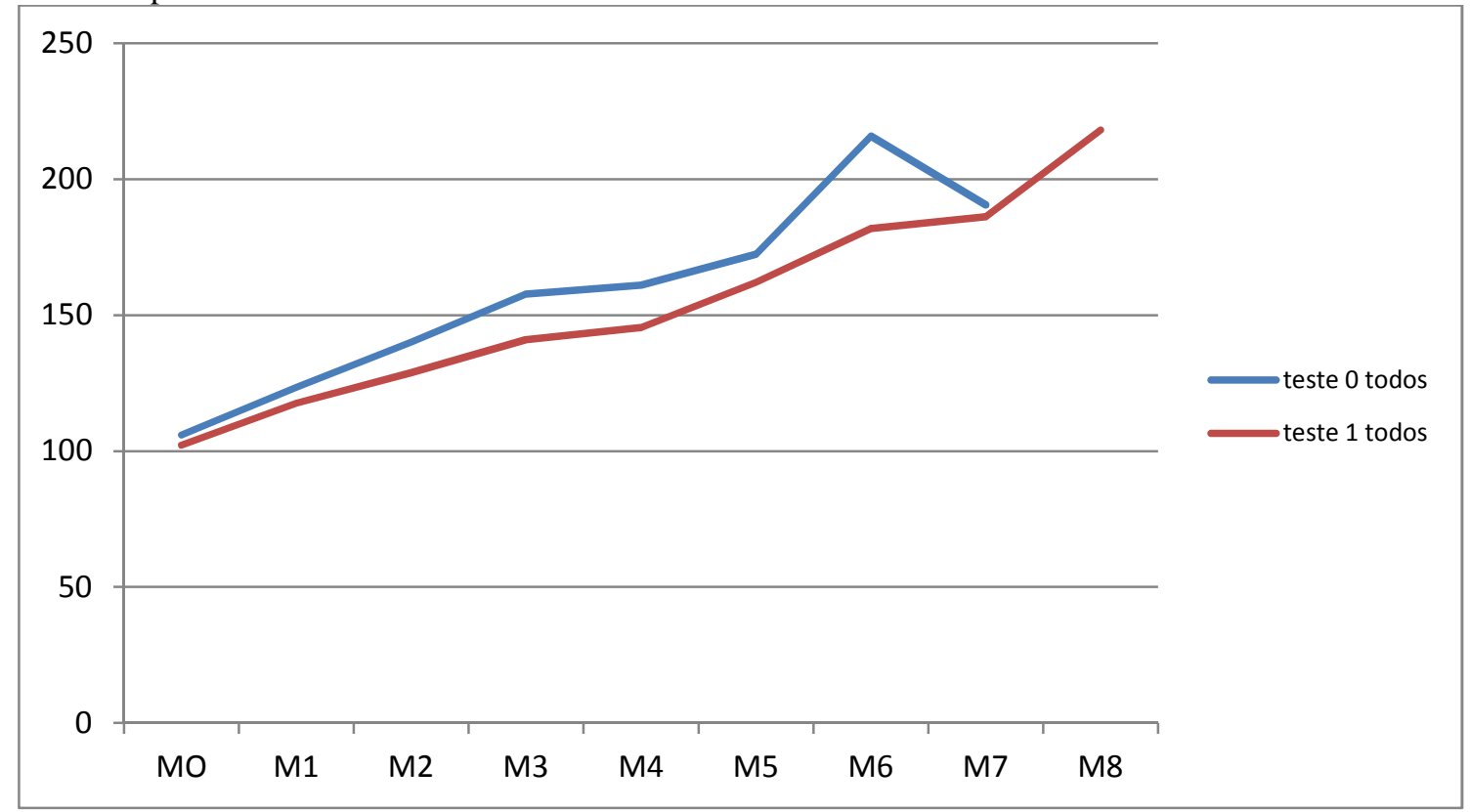

Quando reagrupados em relação ao tipo de treinamento, os resultados estão demonstrados nos gráficos 8 a 11. 
Gráfico 8 - Valores da PAS obtidos no teste progressivo escalonado de esforço máximo inicial e após 90 dias de treinamento a campo

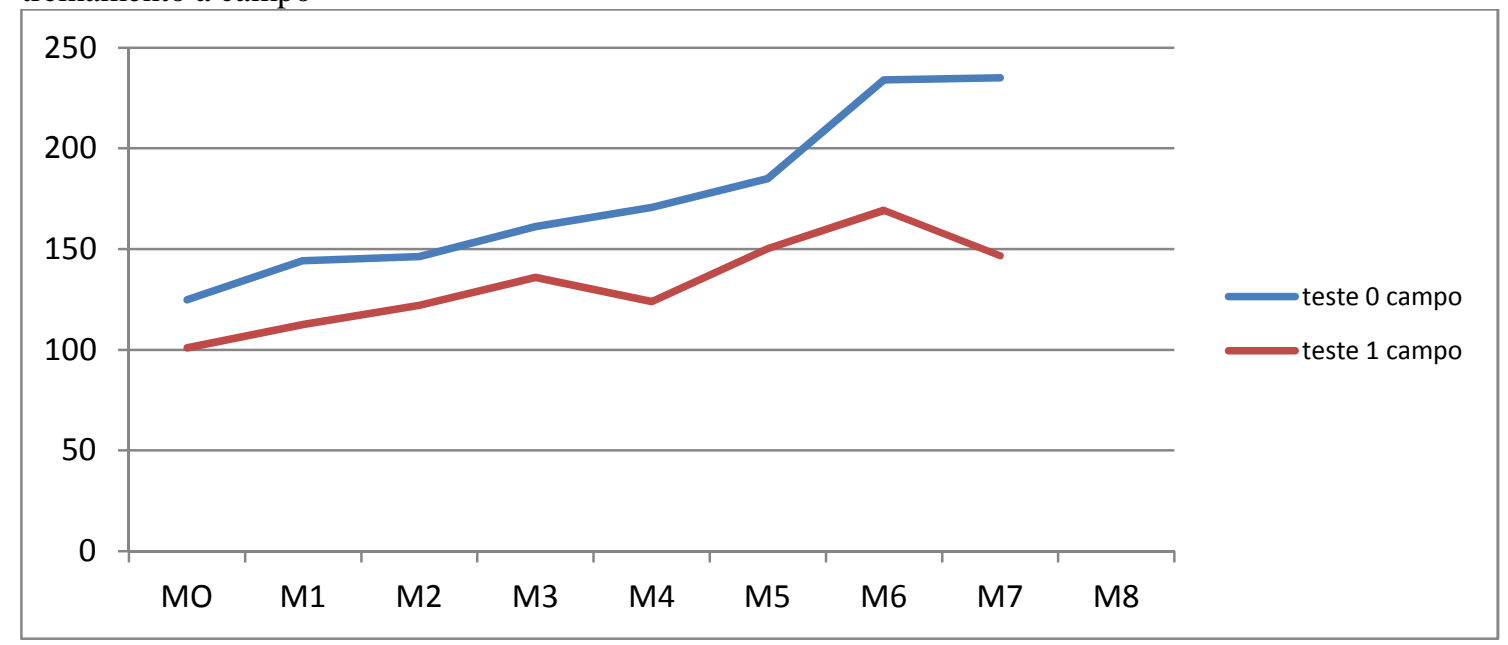

Gráfico 9 - Valores da PAS obtidos no teste progressivo escalonado de esforço máximo inicial e após 90 dias de treinamento na esteira controlado

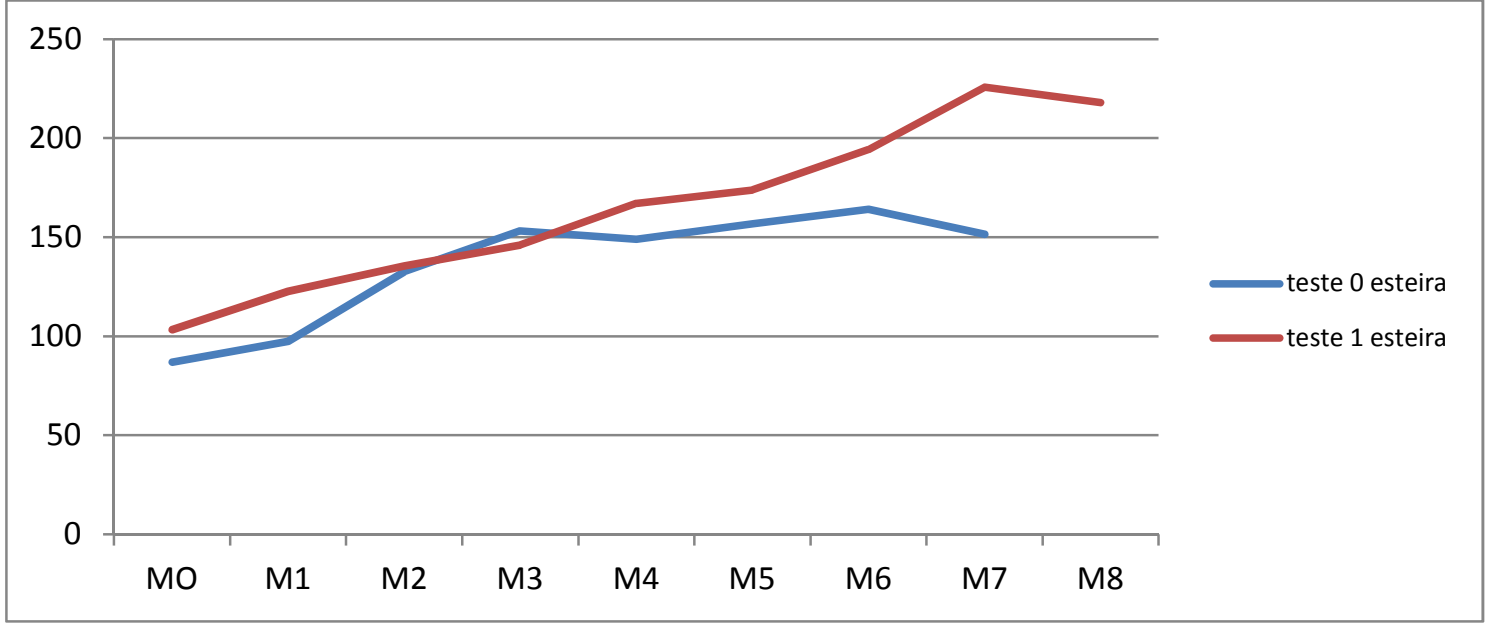


Gráfico 10 - Gráfico comparativo dos valores da PAS obtidas no teste inicial dos subgrupos treinados a campo e na esteira

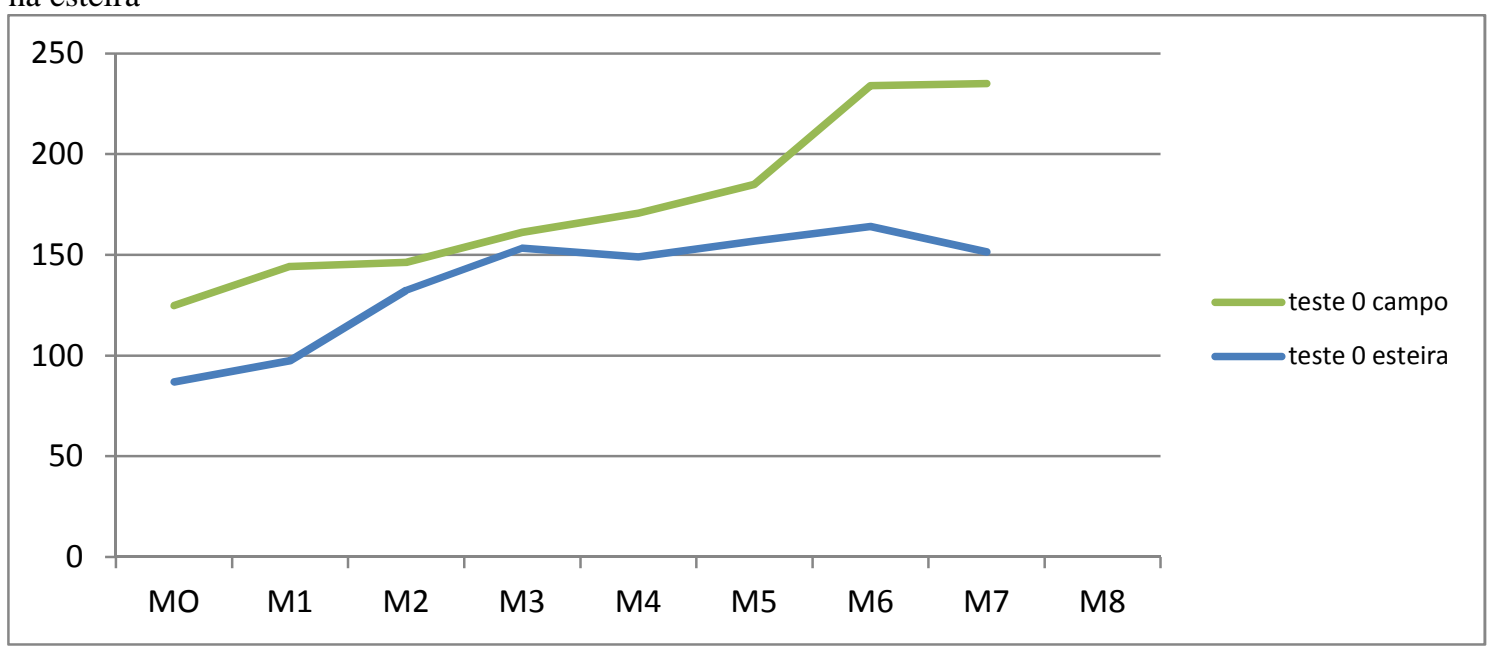

Gráfico 11 - Gráfico comparativo dos valores da PAS obtidas no teste após 90 dias de treinamento dos subgrupos treinados a campo e na esteira

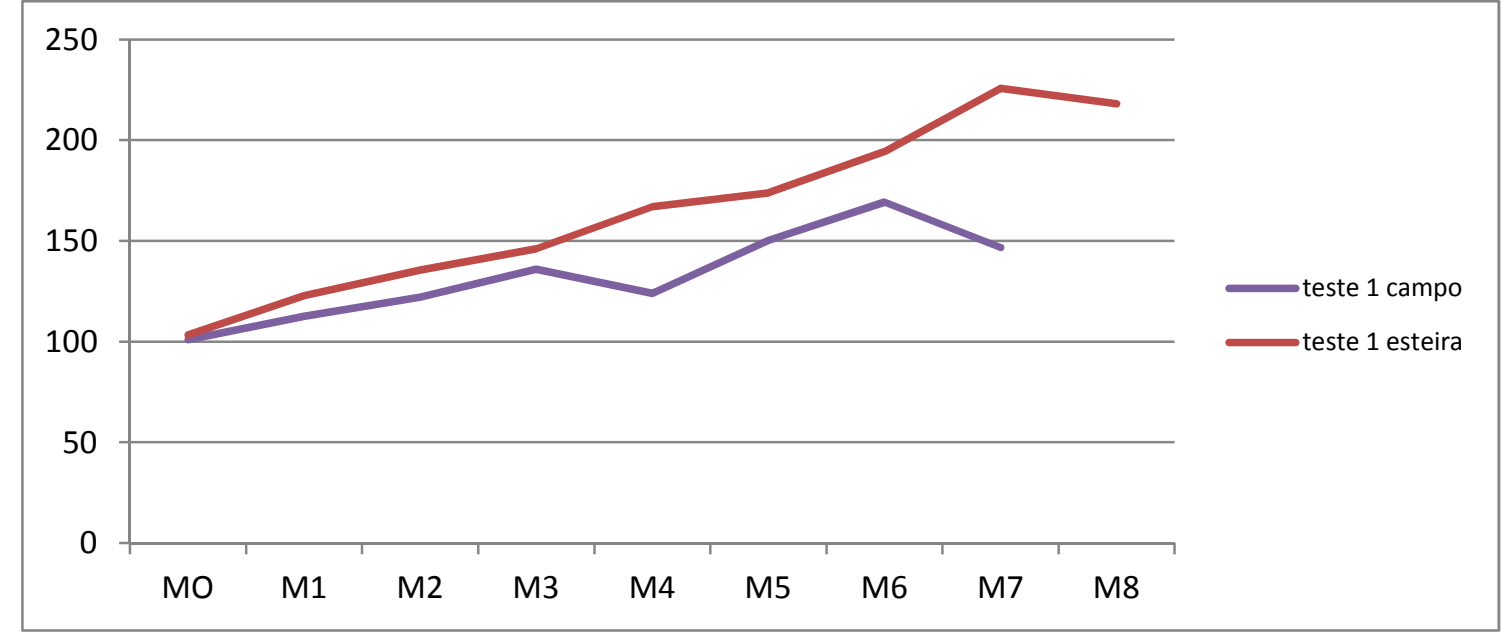




\subsection{Pressão arterial diastólica}

Os valores da PAD obtidos nos testes iniciais e após 90 dias de treinamento com todos os animais estão demonstrados nas tabelas 6 e 7 e gráfico12.

Tabela 6 - Valores da PAD obtidos no teste progressivo escalonado de esforço máximo inicial - São Paulo 2013

\begin{tabular}{|c|c|c|c|c|c|c|c|c|c|c|}
\hline \multirow{11}{*}{$\begin{array}{c}\text { Inicial } \\
\text { T0 }\end{array}$} & ANIMAIS & $\mathrm{MO}$ & M1 & M2 & M3 & M4 & M5 & M6 & M7 & M8 \\
\hline & 1 & 93 & 44 & 50 & 47 & 55 & 30 & 52 & \multirow[t]{5}{*}{43} & \\
\hline & 2 & & 64 & 46 & 17 & 89 & 81 & & & \\
\hline & 3 & 92 & 53 & 65 & 64 & 75 & 87 & 60 & & \\
\hline & 4 & 112 & 90 & 68 & 60 & 72 & 41 & 48 & & \\
\hline & 5 & 89 & 75 & 70 & 68 & 45 & 22 & 11 & & \\
\hline & 6 & 39 & 51 & 48 & 85 & 73 & 50 & 36 & \multirow[t]{3}{*}{39} & \\
\hline & 7 & 83 & 61 & 35 & 23 & 8 & 31 & 42 & & \\
\hline & 8 & 61 & 58 & 72 & 71 & 67 & 75 & & & \\
\hline & 9 & 35 & 36 & 69 & 105 & 76 & 52 & 41 & 33 & \\
\hline & média & 76 & 59 & 58 & 60 & 62 & 52 & 42 & 41 & \\
\hline
\end{tabular}


Tabela 7 - Valores da PAD obtidos no teste progressivo escalonado de esforço máximo após 90 dias de treinamento aeróbico - São Paulo - 2013

\begin{tabular}{|c|c|c|c|c|c|c|c|c|c|c|}
\hline \multirow{11}{*}{$\begin{array}{c}90 \text { dias } \\
\mathrm{T} 1\end{array}$} & ANIMAIS & $\mathrm{MO}$ & M1 & M2 & M3 & M4 & M5 & M6 & M7 & M8 \\
\hline & 1 & & & & & & & & & \\
\hline & 2 & 82 & 78 & 49 & 57 & 41 & 38 & 29 & 60 & \multirow{8}{*}{63} \\
\hline & 3 & 72 & 69 & 58 & 50 & 52 & 55 & 74 & & \\
\hline & 4 & 71 & 62 & 42 & 41 & 28 & 36 & 38 & 31 & \\
\hline & 5 & 74 & 77 & 51 & 56 & 41 & 27 & 45 & 40 & \\
\hline & 6 & 47 & 43 & & 59 & 71 & 57 & 62 & 77 & \\
\hline & 7 & 37 & 21 & 35 & 60 & 73 & 51 & 67 & & \\
\hline & 8 & 61 & 71 & 74 & 57 & 68 & 47 & 77 & 79 & \\
\hline & 9 & 81 & 69 & 61 & 73 & 108 & 91 & 53 & 94 & \\
\hline & média & 66 & 61 & 53 & 57 & 60 & 50 & 56 & 64 & 63 \\
\hline
\end{tabular}

Gráfico 12 - Valores da PAD obtidos no teste progressivo escalonado de esforço máximo inicial e após 90 dias de treinamento

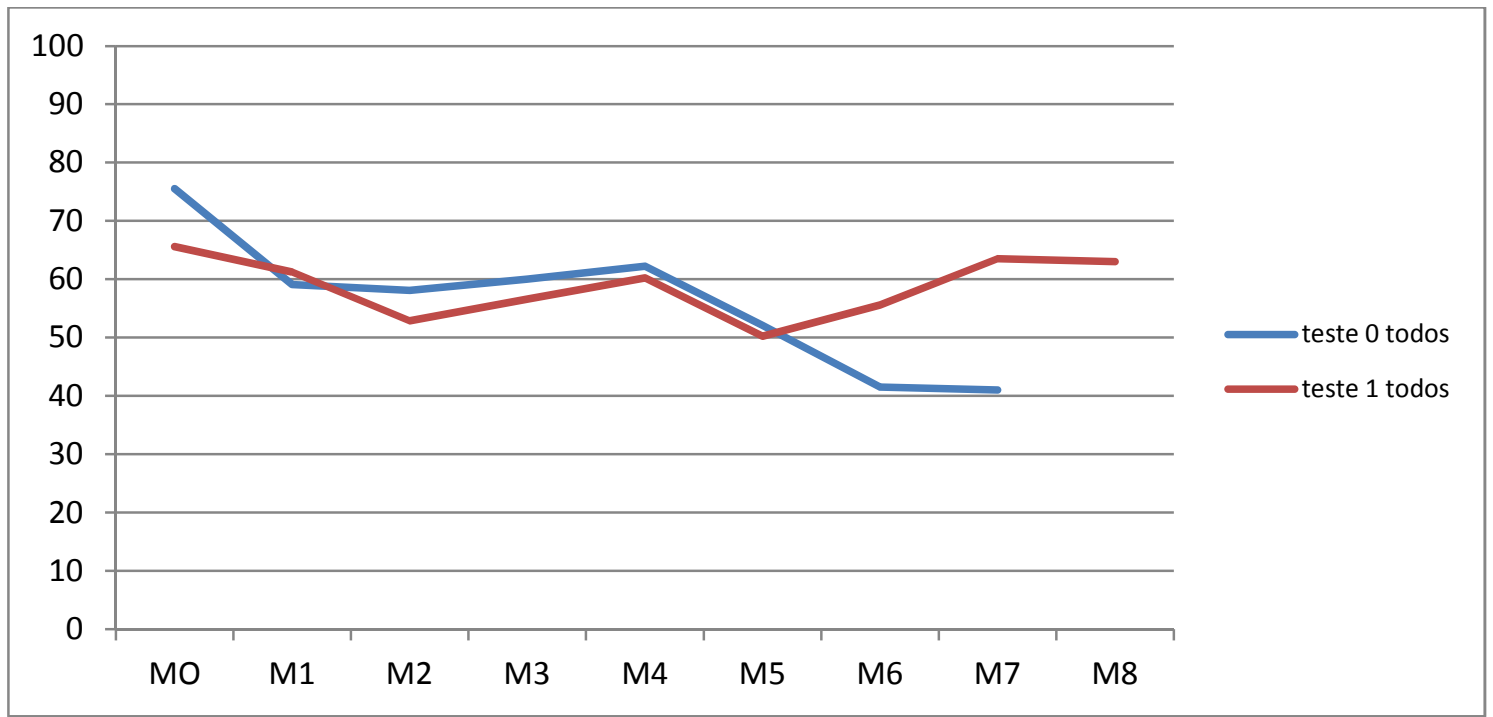

Quando reagrupados em relação ao tipo de treinamento, os resultados estão demonstrados nos gráficos 13 a 16. 
Gráfico 13 - Valores da PAD obtidos no teste progressivo escalonado de esforço máximo inicial e após 90 dias de treinamento a campo

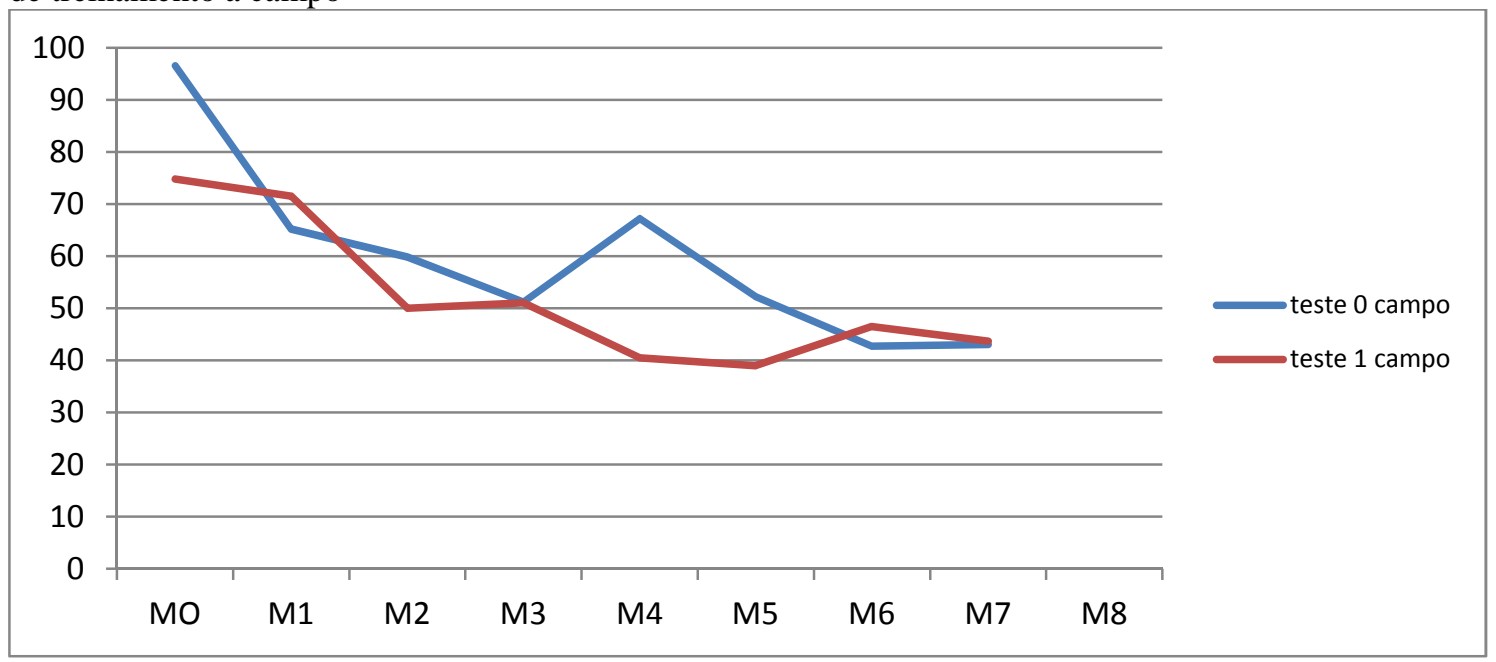

Gráfico 14 - Valores da PAD obtidos no teste progressivo escalonado de esforço máximo inicial e após 90 dias de treinamento na esteira controlado

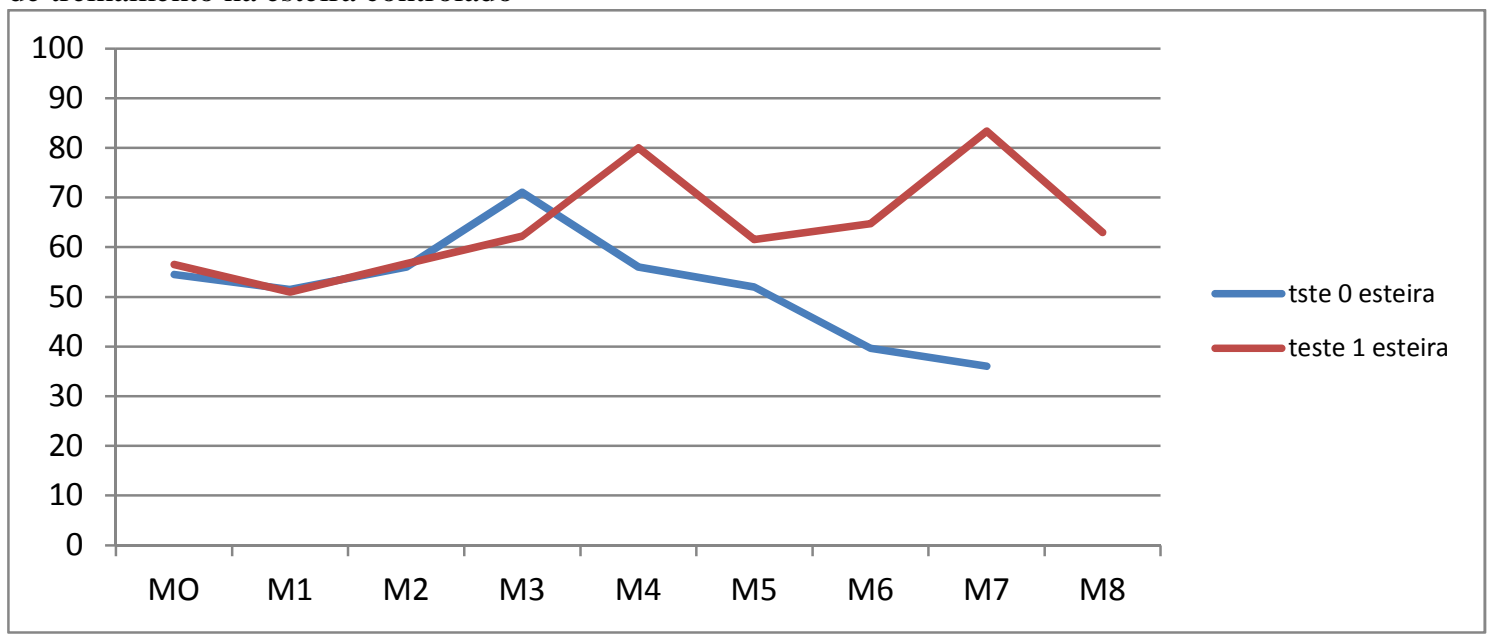


Gráfico 15 - Gráfico comparativo dos valores da PAD obtidas no teste inicial dos subgrupos treinados a campo e na esteira

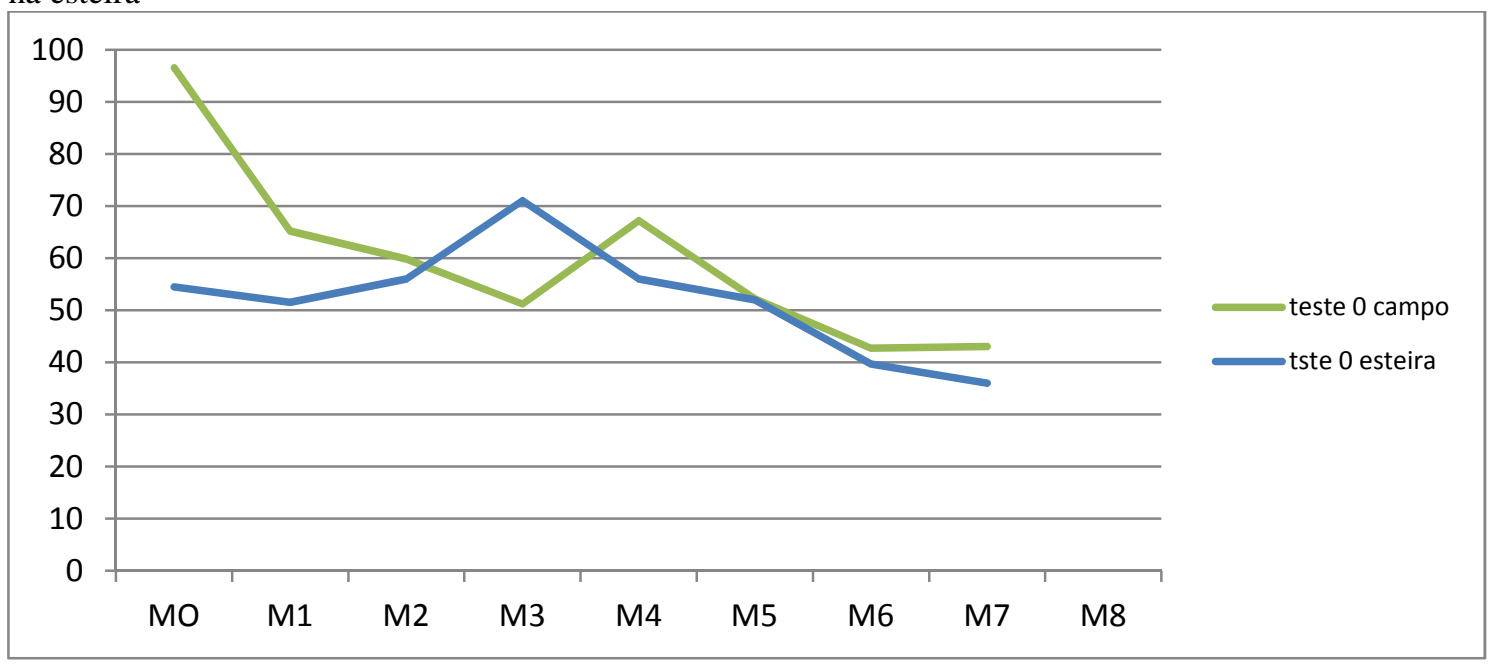

Gráfico 16 - Gráfico comparativo dos valores da PAD obtidas no teste após 90 dias de treinamento dos subgrupos treinados a campo e na esteira

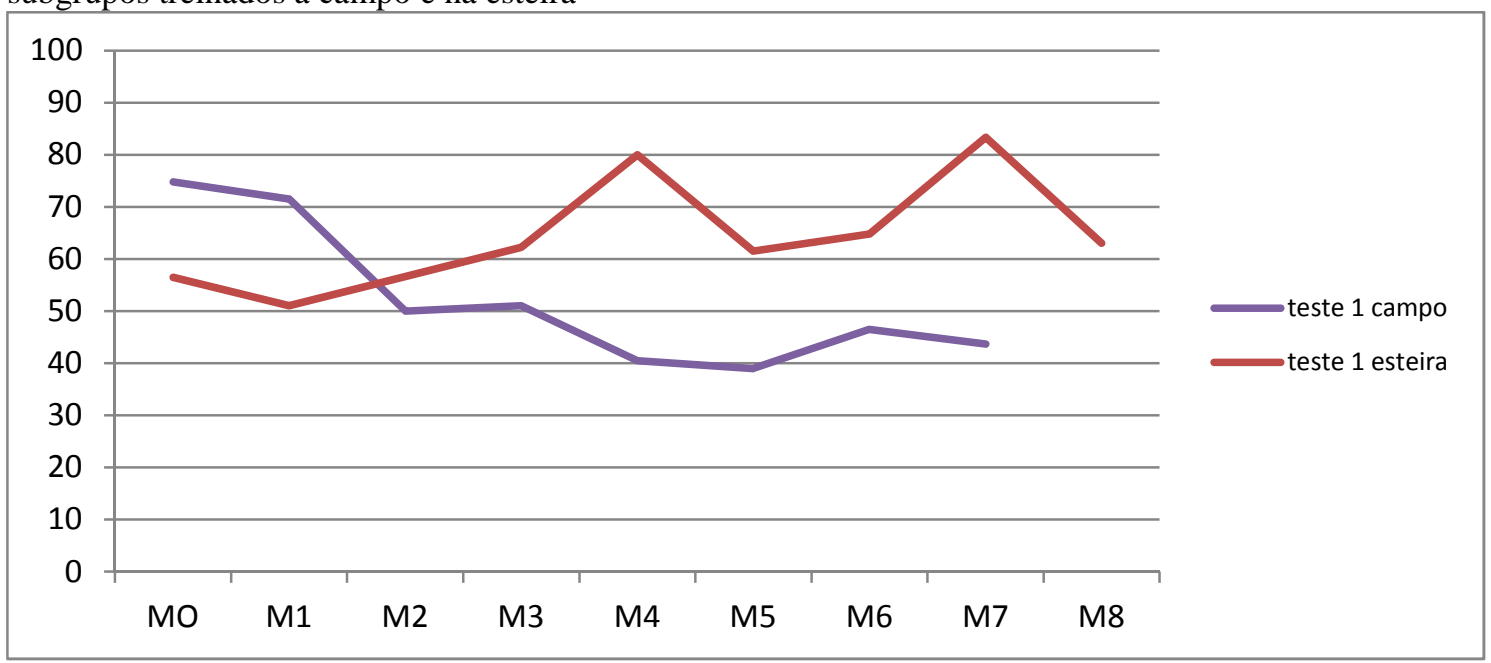




\subsection{Pressão arterial média}

Os valores da PAM obtidos nos testes iniciais e após 90 dias de treinamento com todos os animais estão demonstrados nas tabelas 8 e 9 e gráfico 17 .

Tabela 8 - Valores da PAM obtidos no teste progressivo escalonado de esforço máximo inicial - São Paulo 2013

\begin{tabular}{ccccccccccc}
\hline & ANIMAIS & MO & M1 & M2 & M3 & M4 & M5 & M6 & M7 & M8 \\
\cline { 2 - 10 } & 1 & 109 & 94 & 99 & 103 & 108 & 116 & 113 & 124 & \\
& 2 & & 92 & 80 & 100 & 89 & 105 & & & \\
Inicial & 4 & 98 & 85 & 95 & 97 & 100 & 121 & 123 & & \\
T0 & 5 & 131 & 145 & 120 & 132 & 128 & 128 & 145 & & \\
& 6 & 53 & 61 & 67 & 102 & 92 & 74 & 82 & 88 \\
& 7 & 101 & 83 & 111 & 109 & 111 & 132 & 137 & \\
& 8 & 70 & 72 & 97 & 95 & 100 & 108 & & & \\
& 9 & 54 & 67 & 94 & 122 & 105 & 85 & 89 & 85 & \\
\hline
\end{tabular}


Tabela 9 - Valores da PAM obtidos no teste progressivo escalonado de esforço máximo após 90 dias de treinamento aeróbico - São Paulo - 2013

\begin{tabular}{|c|c|c|c|c|c|c|c|c|c|c|}
\hline \multirow{11}{*}{$\begin{array}{c}90 \text { dias } \\
\text { T1 }\end{array}$} & ANIMAIS & MO & M1 & M2 & M3 & M4 & M5 & M6 & M7 & M8 \\
\hline & 1 & & & & & & & & & \\
\hline & 2 & 94 & 112 & 84 & 93 & 89 & 111 & 90 & 101 & \\
\hline & 3 & 80 & 93 & 104 & 86 & 93 & 109 & 113 & & \\
\hline & 4 & 98 & 78 & 75 & 79 & 64 & 77 & 71 & 71 & \\
\hline & 5 & 72 & 80 & 68 & 84 & 62 & 69 & 87 & 96 & \\
\hline & 6 & 68 & 69 & 57 & 94 & 100 & 108 & 117 & 121 & 130 \\
\hline & 7 & 66 & 56 & 68 & 73 & 102 & 96 & 107 & & \\
\hline & 8 & 88 & 105 & 110 & 116 & 127 & 121 & 137 & 141 & \\
\hline & 9 & 84 & 101 & 103 & 108 & 139 & 129 & 151 & 160 & \\
\hline & média & 81 & 87 & 84 & 92 & 97 & 103 & 109 & 115 & 130 \\
\hline
\end{tabular}

Gráfico 17 - Valores da PAM obtidos no teste progressivo escalonado de esforço máximo inicial e após 90 dias de treinamento

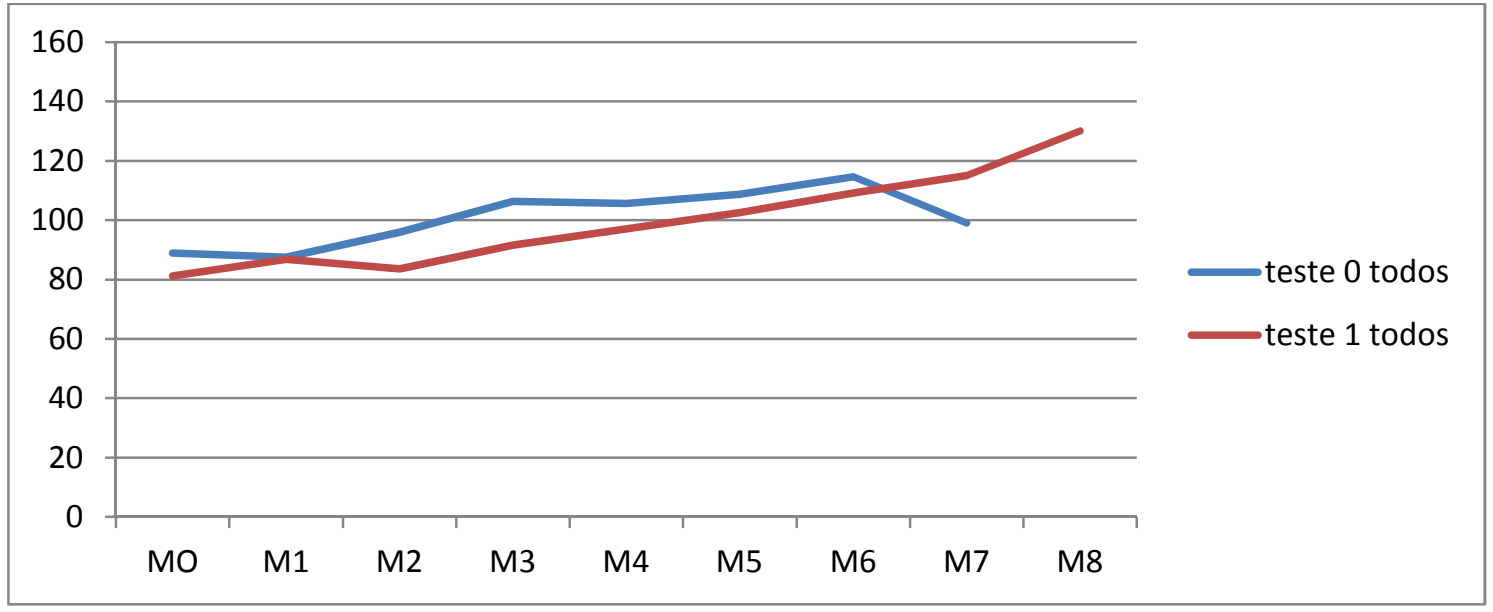

Quando reagrupados em relação ao tipo de treinamento, os resultados estão demonstrados nos gráficos 18 a 21 . 
Gráfico 18 - Valores da PAM obtidos no teste progressivo escalonado de esforço máximo inicial e após 90 dias de treinamento a campo

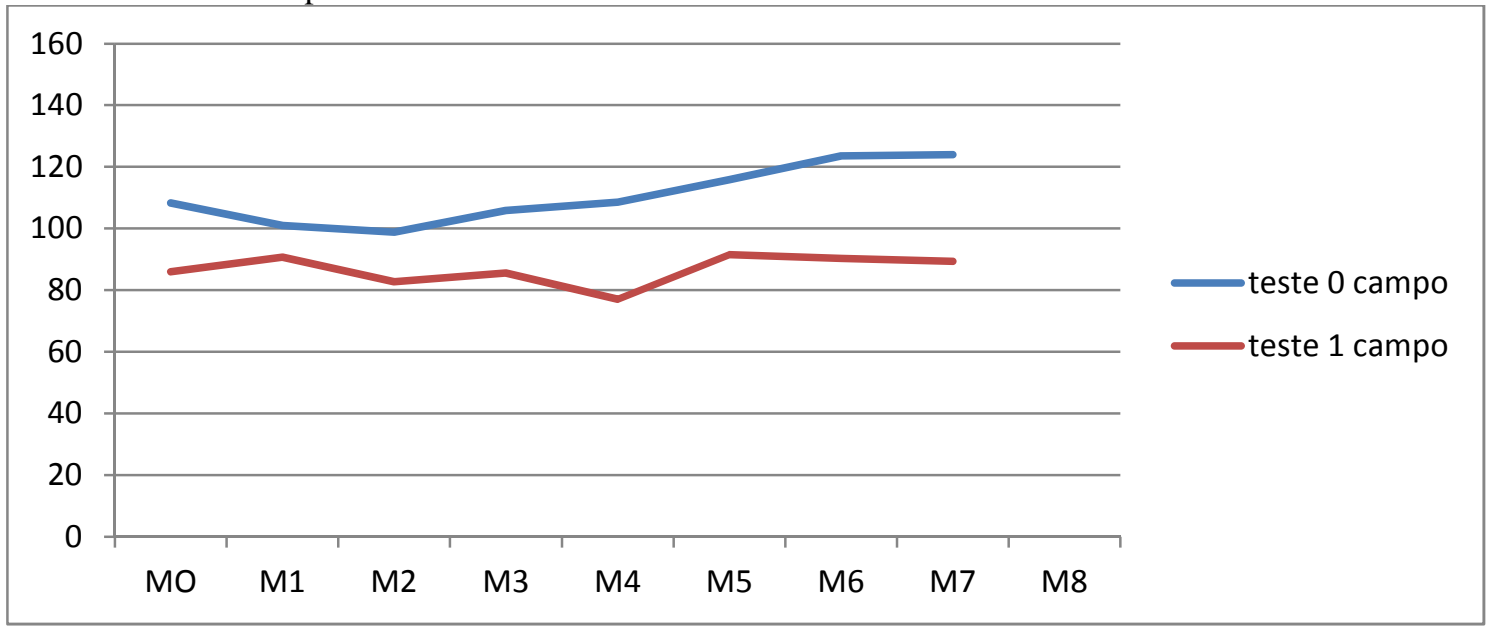

Gráfico 19 - Valores da PAM obtidos no teste progressivo escalonado de esforço máximo inicial e após 90 dias de treinamento na esteira controlado

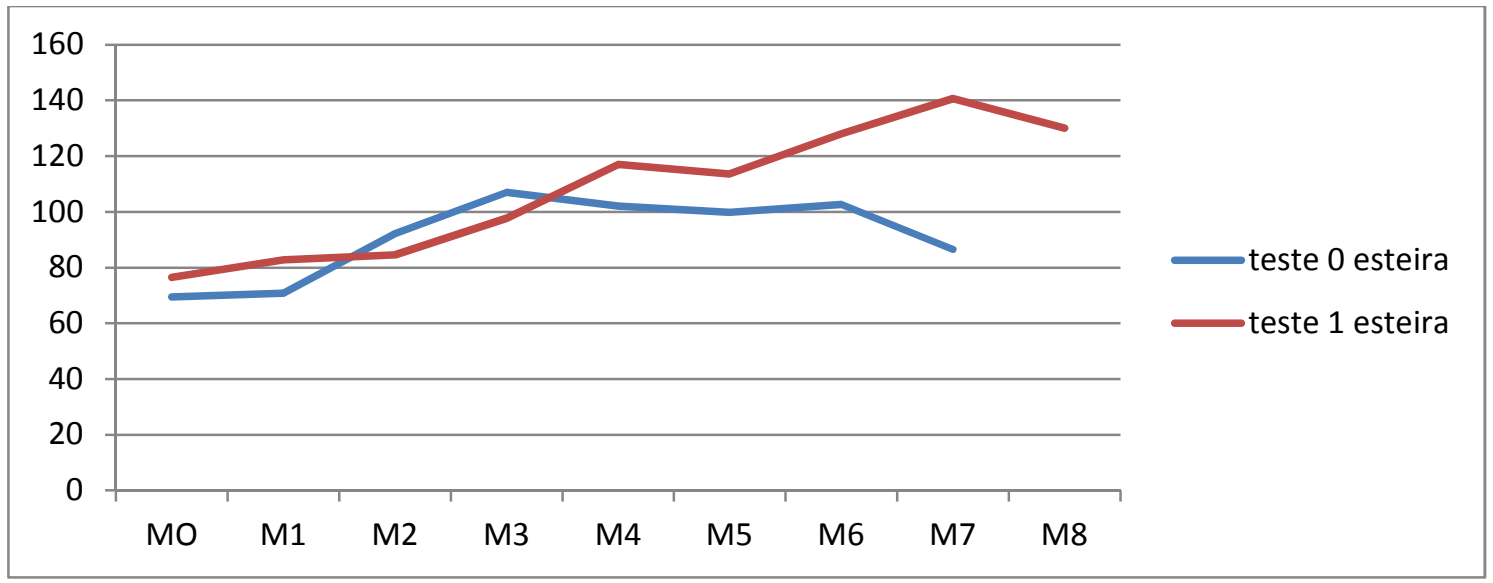


Gráfico 20 - Gráfico comparativo dos valores da PAM obtidas no teste inicial dos subgrupos treinados a campo e na esteira

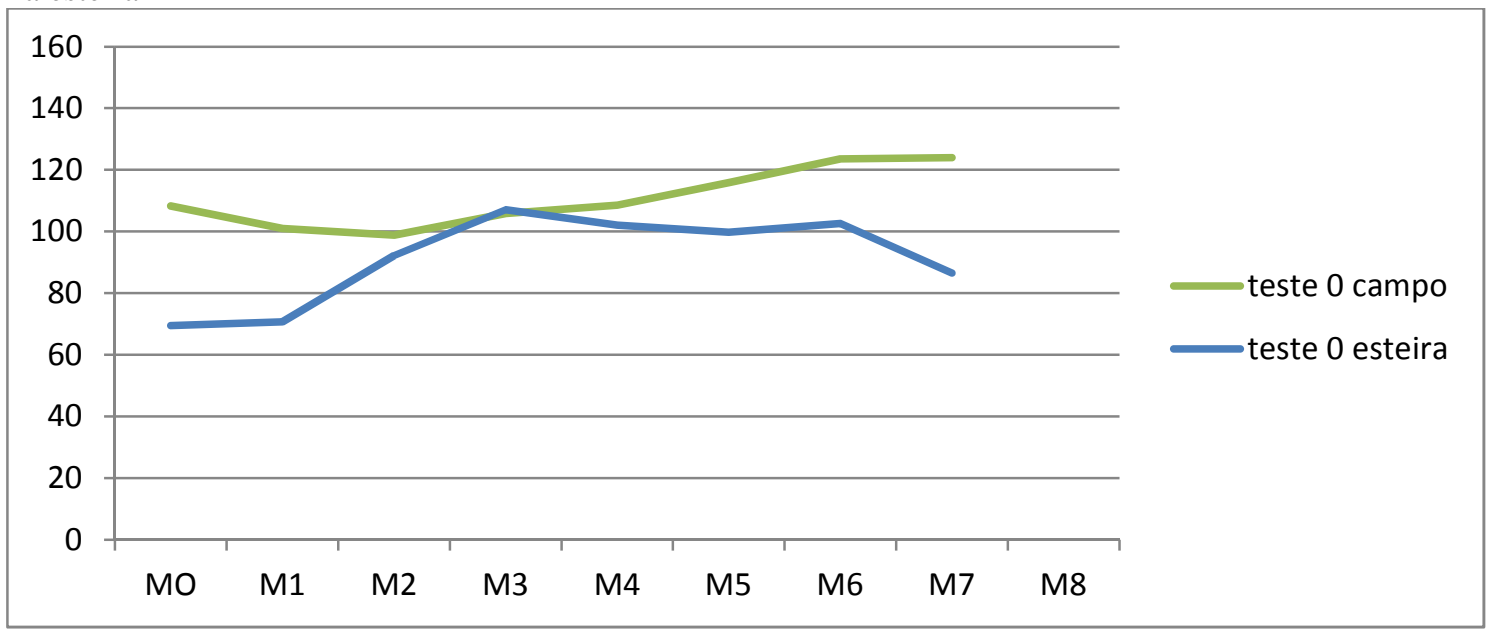

Gráfico 21 - Gráfico comparativo dos valores da PAM obtidas no teste após 90 dias de treinamento dos subgrupos treinados a campo e na esteira

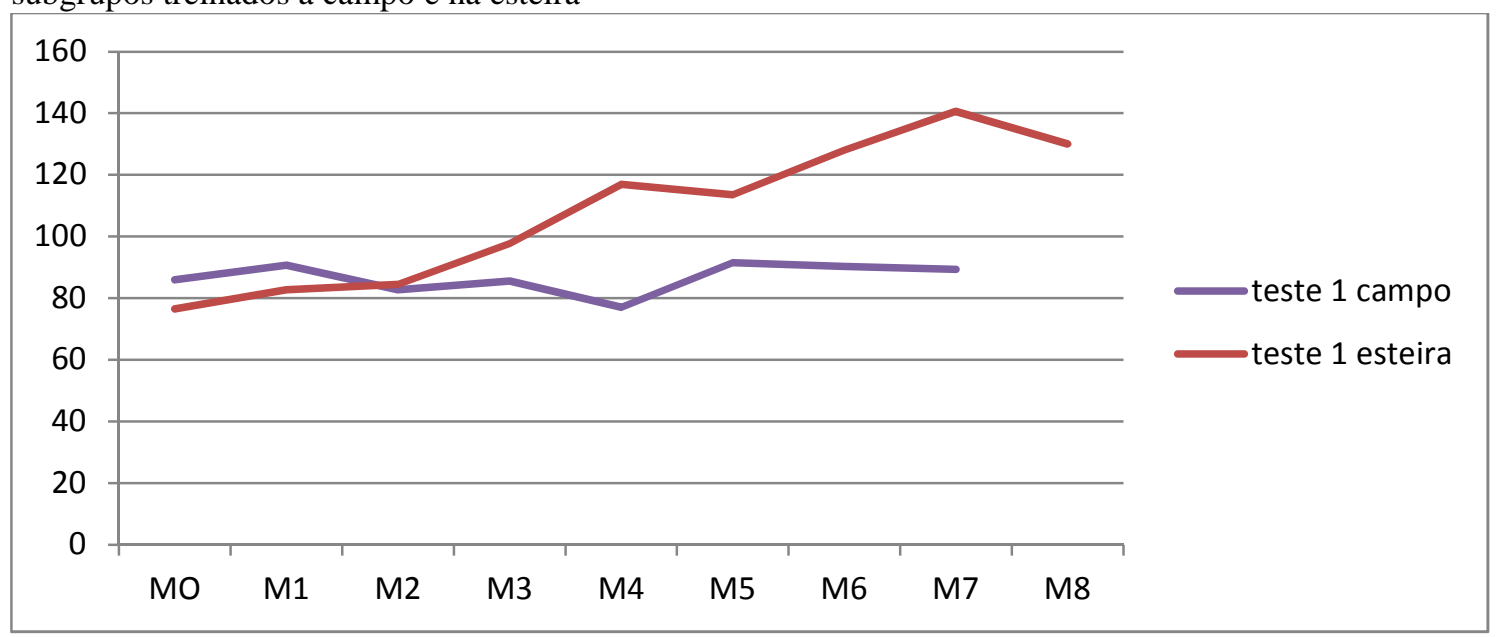




\subsection{Lactato}

Os valores da concentração de lactato sanguíneo obtidos nos testes iniciais e após 90 dias de treinamento com todos os animais estão demonstrados nas tabelas 10 e 11 e gráfico 22.

Tabela 10 - Valores da concentração de lactato sanguíneo obtidos no teste progressivo escalonado de esforço máximo inicial - São Paulo - 2013

\begin{tabular}{ccccccccccc}
\hline & animais & M0 & M1 & M2 & M3 & M4 & M5 & M6 & M7 & M8 \\
\cline { 2 - 10 } & 1 & 0,95 & 0,95 & 0,69 & 0,70 & 0,93 & 2,12 & 3,55 & 4,71 & \\
& 2 & 1,21 & 0,89 & 0,93 & 1,28 & 2,44 & 3,83 & & & \\
Inicial & 4 & 1,13 & 0,88 & 0,77 & 0,83 & 1,10 & 2,31 & 3,98 & & \\
T 0 & 5 & 1,24 & 1,24 & 1,25 & 1,31 & 1,34 & 1,72 & 2,80 & & \\
& 10 & 0,67 & 0,74 & 1,24 & 5,37 & 8,95 & 11,00 & 14,63 & 20,15 \\
& 12 & 0,61 & 1,71 & 2,87 & 4,05 & 4,77 & 11,07 & 17,72 & & \\
& 13 & 1,41 & 1,54 & 1,35 & 1,39 & 3,55 & 6,27 & & & \\
& 14 & 0,81 & 1,05 & 2,03 & 6,36 & 7,77 & 19,41 & 10,55 & 6,67 & \\
\cline { 2 - 9 } & MÉDIA & 1,02 & 1,12 & 1,36 & 2,49 & 3,58 & 6,64 & 8,12 & 10,51 & \\
\hline
\end{tabular}


Tabela 11 - Valores da concentração de lactato sanguíneo obtidos no teste progressivo escalonado de esforço máximo após 90 dias de treinamento aeróbico - São Paulo - 2013

\begin{tabular}{|c|c|c|c|c|c|c|c|c|c|c|}
\hline \multirow{11}{*}{$\begin{array}{c}90 \text { dias } \\
\text { T } 1\end{array}$} & animais & M0 & M1 & M2 & M3 & M4 & M5 & M6 & M7 & M8 \\
\hline & 1 & 0,75 & 0,57 & 0,54 & 0,60 & 0,71 & 1,71 & 2,62 & 3,22 & \\
\hline & 2 & 1,14 & 0,92 & 0,63 & 0,69 & 0,46 & 2,79 & 2,94 & 4,15 & \\
\hline & 3 & 2,52 & 2,11 & 1,29 & 0,97 & 1,08 & 2,11 & 4,15 & & \\
\hline & 4 & 1,12 & 1,13 & 1,04 & 0,83 & 0,94 & 2,18 & 4,78 & 7,58 & \\
\hline & 5 & 0,87 & 0,60 & 1,07 & 0,90 & 2,90 & 5,89 & 7,64 & 10,16 & \\
\hline & 10 & 1,34 & 0,60 & 0,62 & 0,64 & 1,34 & 4,44 & 10,10 & 15,54 & 16,61 \\
\hline & 12 & 1,14 & 1,08 & 1,08 & 1,18 & 1,59 & 4,25 & 11,43 & & \\
\hline & 13 & 1,15 & 0,77 & 0,88 & 0,79 & 0,79 & 1,52 & 4,45 & 7,46 & \\
\hline & 14 & 1,67 & 3,53 & 1,27 & 1,02 & 3,41 & 5,61 & 26,75 & 30,97 & \\
\hline & MÉDIA & 1,30 & 1,26 & 0,93 & 0,85 & 1,47 & 3,39 & 8,32 & 11,30 & 16,61 \\
\hline
\end{tabular}

Gráfico 22 - Valores da concentração de lactato sanguíneo obtidos no teste progressivo escalonado de esforço máximo inicial e após 90 dias de treinamento

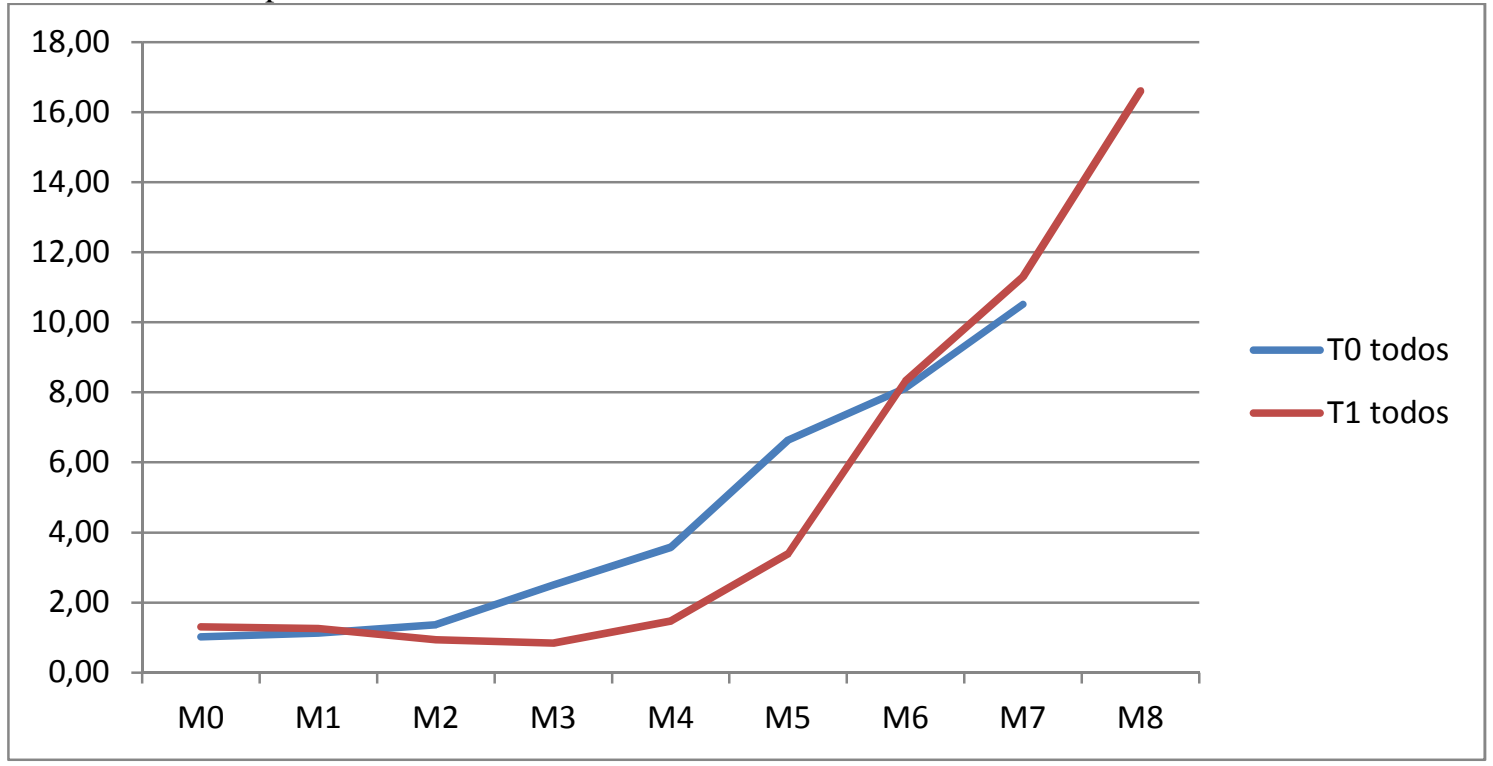

Quando reagrupados em relação ao tipo de treinamento, os resultados estão demonstrados nos gráficos 23 a 26. 
Gráfico 23 - Valores da concentração de lactato sanguíneo obtidos no teste progressivo escalonado de esforço máximo inicial e após 90 dias de treinamento a campo

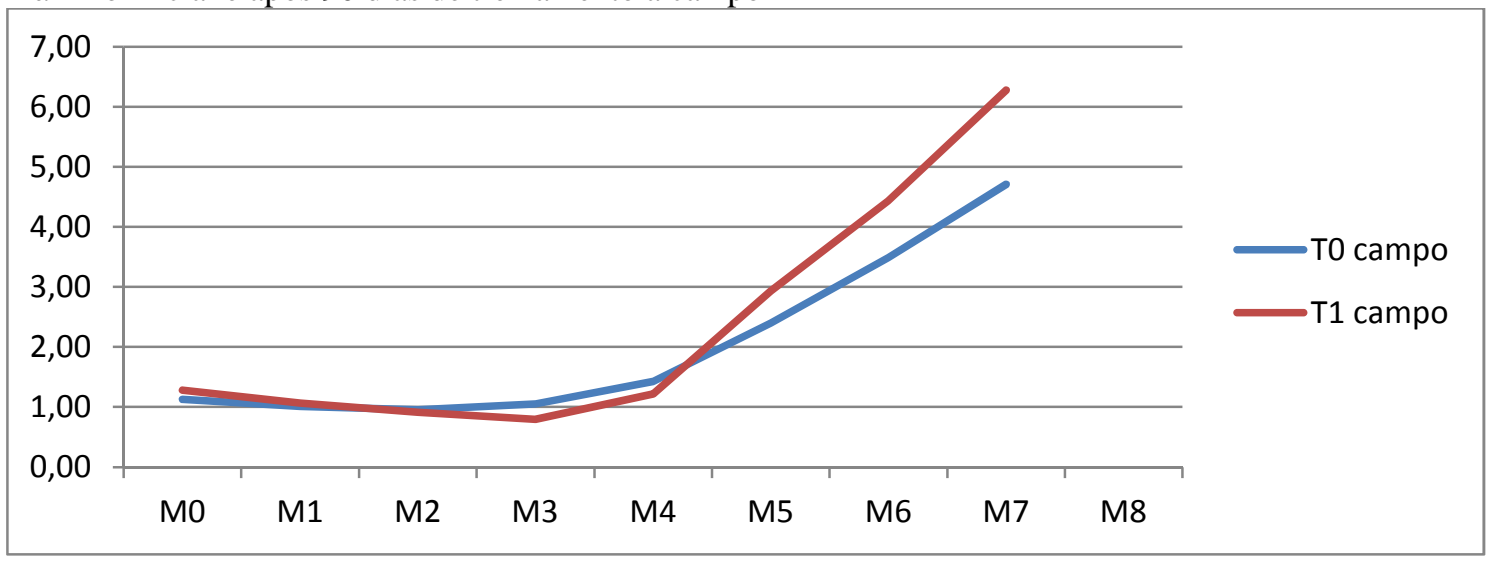

Gráfico 24 - Valores da concentração de lactato sanguíneo obtidos no teste progressivo escalonado de esforço máximo inicial e após 90 dias de treinamento na esteira controlado

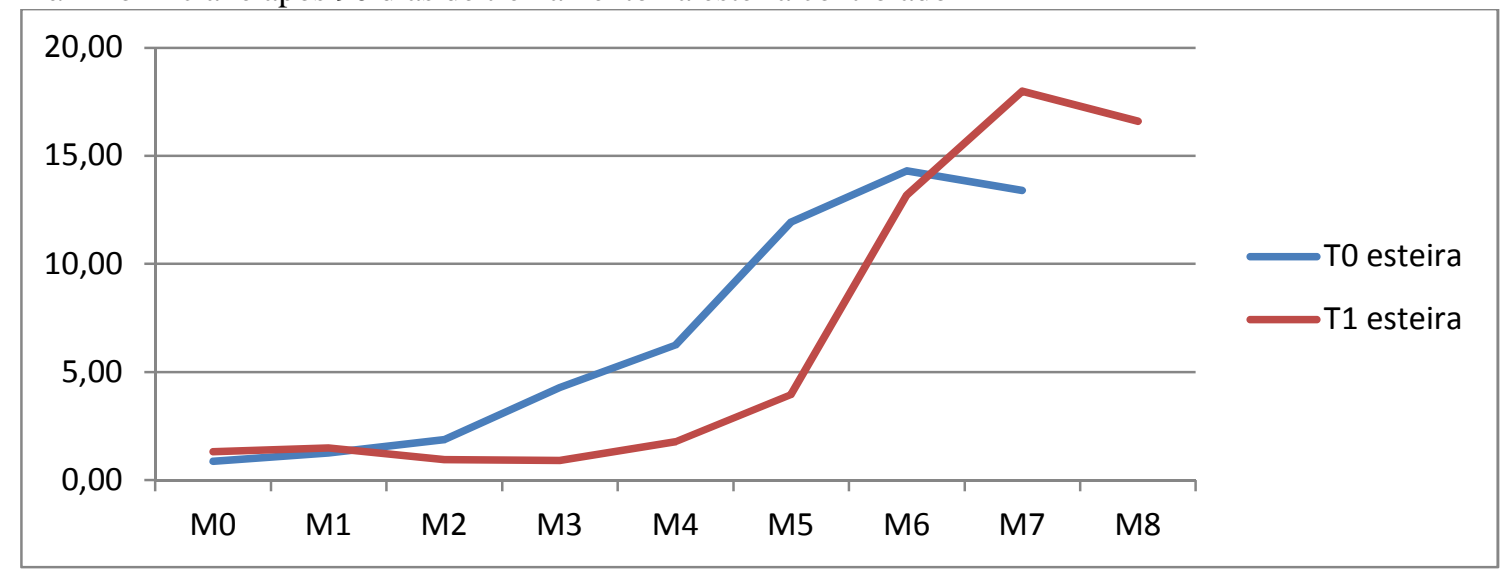


Gráfico 25 - Gráfico comparativo dos valores da concentração de lactato sanguíneo obtido no teste inicial dos subgrupos treinados a campo e na esteira

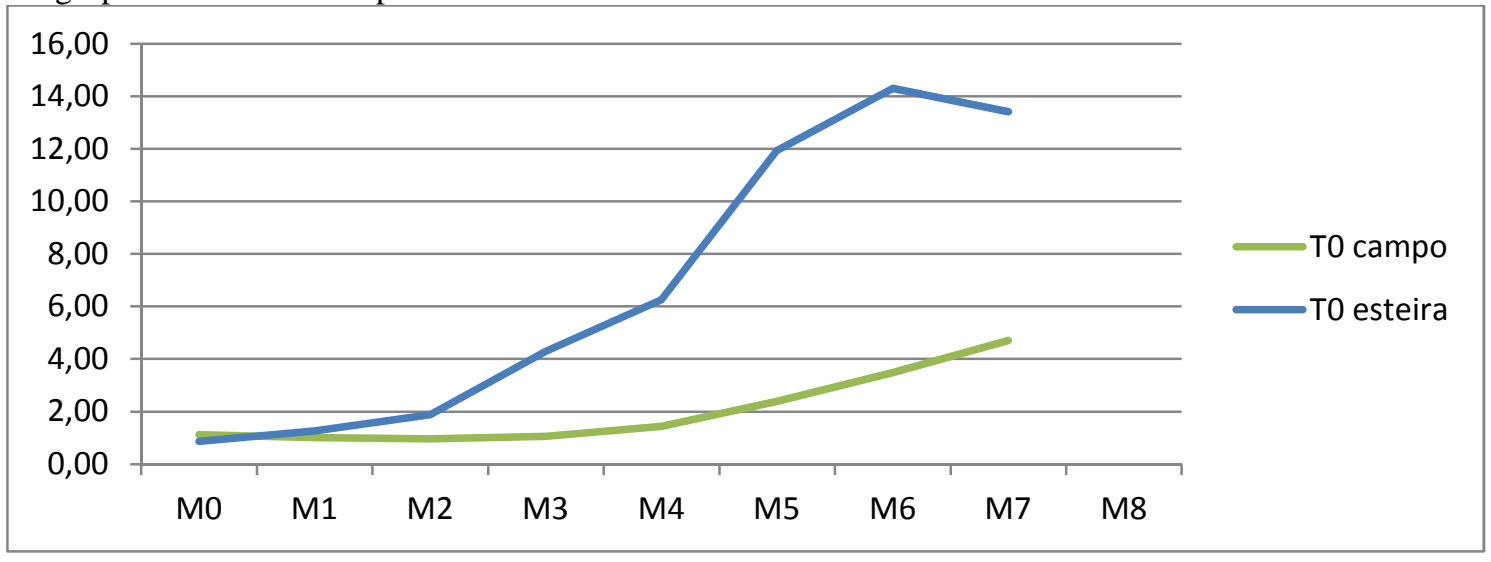

Gráfico 26 - Gráfico comparativo dos valores da concentração de lactato sanguíneo obtido no teste após 90 dias de treinamento dos subgrupos treinados a campo e na esteira

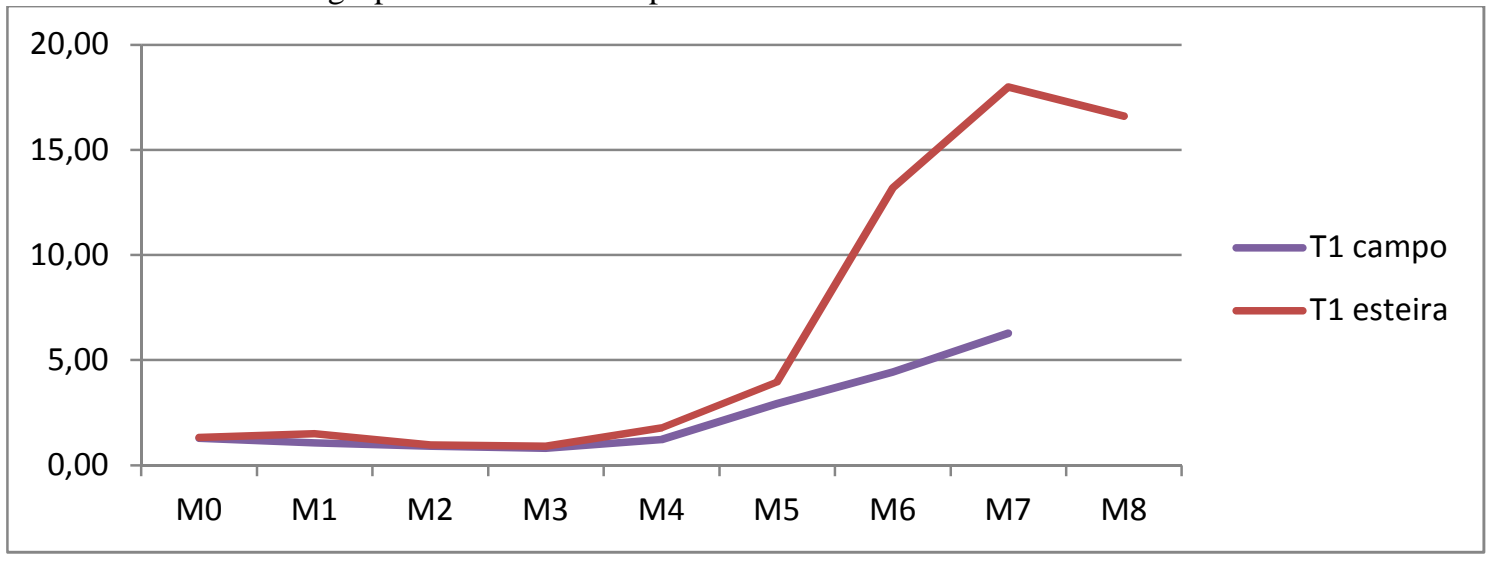




\section{$4.6 \mathrm{pH}$}

Os valores da concentração de hidrogênio sanguíneo $(\mathrm{pH})$ obtidos nos testes iniciais e após 90 dias de treinamento com todos os animais estão demonstrados nas tabelas 12 e 13 e gráfico 27.

Tabela 12 - Valores da concentração de hidrogênio sanguíneo $(\mathrm{pH})$ obtidos no teste progressivo escalonado de esforço máximo inicial - São Paulo - 2013

\begin{tabular}{cccccccccccc}
\hline & ANIMAIS & 1 & 2 & 3 & 4 & 5 & 6 & 7 & 8 & 9 & MEDIA \\
\cline { 2 - 10 } & MO & 7,473 & 7,477 & 7,395 & 7,411 & 7,437 & 7,447 & 7,442 & 7,433 & 7,48 & 7,444 \\
\multirow{6}{*}{ Inicial } & M1 & 7,452 & 7,476 & 7,441 & 7,438 & 7,459 & 7,52 & 7,501 & 7,501 & 7,504 & 7,477 \\
T0 & M2 & 7,455 & 7,472 & 7,441 & 7,455 & 7,452 & 7,513 & 7,505 & 7,504 & 7,464 & 7,473 \\
& M4 & 7,479 & 7,476 & 7,46 & 7,447 & 7,469 & 7,375 & 7,496 & 7,5 & 7,384 & 7,454 \\
& M5 & 7,513 & 7,473 & 7,45 & 7,459 & 7,483 & 7,468 & 7,482 & 7,485 & 7,527 & 7,482 \\
& M6 & 7,537 & & 7,429 & 7,473 & 7,459 & 7,374 & 7,459 & & 7,464 & 7,456 \\
& M7 & 7,45 & & & & & 7,263 & & & 7,333 & 7,349 \\
\hline
\end{tabular}


Tabela 13 - Valores da concentração hidrogênio sanguíneo $(\mathrm{pH})$ obtidos no teste progressivo escalonado de esforço máximo após 90 dias de treinamento aeróbico - São Paulo - 2013

\begin{tabular}{cccccccccccc}
\hline & & 1 & 2 & 3 & 4 & 5 & 6 & 7 & 8 & 9 & MÉDIA \\
\cline { 2 - 10 } & MO & 7,391 & 7,396 & 7,35 & 7,466 & 7,448 & 7,442 & 7,449 & 7,48 & 7,428 \\
& M1 & 7,393 & 7,4 & 7,411 & 7,469 & 7,489 & 7,472 & 7,471 & 7,464 & 7,446 \\
& M2 & 7,367 & 7,392 & 7,424 & 7,459 & 7,462 & 7,473 & 7,478 & 7,496 & 7,444 \\
T1ias & M3 & 7,387 & 7,431 & 7,437 & 7,489 & 7,51 & 7,459 & 7,486 & 7,483 & 7,460 \\
& M4 & 7,385 & 7,417 & 7,434 & 7,486 & 7,524 & 7,465 & 7,484 & 7,459 & 7,457 \\
& M5 & 7,399 & 7,382 & 7,45 & 7,508 & 7,47 & 7,467 & 7,516 & 7,478 & 7,459 \\
& M6 & 7,368 & 7,416 & 7,434 & 7,523 & 7,451 & 7,391 & 7,499 & 7,27 & 7,419 \\
& M7 & 7,358 & 7,374 & & 7,476 & 7,423 & & & 7,45 & 7,199 & 7,380 \\
\hline
\end{tabular}

Gráfico 27 - Valores da concentração de hidrogênio sanguíneo (pH) obtidos no teste progressivo escalonado de esforço máximo inicial e após 90 dias de treinamento

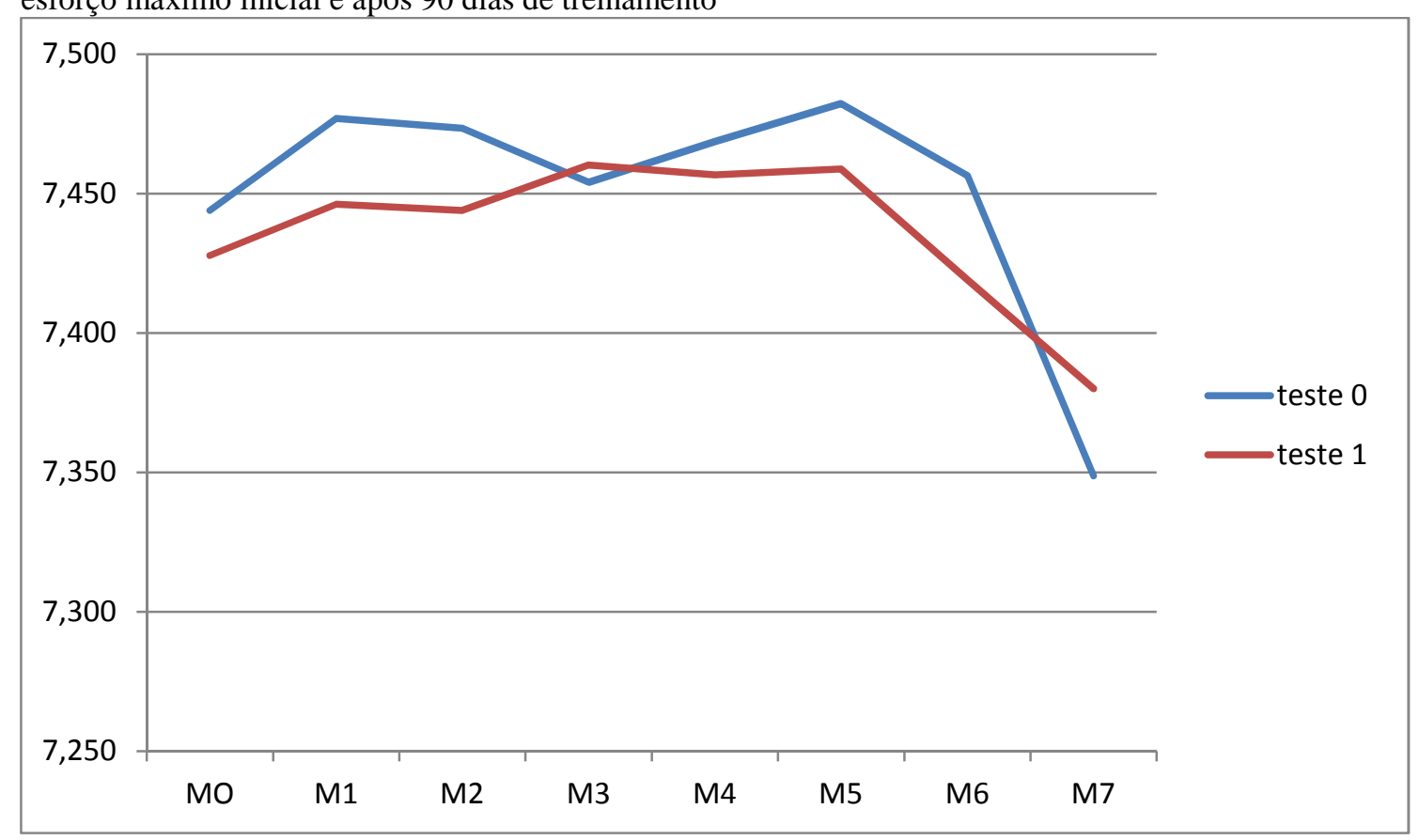

Quando reagrupados em relação ao tipo de treinamento, os resultados estão demonstrados nos gráficos 28 a 31 . 
Gráfico 28 - Valores da concentração hidrogênio sanguíneo (pH) obtidos no teste progressivo escalonado de esforço máximo inicial e após 90 dias de treinamento a campo

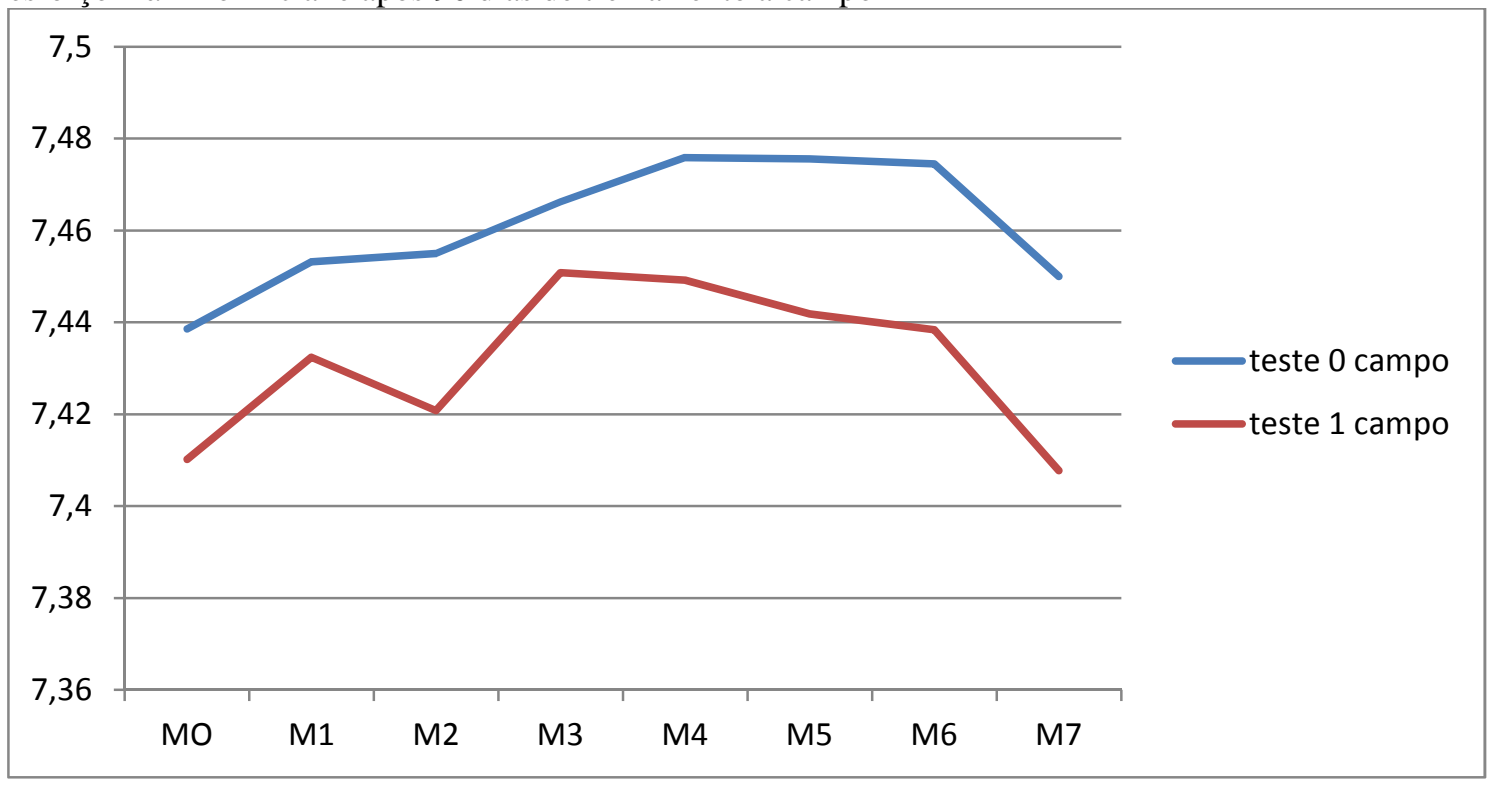

Gráfico 29 - Valores da concentração de hidrogênio sanguíneo $(\mathrm{pH})$ obtidos no teste progressivo escalonado de esforço máximo inicial e após 90 dias de treinamento na esteira controlado

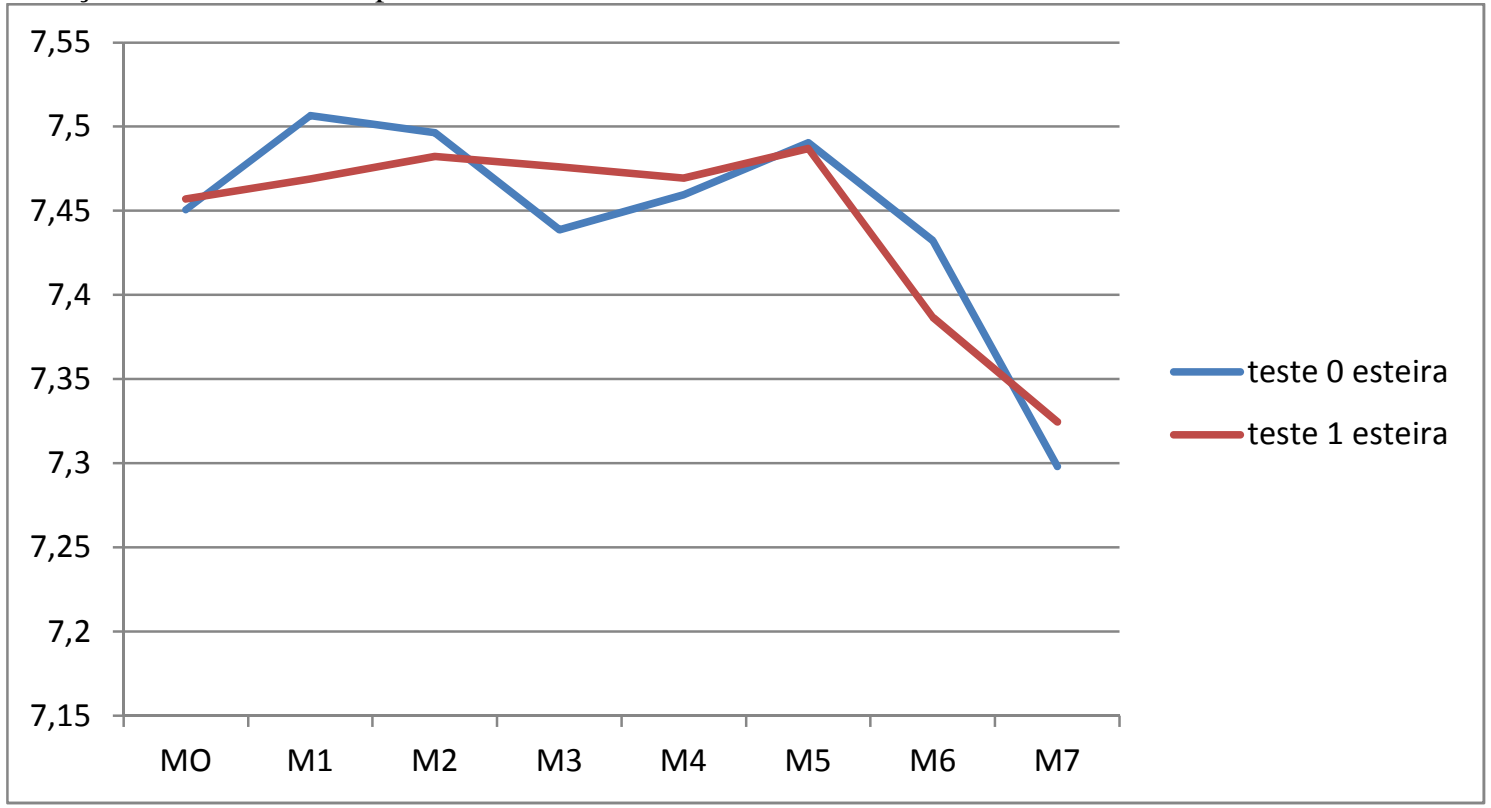


Gráfico 30 - Gráfico comparativo dos valores da concentração de hidrogênio sanguíneo (pH) obtidas no teste inicial dos subgrupos treinados a campo e na esteira

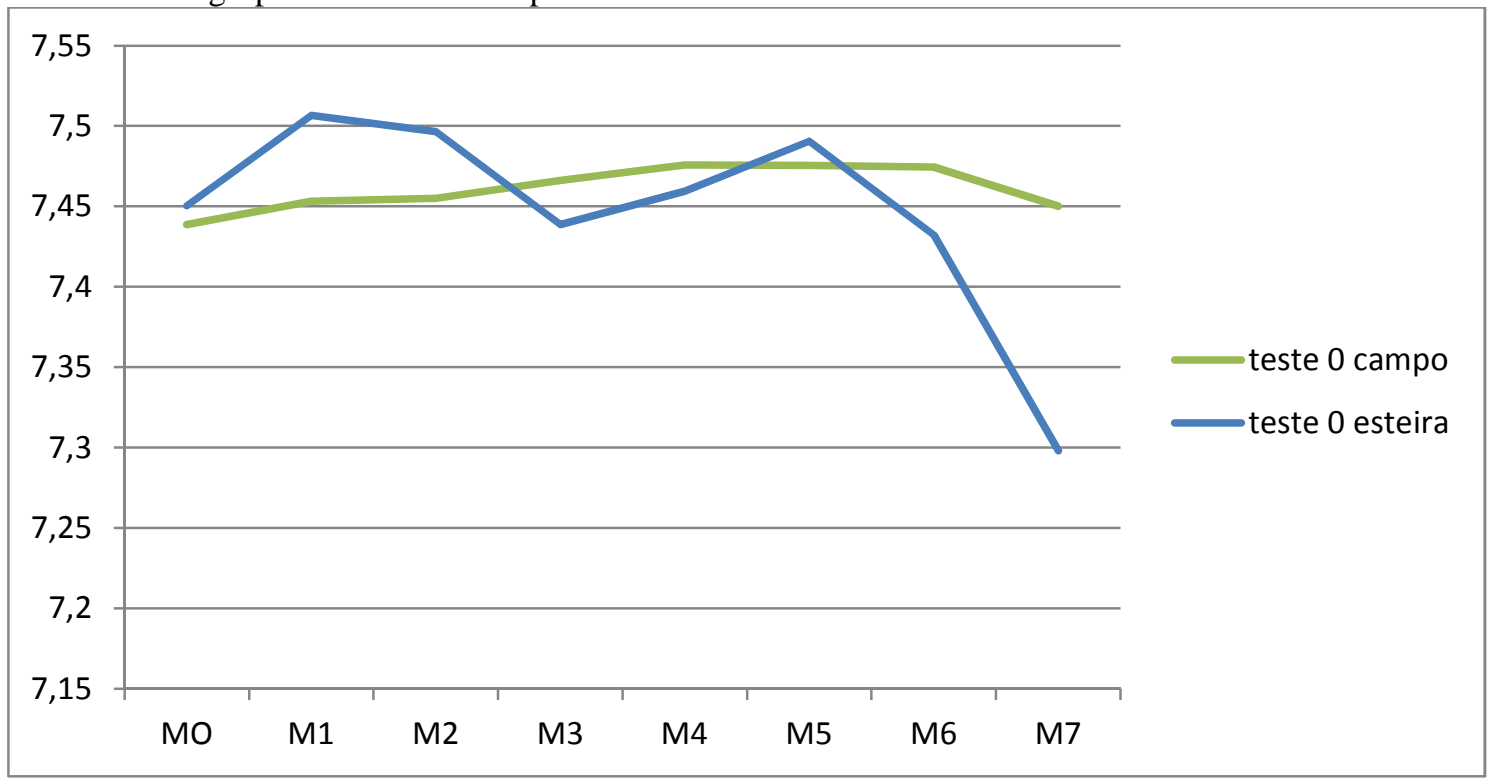

Gráfico 31 - Gráfico comparativo dos valores da concentração de hidrogênio sanguíneo (pH) obtidas no teste após 90 dias de treinamento dos subgrupos treinados a campo e na esteira

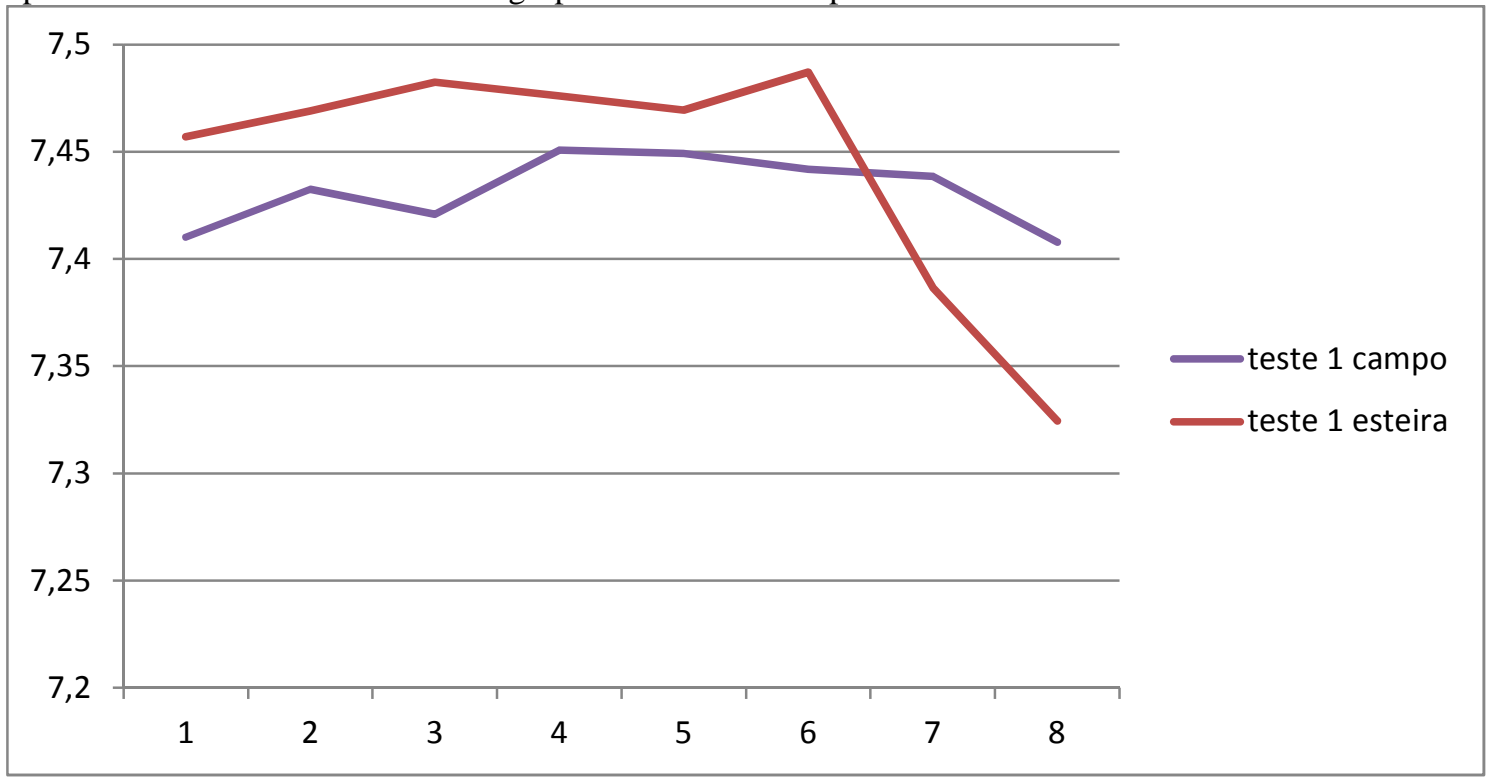




\section{7 $\mathrm{PO}_{2}$}

Os valores da concentração de oxigênio sanguíneo $\left(\mathrm{PO}_{2}\right)$ obtidos nos testes iniciais e após 90 dias de treinamento com todos os animais estão demonstrados nas tabelas 14 e 15 e gráfico 32.

Tabela 14 - Valores da concentração de oxigênio sanguíneo $\left(\mathrm{PO}_{2}\right)$ obtidos no teste progressivo escalonado de esforço máximo inicial - São Paulo - 2013

\begin{tabular}{rccccccccccr}
\hline & ANIMAIS & 1 & 2 & 3 & 4 & 5 & 10 & 11 & 13 & 14 & MEDIA \\
\cline { 2 - 11 } & MO & 99,1 & 108,7 & 91,9 & 102 & 96,1 & 109,7 & 120 & 103,5 & 102,7 & 103,74 \\
\multirow{4}{*}{ Inicial } & M1 & 112,7 & 99,7 & 78,6 & 89,3 & 90,9 & 92,9 & 101,8 & 99,1 & 108,8 & 97,09 \\
T0 & M2 & 109,7 & 132,3 & 86,2 & 99,9 & 87,9 & 95,1 & 98,8 & 101,7 & 89,3 & 100,10 \\
& M4 & 97,1 & 94,7 & 87,5 & 94,7 & 91,2 & 70,4 & 93,1 & 94,7 & 75,2 & 88,73 \\
& M5 & 102,9 & 83,4 & 77,1 & 88,2 & 192,6 & 82,6 & 82,9 & 87,6 & 87,1 & 98,27 \\
& M6 & 94,8 & & 86,6 & 82 & 71,4 & 63,3 & 75,2 & & 78,7 & 78,86 \\
& M7 & 84 & & & & & 61,3 & & & 68,9 & 71,40 \\
\hline
\end{tabular}


Tabela 15 - Valores da concentração oxigênio sanguíneo $\left(\mathrm{PO}_{2}\right)$ obtidos no teste progressivo escalonado de esforço máximo após 90 dias de treinamento aeróbico São Paulo - 2013

\begin{tabular}{|c|c|c|c|c|c|c|c|c|c|c|c|}
\hline \multirow{9}{*}{$\begin{array}{c}90 \text { dias } \\
\text { T1 }\end{array}$} & & 1 & 2 & 3 & 4 & 5 & 10 & 12 & 13 & 14 & MÉDIA \\
\hline & MO & 102,4 & 97,4 & 106,2 & 87,4 & 86 & & 84,7 & 93,6 & 102,5 & 95,03 \\
\hline & M1 & 115,6 & 95,1 & 93,5 & 87 & 82 & & 73,5 & 100,9 & 89,9 & 92,19 \\
\hline & M2 & 105,7 & 91,9 & 83 & 90,2 & 91,6 & & 101,1 & 89,9 & 86,5 & 92,49 \\
\hline & M3 & 99 & 102,2 & 91,4 & 80,9 & 93 & & 90,3 & 89,2 & 98 & 93,00 \\
\hline & M4 & 97,6 & 94,8 & 83,5 & 84,7 & 111 & & 94,2 & 81 & 90,3 & 92,14 \\
\hline & M5 & 94,9 & 98,3 & 82,3 & 121,7 & 99,4 & & 80,3 & 81,6 & 90,8 & 93,66 \\
\hline & M6 & 93,3 & 91,5 & 79,8 & 112,2 & 80,5 & & 74,1 & 68,8 & 61,2 & 82,68 \\
\hline & M7 & 80 & 78,5 & & 75 & 64,6 & & & 63,1 & 57,9 & 69,85 \\
\hline
\end{tabular}

Gráfico 32 - Valores da concentração de oxigênio sanguíneo $\left(\mathrm{PO}_{2}\right)$ obtidos no teste progressivo escalonado de esforço máximo inicial e após 90 dias de treinamento

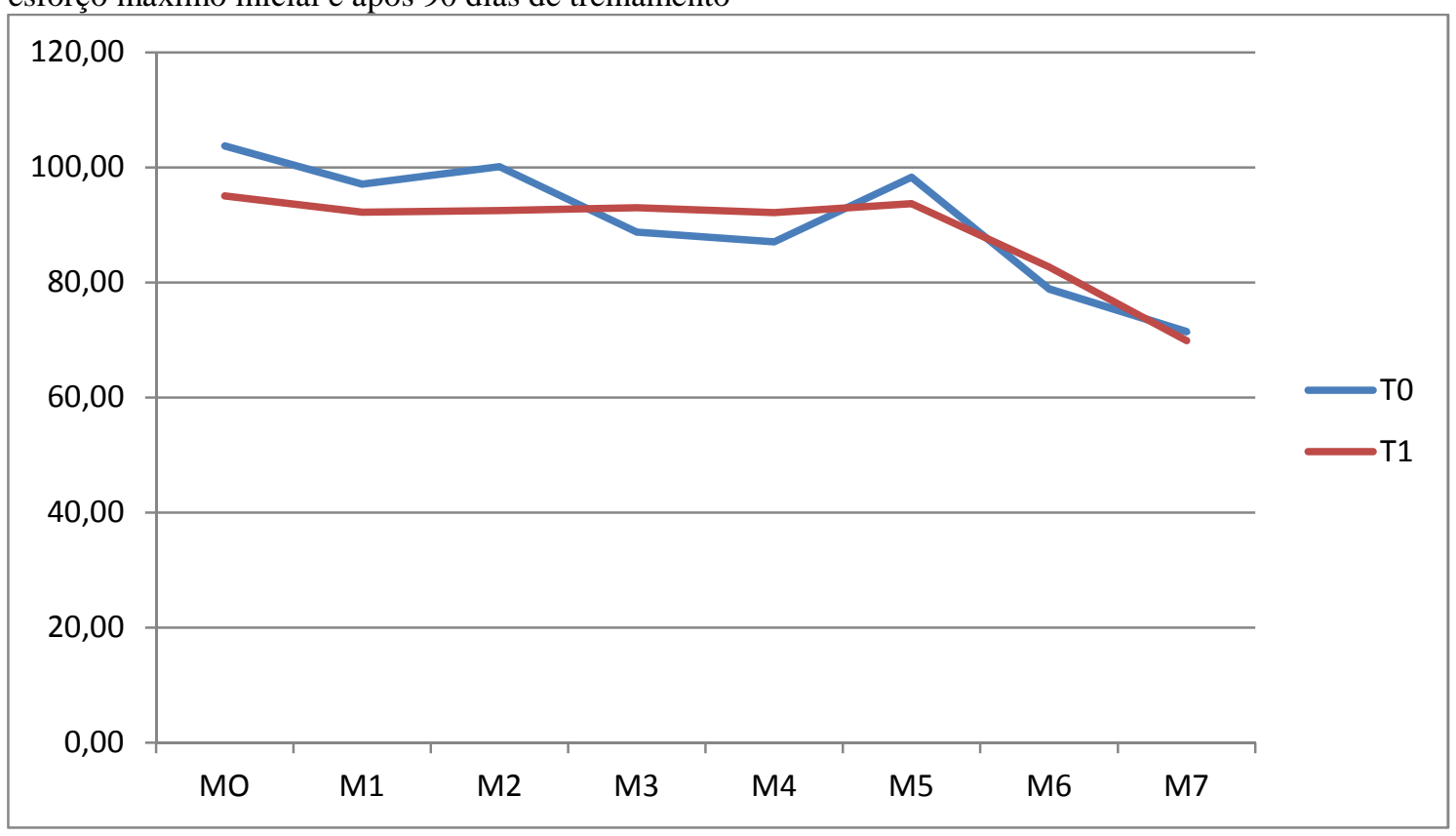

Quando reagrupados em relação ao tipo de treinamento, os resultados estão demonstrados nos gráficos 33 a 36 . 
Gráfico 33 - Valores da concentração oxigênio sanguíneo $\left(\mathrm{PO}_{2}\right)$ obtidos no teste progressivo escalonado de esforço máximo inicial e após 90 dias de treinamento a campo

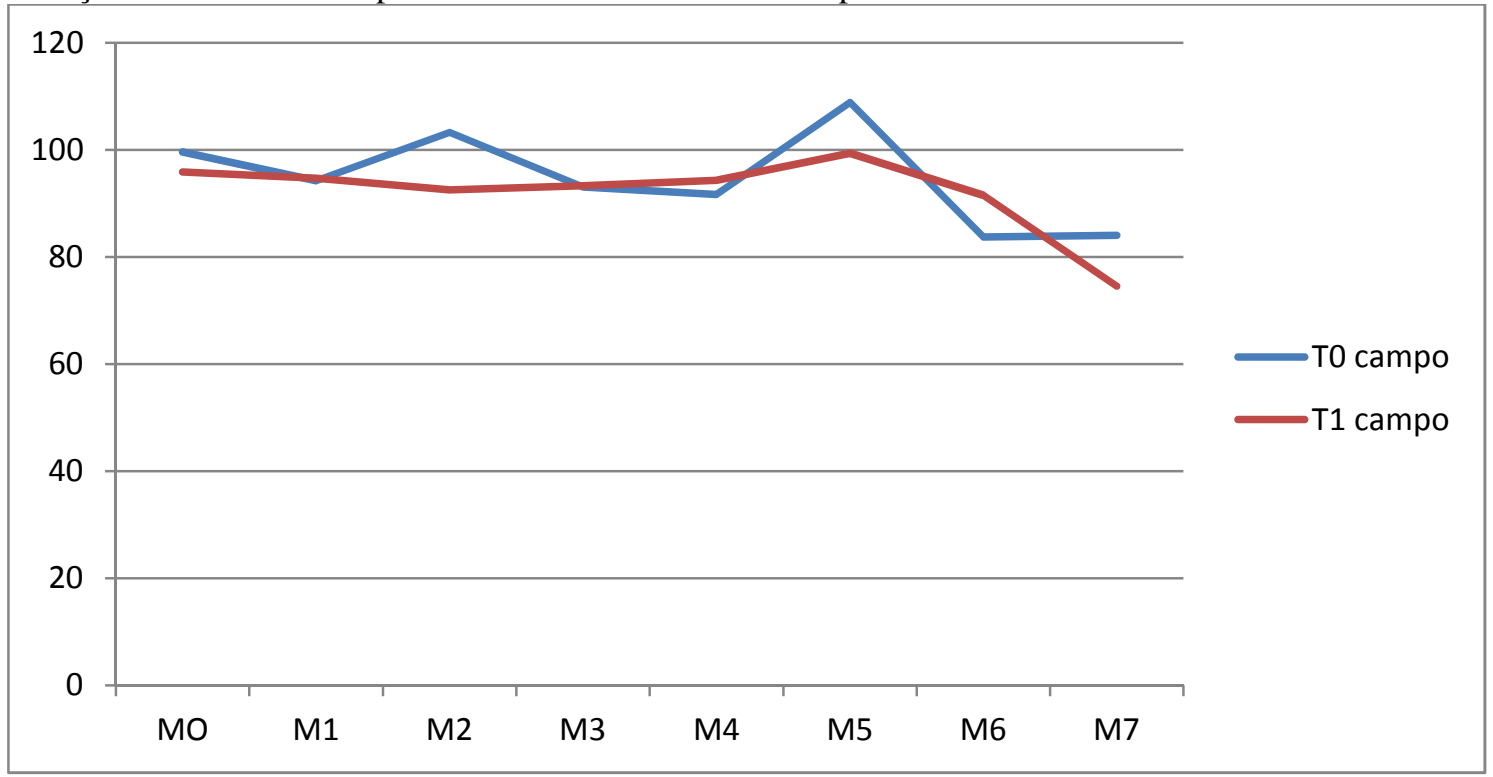

Gráfico 34 - Valores da concentração de oxigênio sanguíneo $\left(\mathrm{PO}_{2}\right)$ obtidos no teste progressivo escalonado de esforço máximo inicial e após 90 dias de treinamento na esteira controlado

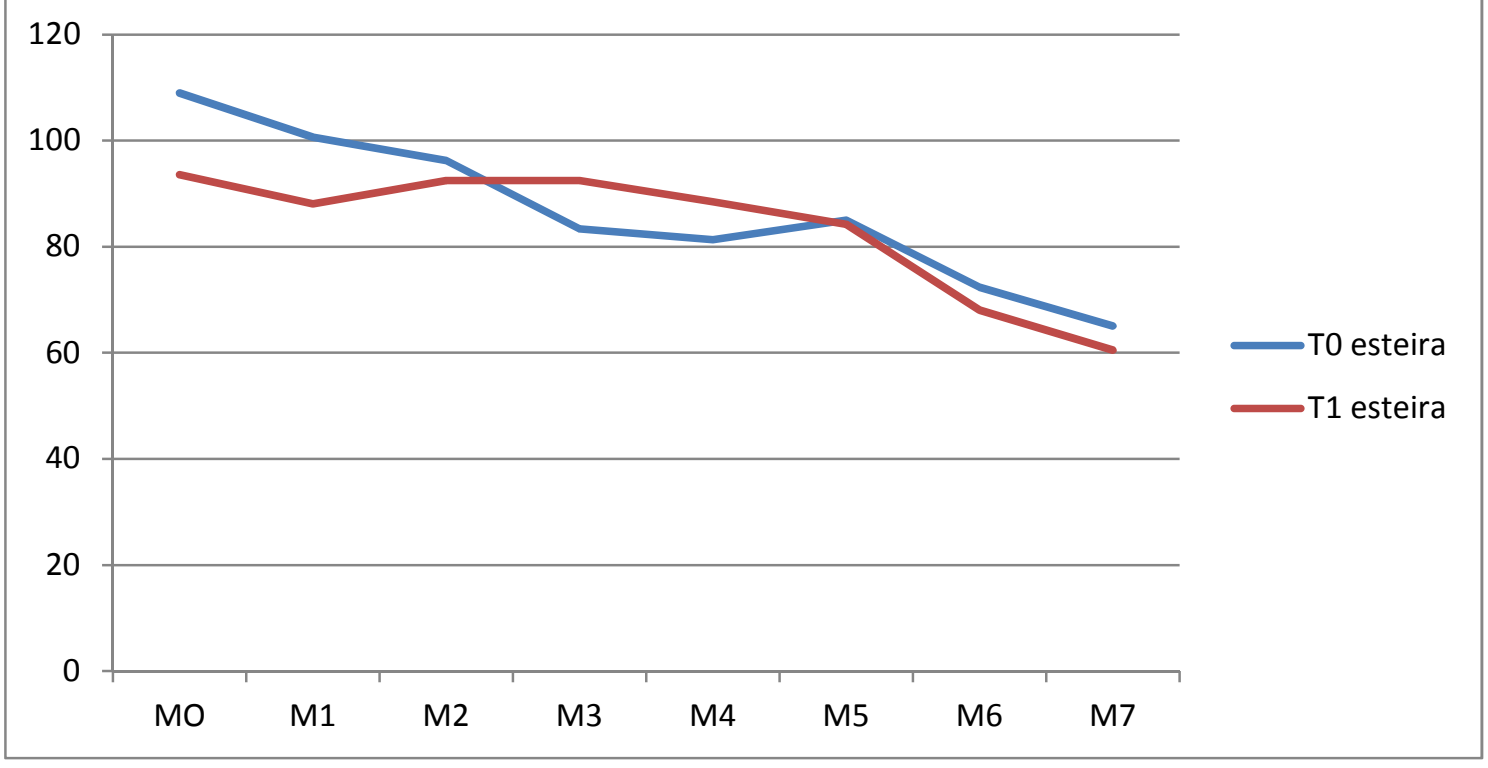


Gráfico 35 - Gráfico comparativo dos valores da concentração de oxigênio sanguíneo $\left(\mathrm{PO}_{2}\right)$ obtidas no teste inicial dos subgrupos treinados a campo e na esteira

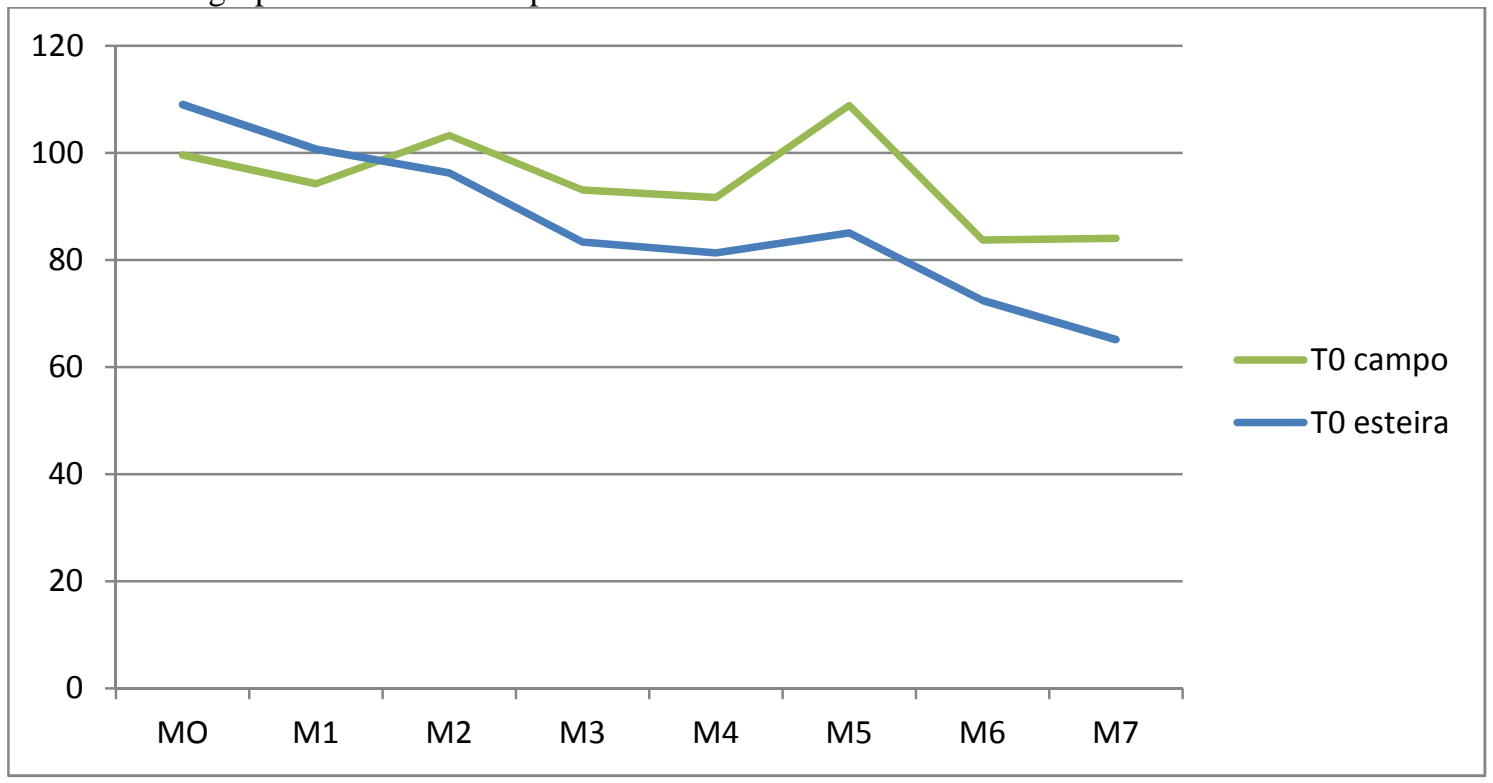

Gráfico 36 - Gráfico comparativo dos valores da concentração de oxigênio sanguíneo $\left(\mathrm{PO}_{2}\right)$ obtidas no teste após 90 dias de treinamento dos subgrupos treinados a campo e na esteira

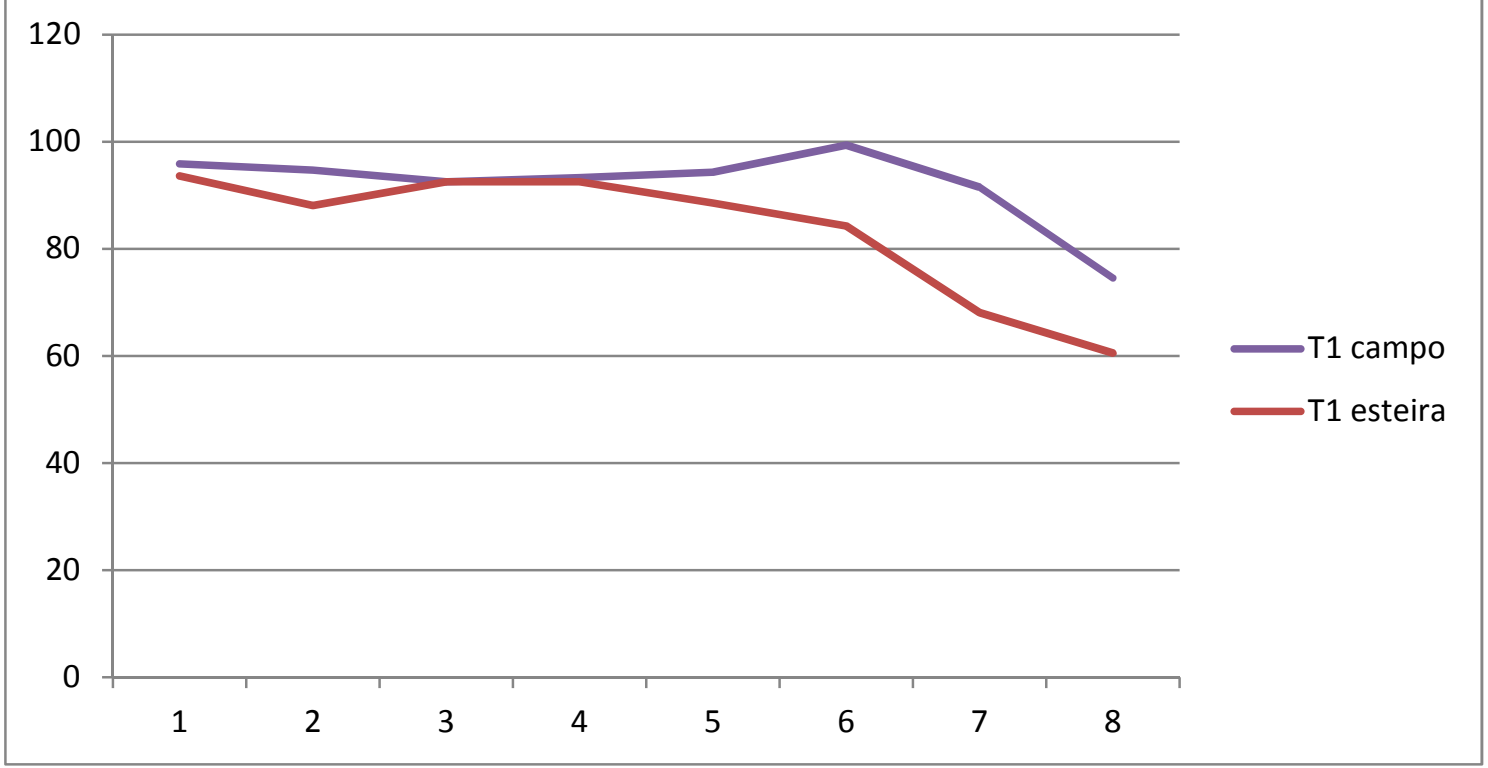




\section{8 $\mathrm{PCO}_{2}$}

Os valores da concentração de gás carbônico sanguíneo $\left(\mathrm{PCO}_{2}\right)$ obtidos nos testes iniciais e após 90 dias de treinamento com todos os animais estão demonstrados nas tabelas 16 e 17 e gráfico 37.

Tabela 16 - Valores da concentração de gás carbônico sanguíneo $\left(\mathrm{PCO}_{2}\right)$ obtidos no teste progressivo escalonado de esforço máximo inicial - São Paulo - 2013

\begin{tabular}{cccccccccccc}
\hline & ANIMAIS & 1 & 2 & 3 & 4 & 5 & 10 & 11 & 13 & 14 & MEDIA \\
\cline { 2 - 11 } & MO & 24,5 & 29,7 & 40,2 & 38,4 & 37,9 & 37,1 & 43,5 & 37,6 & 38,2 & 36,34 \\
\multirow{4}{*}{ Inicial } & M1 & 22,9 & 32,7 & 38,2 & 36 & 35,5 & 28,8 & 36,9 & 30,7 & 34,5 & 32,91 \\
T0 & M3 & 26,4 & 19,2 & 37 & 33,3 & 35,8 & 31,8 & 35,2 & 31,4 & 38,2 & 32,03 \\
& M4 & 29,2 & 27,6 & 35,7 & 33,7 & 34 & 38,8 & 35,9 & 31,9 & 37,1 & 32,77 \\
& M5 & 25,5 & 28,6 & 34,3 & 33,1 & 28,2 & 24,9 & 33,8 & 28,8 & 26,5 & 29,30 \\
& M6 & 23 & & 31,5 & 29,3 & 31,4 & 29,8 & 31,4 & & 27,4 & 29,11 \\
& M7 & 25,7 & & & & & 25,9 & & & 26,3 & 25,97 \\
\hline
\end{tabular}


Tabela 17 - Valores da concentração gás carbônico sanguíneo $\left(\mathrm{PCO}_{2}\right)$ obtidos no teste progressivo escalonado de esforço máximo após 90 dias de treinamento aeróbico - São Paulo - 2013

\begin{tabular}{cccccccccccc}
\hline & & 1 & 2 & 3 & 4 & 5 & 10 & 12 & 13 & 14 & MÉDIA \\
\cline { 2 - 12 } & MO & 30,5 & 31 & 41,7 & 39 & 38,3 & 32,5 & 34,8 & 21,8 & 33,70 \\
& M1 & 29,7 & 32 & 37,8 & 33,1 & 32,3 & & 29,7 & 24,1 & 36,2 & 31,86 \\
\multirow{4}{*}{ 90 dias } & M1 & 33 & 33,9 & 38,7 & 21,5 & 32 & & 26,5 & 30 & 30,1 & 30,71 \\
T1 & 31 & 28,3 & 36,6 & 22,8 & 22,7 & & 32,2 & 33,8 & 31,4 & 29,85 \\
& M4 & 31,7 & 30,3 & 36,7 & 18,6 & 20,2 & & 31,5 & 32,8 & 31,6 & 29,18 \\
& M5 & 28,6 & 30,7 & 33,5 & 27,3 & 21,2 & & 18,9 & 26,9 & 28,8 & 26,99 \\
& M6 & 29,8 & 27,1 & 30,6 & 27,1 & 23,5 & & 24,8 & 25,5 & 29,4 & 27,23 \\
& M7 & 29,5 & 27,4 & & 29,9 & 30,7 & & 30,3 & 28,3 & 29,35 \\
\hline
\end{tabular}

Gráfico 37 - Valores da concentração de gás carbônico sanguíneo $\left(\mathrm{PCO}_{2}\right)$ obtidos no teste progressivo escalonado de esforço máximo inicial e após 90 dias de treinamento.

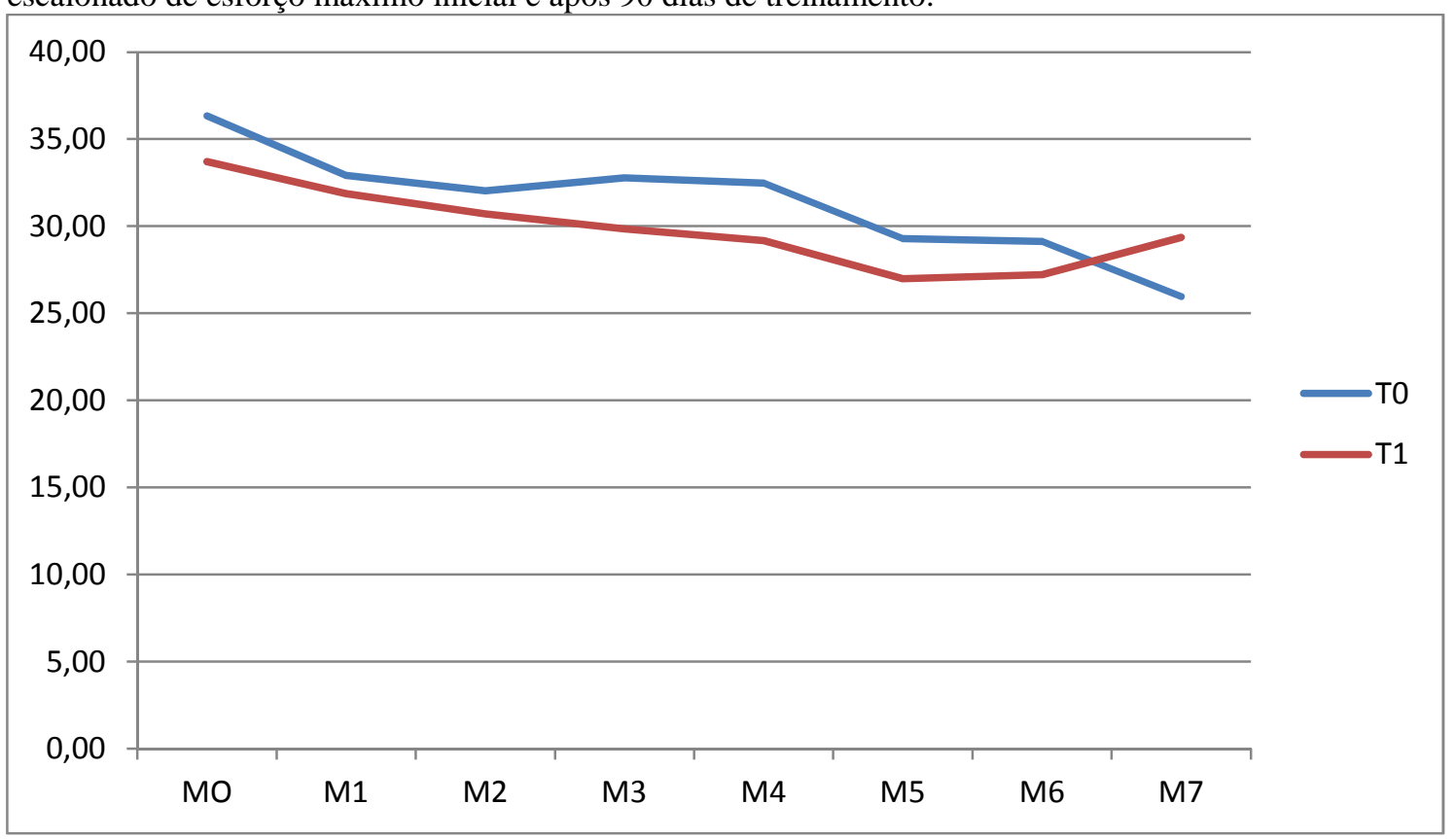

Quando reagrupados em relação ao tipo de treinamento, os resultados estão demonstrados nos gráficos 38 a 41 . 
Gráfico 38 - Valores da concentração gás carbônico sanguíneo $\left(\mathrm{PCO}_{2}\right)$ obtidos no teste progressivo escalonado de esforço máximo inicial e após 90 dias de treinamento a campo

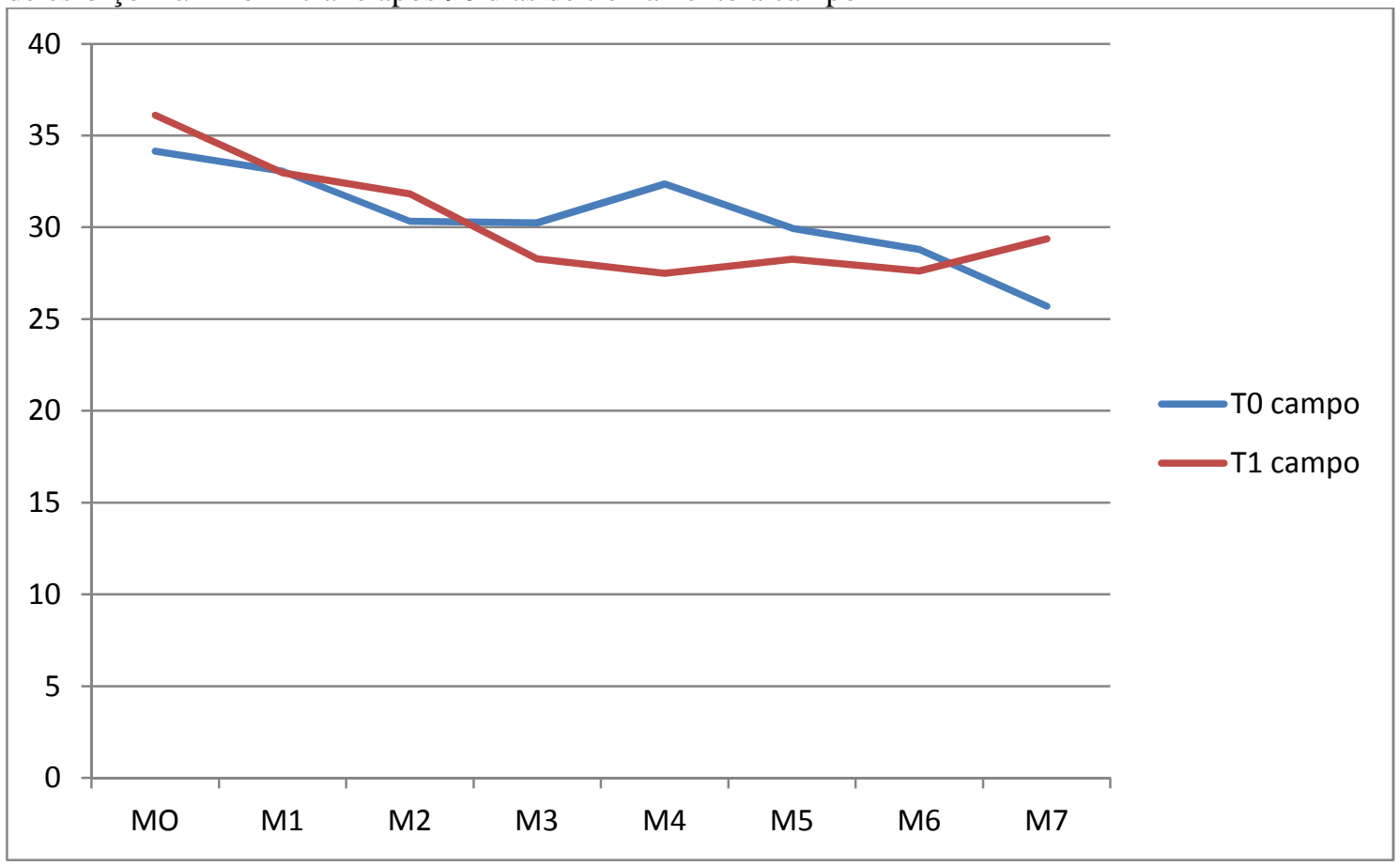

Gráfico 39 -Valores da concentração de gás carbônico sanguíneo $\left(\mathrm{PCO}_{2}\right)$ obtidos no teste progressivo escalonado de esforço máximo inicial e após 90 dias de treinamento na esteira controlado

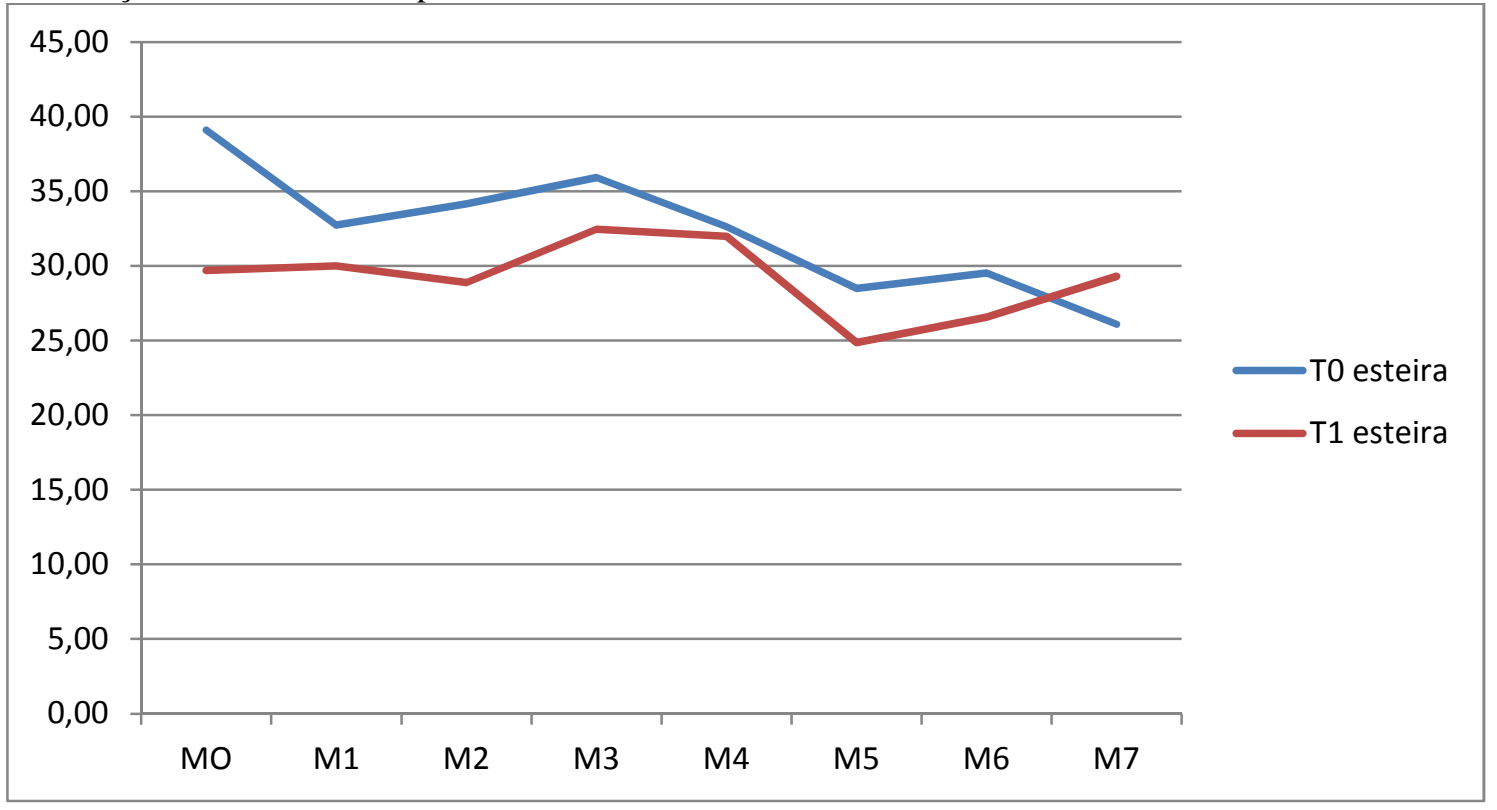


Gráfico 40 - Gráfico comparativo dos valores da concentração de gás carbônico sanguíneo $\left(\mathrm{PCO}_{2}\right)$ obtidas no teste inicial dos subgrupos treinados a campo e na esteira

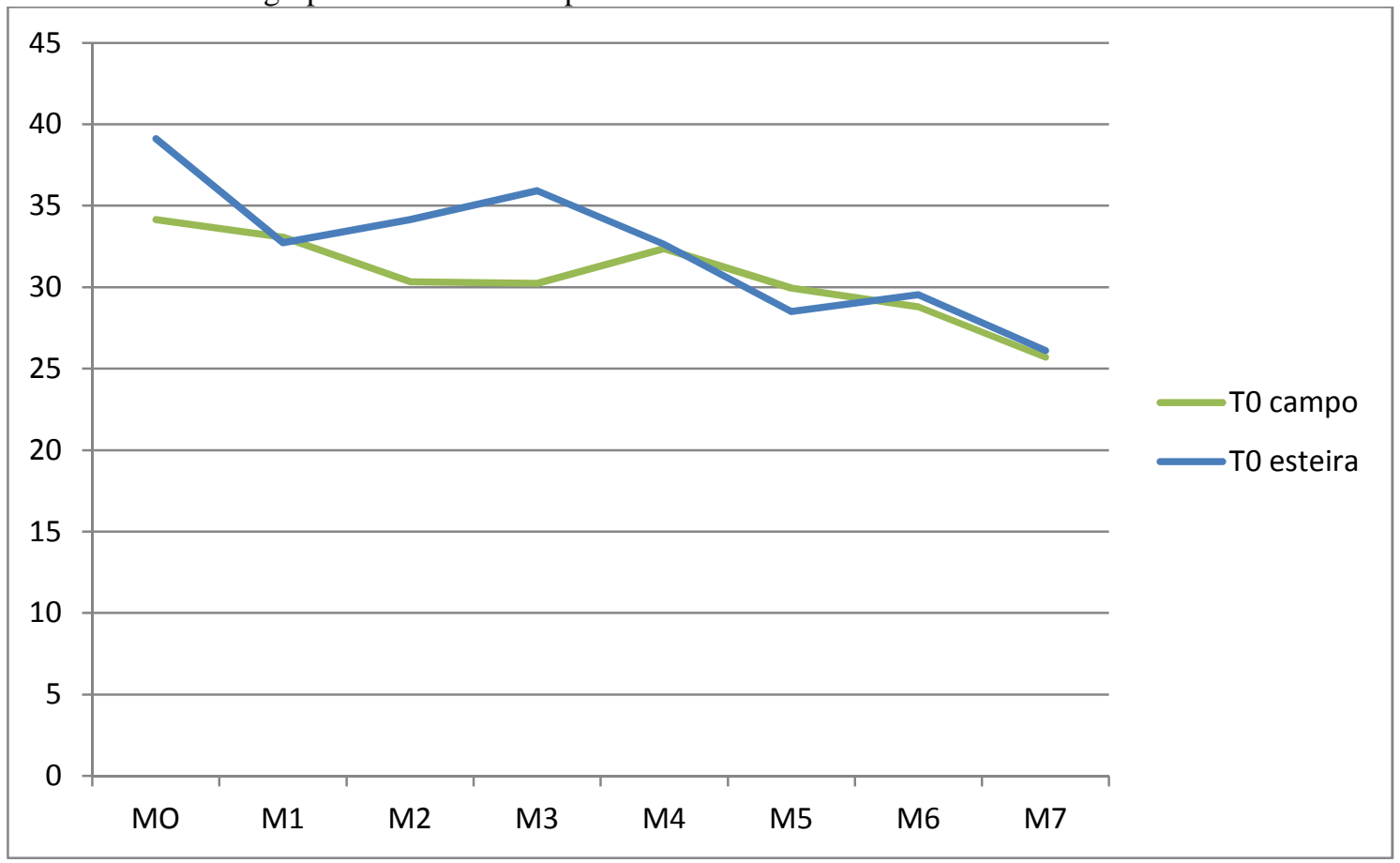

Gráfico 41 - Gráfico comparativo dos valores da concentração de gás carbônico sanguíneo $\left(\mathrm{PCO}_{2}\right)$ obtidas no teste após 90 dias de treinamento dos subgrupos treinados a campo e na esteira

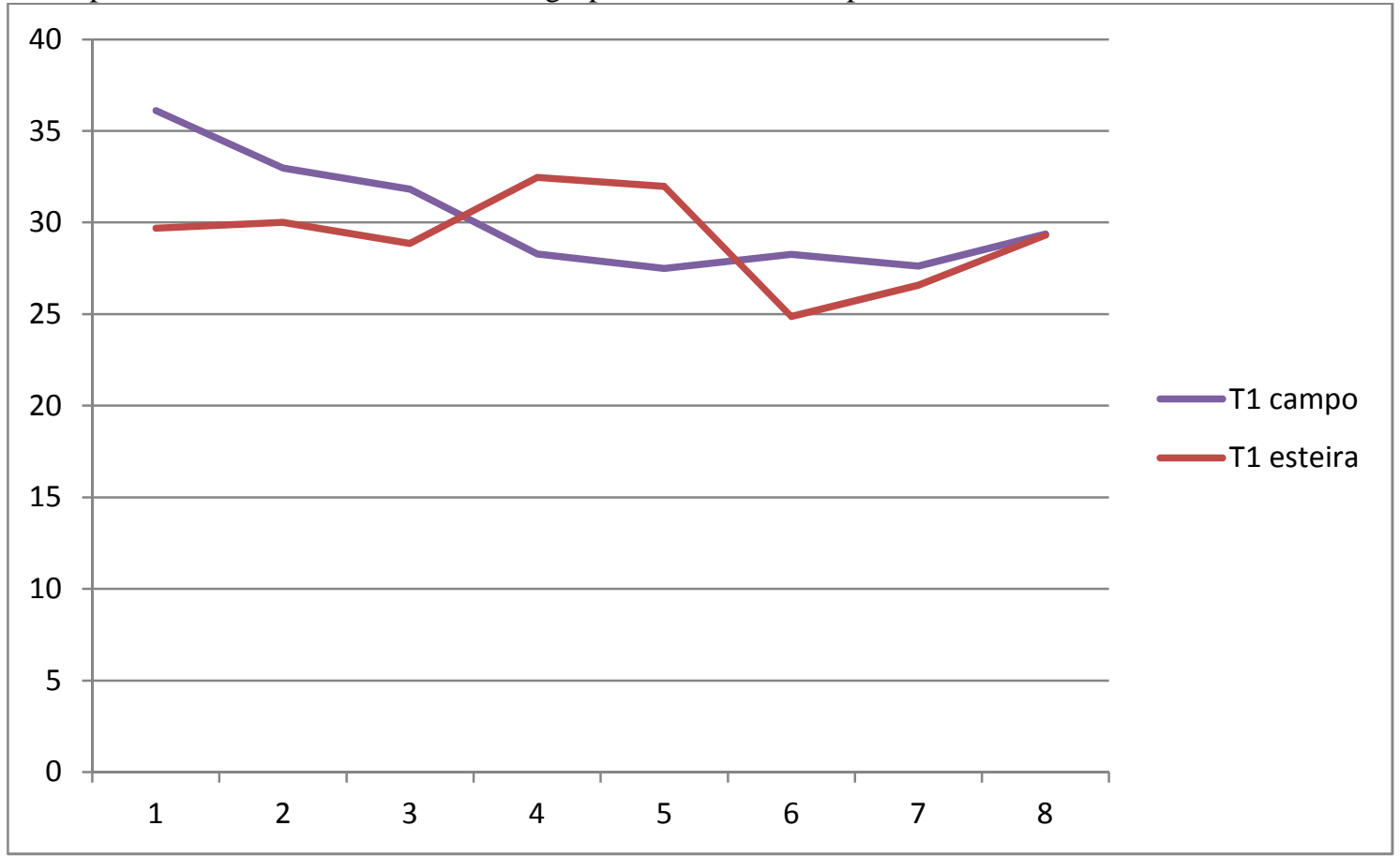




\section{$4.9 \mathrm{SO}_{2} \%$}

Os valores da porcentagem da concentração de oxigênio sanguíneo $\left(\mathrm{SO}_{2} \%\right)$ obtidos nos testes iniciais e após 90 dias de treinamento com todos os animais estão demonstrados nas tabelas 18 e 19 e gráfico 42.

Tabela 18 - Valores da porcentagem da concentração de oxigênio sanguíneo $\left(\mathrm{SO}_{2} \%\right)$ obtidos no teste progressivo escalonado de esforço máximo inicial - São Paulo - 2013

\begin{tabular}{ccccccccccr} 
ANIMAIS & 1 & 2 & 3 & 4 & 5 & 6 & 7 & 8 & 9 & MEDIA \\
\hline MO & 98 & 98,6 & 97 & 97,9 & 97,7 & 98,5 & 98,8 & 98,1 & 98,4 & 98,11 \\
M1 & 98,5 & 98,2 & 96,1 & 97,2 & 97,5 & 98,1 & 98,5 & 98,3 & 98,7 & 97,90 \\
M2 & 98,4 & 99,1 & 96,9 & 98,1 & 97,2 & 98,2 & 98,3 & 98,4 & 97,5 & 98,01 \\
M3 & 97,9 & 97,8 & 97,3 & 97,7 & 97,6 & 93,3 & 98 & 98,1 & 94,5 & 96,91 \\
M4 & 97,8 & 96,6 & 98,4 & 97,4 & 97,7 & 91,4 & 98,1 & 98,1 & 95,2 & 96,74 \\
M5 & 98,5 & 96,9 & 95,9 & 97,3 & 99,7 & 96,7 & 97 & 97,4 & 97,7 & 97,46 \\
M6 & 98,2 & & 96,8 & 96,8 & 95 & 90,7 & 95,7 & & 96,2 & 95,63 \\
M7 & 96,6 & & & & & 85,6 & & & 91,4 & 91,20
\end{tabular}


Tabela 19 - Valores da porcentagem da concentração de oxigênio sanguíneo $\left(\mathrm{SO}_{2} \%\right)$ obtidos no teste progressivo escalonado de esforço máximo após 90 dias de treinamento aeróbico - São Paulo - 2013

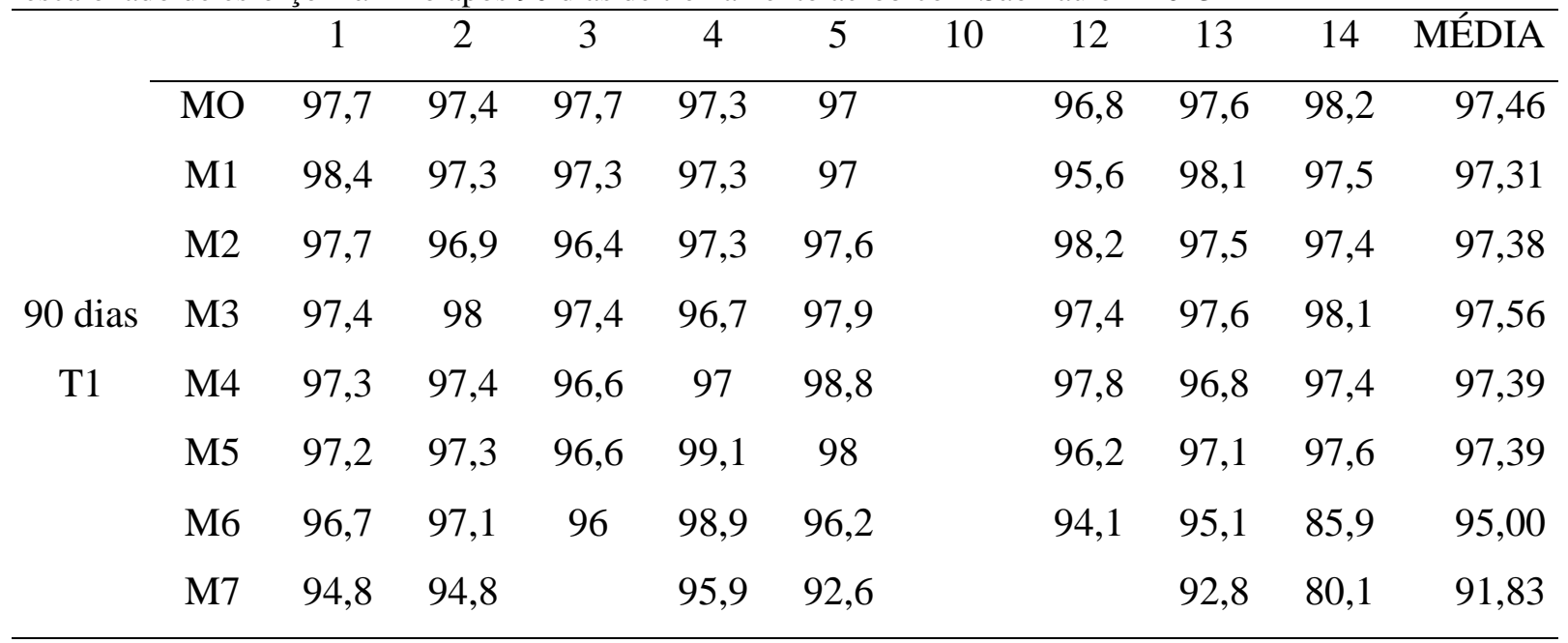

Gráfico 42 - Valores da porcentagem da concentração de oxigênio sanguíneo $\left(\mathrm{SO}_{2} \%\right)$ obtidos no teste progressivo escalonado de esforço máximo inicial e após 90 dias de treinamento

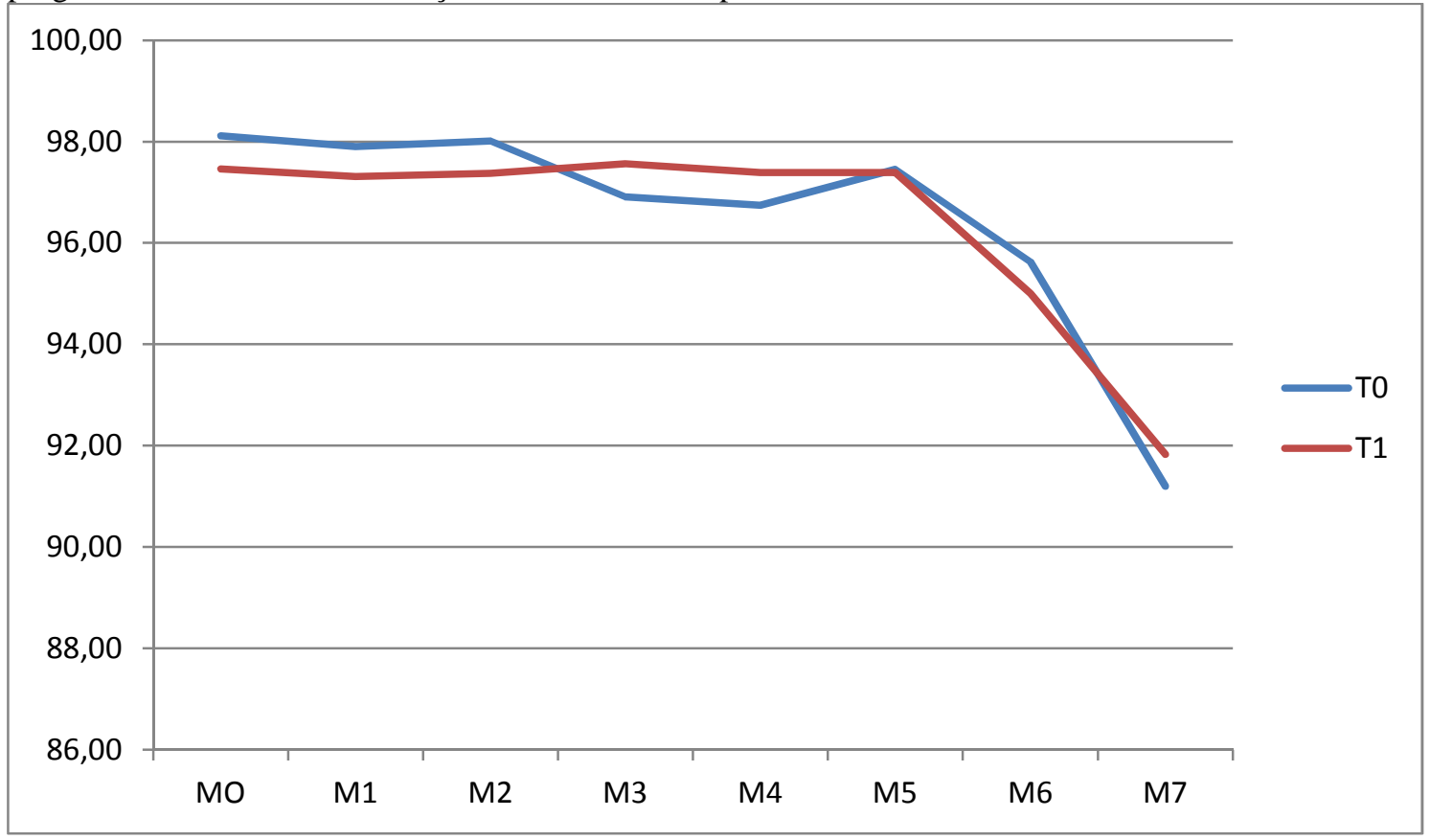

Quando reagrupados em relação ao tipo de treinamento, os resultados estão demonstrados nos gráficos 43 a 46 . 
Gráfico 43 - Valores da porcentagem da concentração de oxigênio sanguíneo $\left(\mathrm{SO}_{2} \%\right)$ obtidos no teste progressivo escalonado de esforço máximo inicial e após 90 dias de treinamento a campo

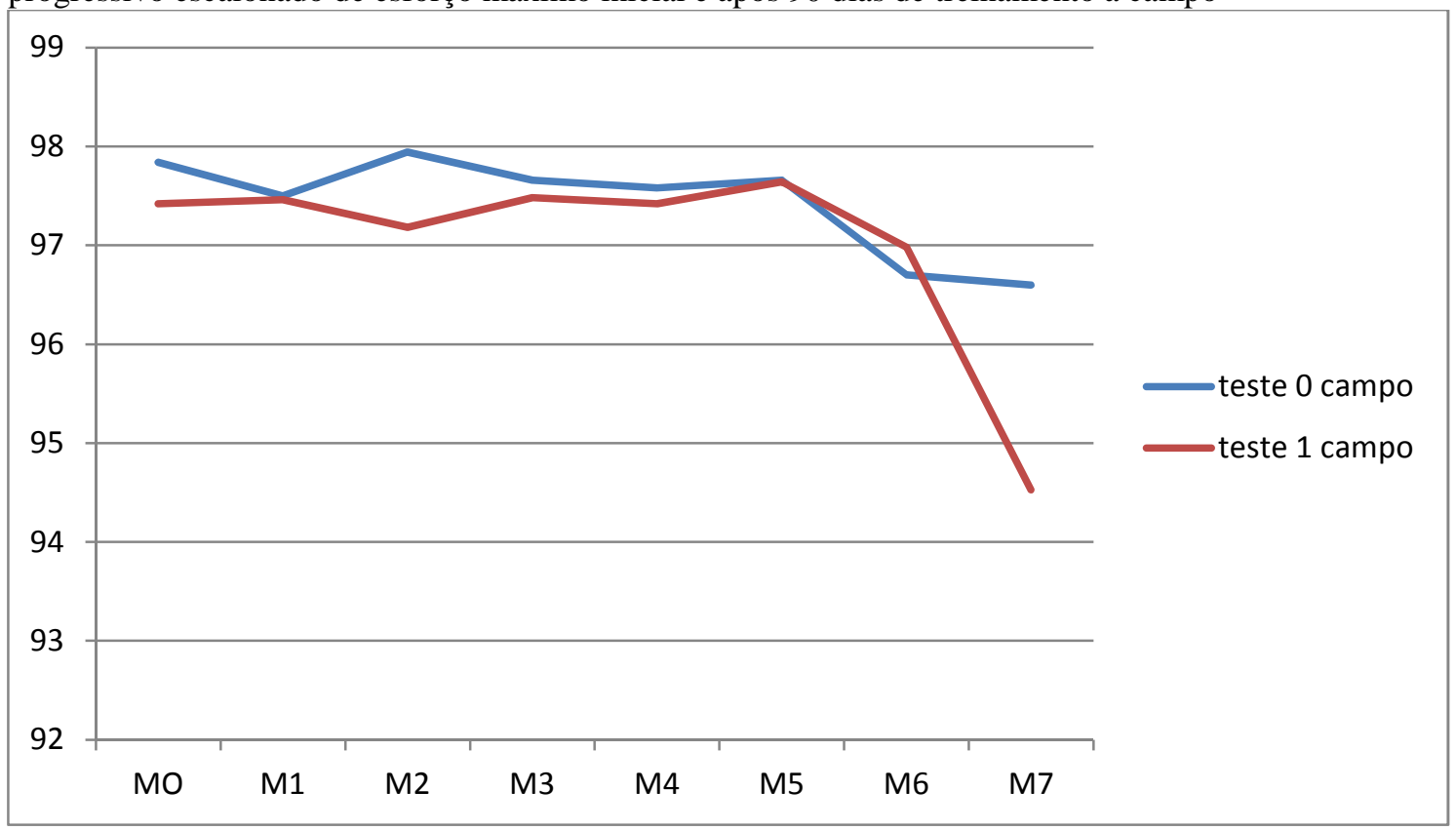

Gráfico 44 - Valores da porcentagem da concentração de oxigênio sanguíneo $\left(\mathrm{SO}_{2} \%\right)$ obtidos no teste progressivo escalonado de esforço máximo inicial e após 90 dias de treinamento na esteira controlado

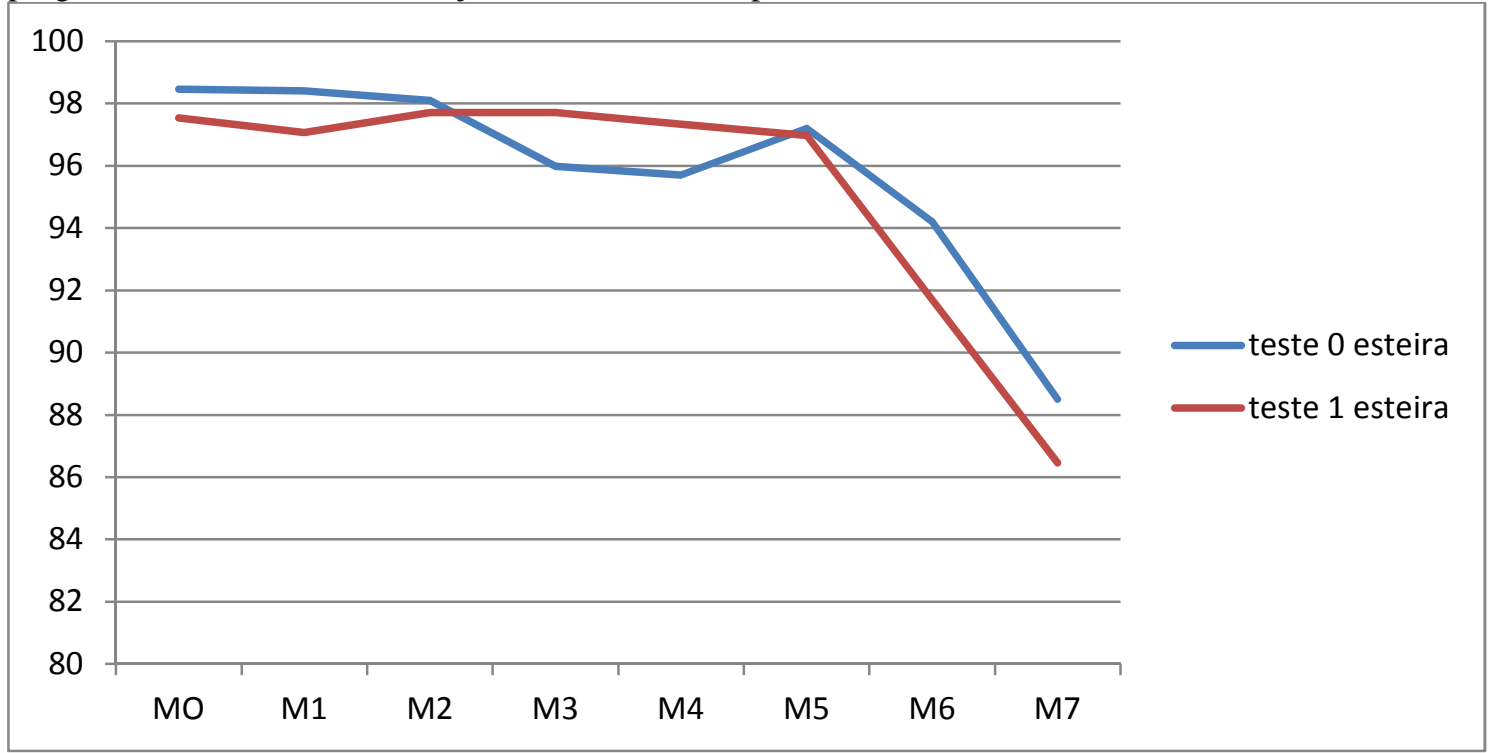


Gráfico 45 - Gráfico comparativo dos valores da porcentagem da concentração de oxigênio sanguíneo $\left(\mathrm{SO}_{2} \%\right)$ obtidas no teste inicial dos subgrupos treinados a campo e na esteira

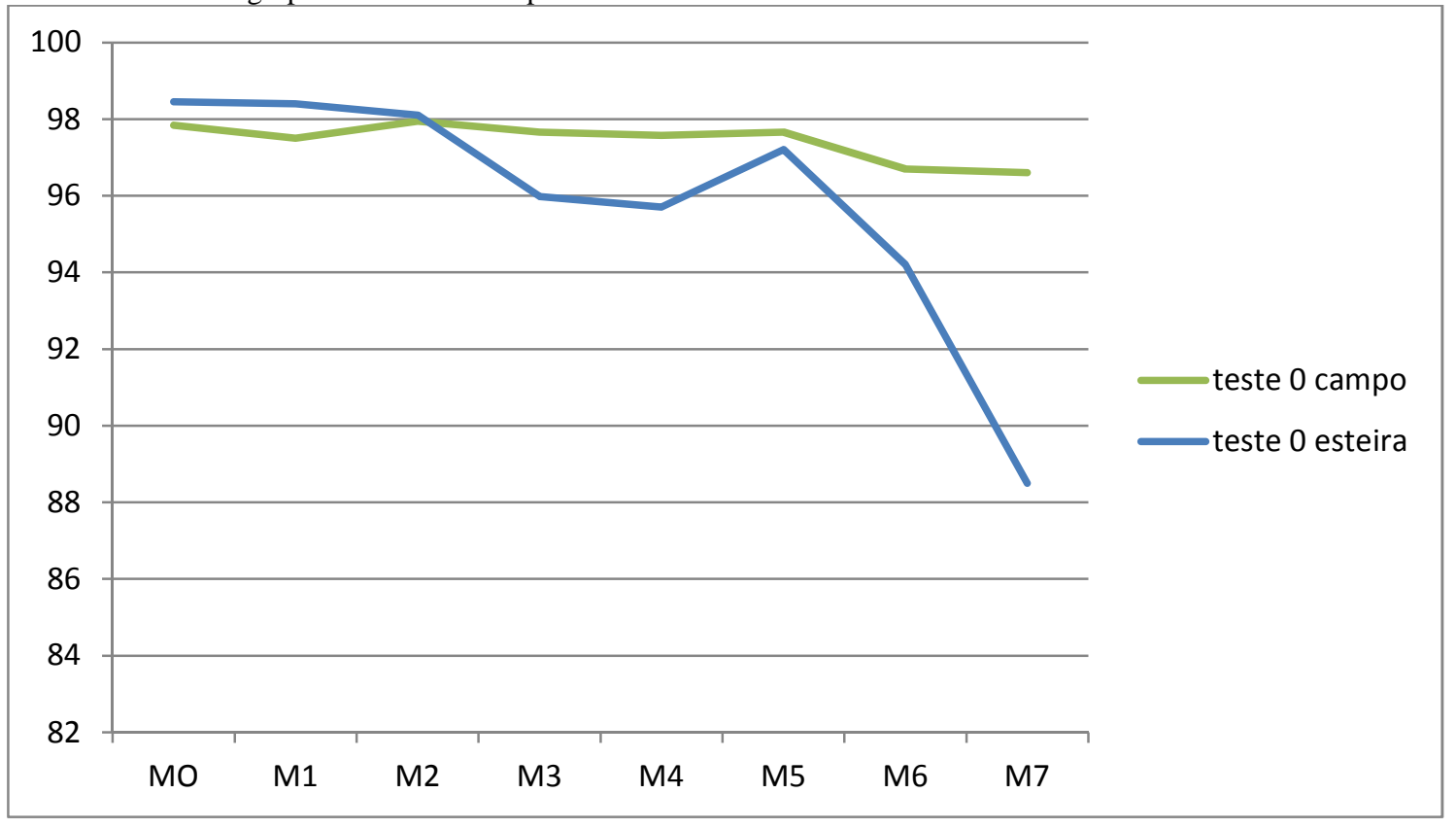

Gráfico 46 - Gráfico comparativo dos valores da porcentagem da concentração de oxigênio sanguíneo $\left(\mathrm{SO}_{2} \%\right)$ obtidas no teste após 90 dias de treinamento dos subgrupos treinados a campo e na esteira

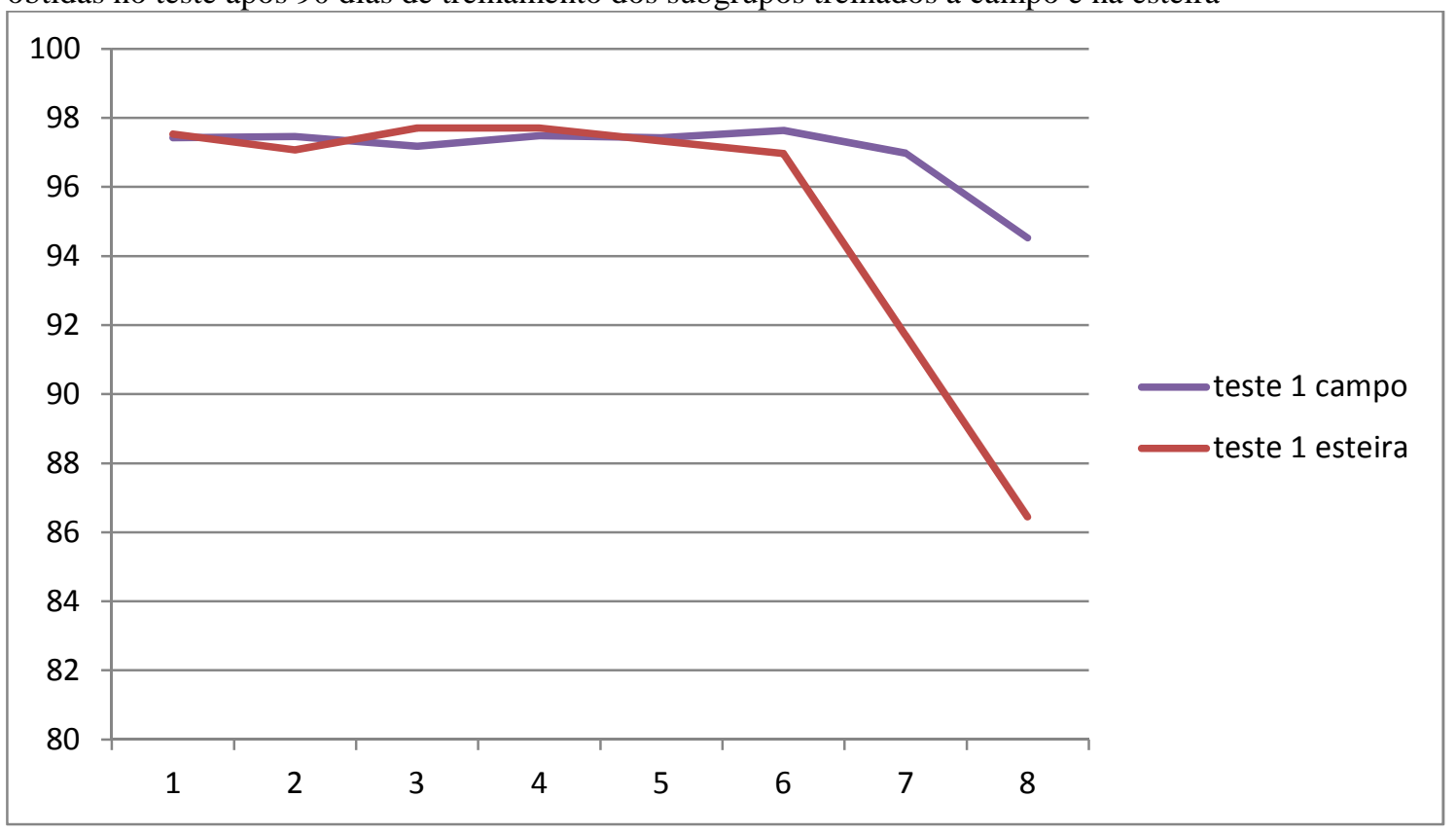




\subsection{Ecocardiograma de repouso}

Os valores das análises do ecocardiograma (FC; volume final circulante, débito cardíaco, fração de ejeção, diâmetro interno de átrio esquerdo, diâmetro interno da artéria aorta, relação átrio esquerdo e aorta, diâmetro interno de ventrículo direito em diástole, espessura do septo ventricular em diástole, diâmetro interno de ventrículo esquerdo em diástole, espessura da parede livre do ventrículo esquerdo em diástole, espessura de septo ventricular em sístole, diâmetro interno de ventrículo esquerdo em sístole, espessura de parede livre do ventrículo esquerdo em sístole, volume final diastólico do ventrícu;lo esquerdo, volume final sistólico do ventrículo esquerdo, fração de espessamento do septo ventricular, fração de encurtamento do ventrículo esquerdo e fração de espessamento da parede livre do ventrículo esquerdo) obtidos nos testes iniciais e após 90 dias de treinamento com todos os animais estão demonstrados nas tabelas 20 a 23 e gráficos 47 a 57. 
Tabela 20 - Valores de FC; volume final circulante (VFC ml), débito cardíaco (DC 1/mim) e fração de ejeção (FE\%) obtidos nos testes iniciais e após 90 dias de treinamento - São Paulo - 2013

\begin{tabular}{rrrrrrrrr} 
& \multicolumn{3}{c}{ FC } & \multicolumn{4}{c}{ VFC ml } & \multicolumn{2}{c}{ DC 1/min } & \multicolumn{2}{c}{ FE\% } \\
& \multicolumn{1}{r}{ T0 } & T1 & \multicolumn{1}{c}{ T0 } & \multicolumn{1}{c}{ T1 } & \multicolumn{1}{c}{ T0 } & \multicolumn{1}{c}{ T1 } & T0 & T1 \\
\hline 1 & 30 & 29 & 491 & 509 & 14,7 & 14,8 & 63 & 63 \\
2 & 35 & 31 & 490,8 & 459,2 & 17,2 & 14,2 & 61 & 70 \\
3 & 25 & 24 & 302,4 & 268,3 & 7,6 & 6,4 & 57 & 55 \\
4 & 37 & 35 & 371 & 454,2 & 13,7 & 15,9 & 72 & 77 \\
5 & 55 & 36 & 325,9 & 330,9 & 17,9 & 11,9 & 69 & 72 \\
10 & 30 & 27 & 388,3 & 323,9 & 11,6 & 8,7 & 80 & 73 \\
12 & 40 & 42 & 362,9 & 413 & 14,5 & 17,3 & 69 & 85 \\
13 & 30 & 26 & 376,5 & 506,7 & 11,3 & 13,2 & 58 & 67 \\
14 & 42 & 33 & 299,1 & 248,8 & 12,6 & 8,2 & 76 & 69 \\
Média & 36,00 & 31,44 & 378,66 & 390,44 & 13,46 & 12,29 & 67,22 & 70,11 \\
\hline
\end{tabular}

Tabela 21 - Valores de diâmetro interno de átrio esquerdo (AE), diâmetro interno da artéria aorta (Ao), relação átrio esquerdo e aorta (relação AE/Ao), diâmetro interno de ventrículo direito em diástole (VDd), espessura do septo ventricular em diástole (SIVd) obtidos nos testes iniciais e após 90 dias de treinamento - São Paulo - 2013

$$
\text { RELAÇÃO }
$$

\begin{tabular}{rrrrrrrrrr}
\multicolumn{1}{c}{ AE } & \multicolumn{3}{c}{ Ao } & \multicolumn{3}{c}{ AE/Ao } & \multicolumn{2}{c}{ VDd } & \multicolumn{2}{c}{ SIVd } \\
& \multicolumn{1}{c}{ T1 } & \multicolumn{1}{c}{ T0 } & \multicolumn{1}{l}{ T1 } & \multicolumn{1}{c}{ T0 } & \multicolumn{1}{c}{ T1 } & \multicolumn{1}{c}{ T0 } & \multicolumn{1}{l}{ T1 } & \multicolumn{1}{c}{ T0 } & \multicolumn{1}{c}{ T1 } \\
\hline 9,07 & 10,1 & 7,53 & 8,38 & 1,2 & 1,21 & 2,75 & 1,31 & 2,75 & 2,62 \\
8,68 & 8,38 & 7,66 & 7,53 & 1,13 & 1,11 & 3,4 & 2,68 & 3,08 & 2,95 \\
9,06 & 10,1 & 6,28 & 6,87 & 1,44 & 1,47 & 3,47 & 3,99 & 3,47 & 3,54 \\
8,9 & 7,88 & 7,01 & 6,61 & 1,21 & 1,19 & 3,27 & 1,83 & 2,55 & 3,27 \\
9,63 & 9,65 & 6,68 & 6,55 & 1,44 & 1,47 & 3,14 & 2,23 & 2,82 & 3,4 \\
8,72 & 8,78 & 6,87 & 6,28 & 1,27 & 1,4 & 3,47 & 2,95 & 2,82 & 2,95 \\
8,12 & 8,28 & 6,09 & 6,28 & 1,33 & 1,32 & 2,29 & 3,01 & 2,55 & 2,49 \\
9,39 & 9,92 & 7,66 & 6,55 & 1,23 & 1,51 & 3,4 & 4,32 & 3,01 & 2,88 \\
7,88 & 8,23 & 6,42 & 6,94 & 1,23 & 1,19 & 3,14 & 3,73 & 2,68 & 3,27 \\
8,83 & 9,04 & 6,91 & 6,89 & 1,28 & 1,32 & 3,15 & 2,89 & 2,86 & 3,04 \\
\hline
\end{tabular}


Tabela 22 - Valores de diâmetro interno de ventrículo esquerdo em diástole (DVEd), espessura da parede livre do ventrículo esquerdo em diástole (PLVEd), espessura de septo ventricular em sístole (SIVs), diâmetro interno de ventrículo esquerdo em sístole (DVEs), espessura de parede livre do ventrículo esquerdo em sístole (PLVEs), obtidos nos testes iniciais e após 90 dias de treinamento - São Paulo - 2013

\begin{tabular}{rrrrrrrrrrr}
\hline \multicolumn{1}{c}{ DVEd } & \multicolumn{3}{c}{ PLVEd } & \multicolumn{2}{c}{ SIVs } & \multicolumn{2}{c}{ DVEs } & \multicolumn{2}{c}{ PLVEs } \\
T0 & \multicolumn{1}{c}{ T1 } & \multicolumn{1}{c}{ T0 } & \multicolumn{1}{c}{ T1 } & T0 & \multicolumn{1}{c}{ T1 } & T0 & T1 & T0 & T1 \\
\hline 11,6 & 11,8 & 2,62 & 2,42 & 4,45 & 4,12 & 7,4 & 7,53 & 3,4 & 3,6 \\
11,8 & 10,7 & 2,03 & 2,16 & 5,3 & 5,3 & 7,73 & 6,22 & 2,23 & 4,84 \\
9,69 & 9,36 & 3,4 & 2,49 & 3,73 & 3,4 & 6,61 & 6,55 & 3,93 & 3,93 \\
9,62 & 10,2 & 1,9 & 1,96 & 4,19 & 5,04 & 5,5 & 5,3 & 3,27 & 3,8 \\
9,23 & 9,1 & 3,86 & 2,68 & 4,65 & 4,26 & 5,5 & 5,17 & 4,71 & 4,91 \\
9,63 & 8,97 & 2,55 & 2,88 & 4,32 & 4,12 & 4,65 & 5,04 & 3,67 & 3,73 \\
9,69 & 9,36 & 1,9 & 3,14 & 4,39 & 5,96 & 5,76 & 4,12 & 3,01 & 3,34 \\
10,7 & 11,4 & 1,83 & 2,23 & 4,06 & 3,6 & 7,27 & 6,87 & 3,47 & 4,52 \\
8,51 & 8,18 & 2,16 & 2,42 & 3,99 & 3,8 & 4,58 & 4,91 & 3,67 & 3,99 \\
10,05 & 9,90 & 2,47 & 2,49 & 4,34 & 4,40 & 6,11 & 5,75 & 3,48 & 4,07 \\
\hline
\end{tabular}

Tabela 23 - Valores de volume final diastólico do ventrículo esquerdo (VFSVE), volume final sistólico do ventrículo esquerdo (VFDVE), fração de espessamento do septo ventricular (EFSIV), fração de encurtamento do ventrículo esquerdo (RFDVE) e fração de espessamento da parede livre do ventrículo esquerdo (EFPLVE), obtidos nos testes iniciais e após 90 dias de treinamento - São Paulo - 2013

\begin{tabular}{rrrrrrrrrr}
\hline \multicolumn{2}{c}{ VFSVE } & \multicolumn{2}{c}{ VFDVE } & \multicolumn{2}{c}{ EFSIV } & \multicolumn{2}{c}{ RFDVE } & \multicolumn{2}{c}{ EFPLVE } \\
\multicolumn{1}{c}{ T0 } & \multicolumn{1}{c}{ T1 } & \multicolumn{1}{c}{ T0 } & \multicolumn{1}{c}{ T1 } & \multicolumn{1}{c}{ T0 } & \multicolumn{1}{c}{ T1 } & \multicolumn{1}{c}{ T0 } & T1 & T0 & \multicolumn{1}{c}{ T1 } \\
\hline 289,4 & 301 & 780,4 & 809,9 & 61,8 & 57,3 & 36,2 & 36,2 & 29,8 & 48,8 \\
319,2 & 195,4 & 809,9 & 654,6 & 72,1 & 79,7 & 34,5 & 41,9 & 9,85 & 124,1 \\
224,4 & 219,8 & 526,8 & 488,1 & 7,49 & $-3,95$ & 31,8 & 30 & 15,6 & 57,8 \\
147,4 & 135,3 & 518,5 & 589,6 & 64,3 & 54,1 & 42,8 & 48 & 72,1 & 93,9 \\
147,4 & 127,8 & 473,3 & 458,7 & 64,9 & 25,3 & 40,4 & 43,2 & 22 & 83,2 \\
99,8 & 120,15 & 488,1 & 444,3 & 53,2 & 39,7 & 50,3 & 43,8 & 43,9 & 29,5 \\
163,9 & 75,1 & 526,8 & 488,1 & 72,2 & 139,4 & 40,6 & 56 & 58,4 & 6,37 \\
278,1 & 244,8 & 654,6 & 751,5 & 34,9 & 25 & 32,1 & 39,7 & 89,6 & 102,7 \\
96,3 & 113,4 & 395,4 & 362,1 & 48,9 & 16,2 & 46,2 & 40 & 69,9 & 64,9 \\
196,21 & 170,31 & 574,87 & 560,77 & 53,31 & 48,08 & 39,43 & 42,09 & 45,68 & 67,92 \\
\hline
\end{tabular}


Gráfico 47 - Valores de Frequência Cardíaca (FC) obtidos nos testes iniciais e após 90 dias de treinamento

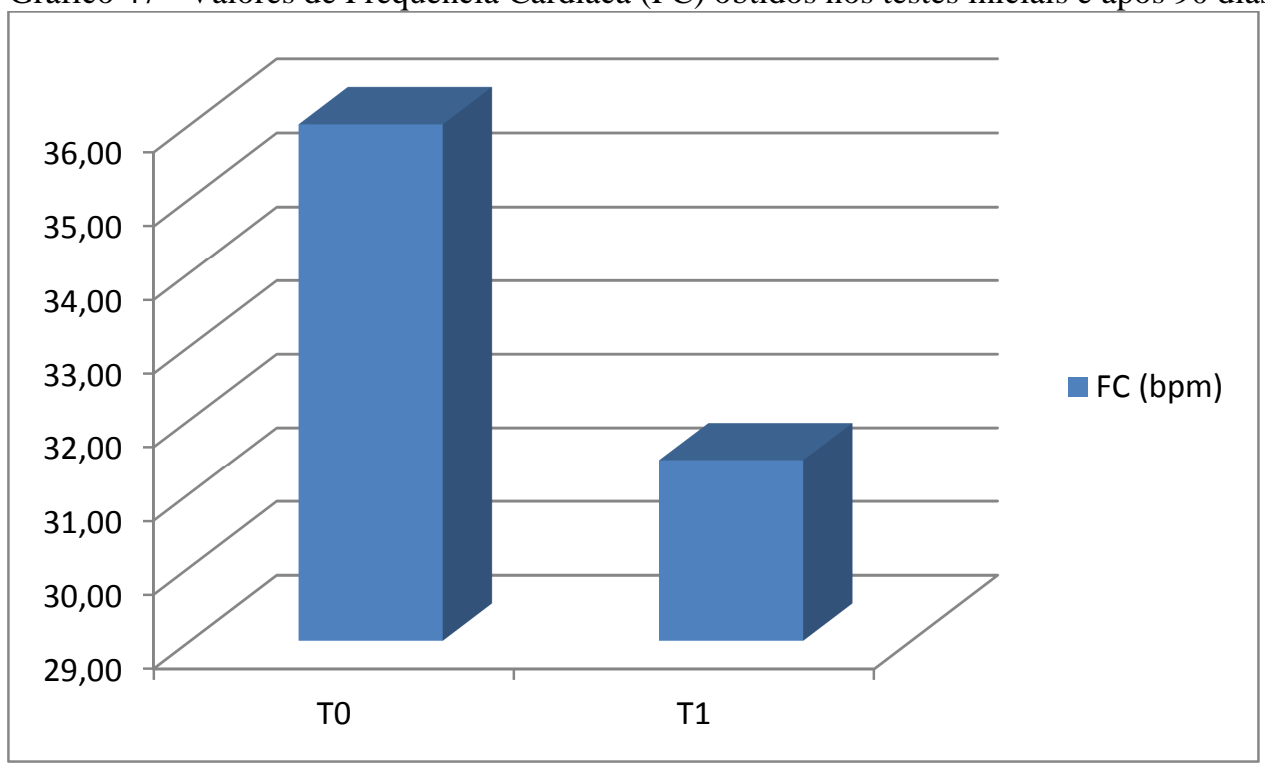

Gráfico 48 - Valores de Volume Final Circulante (VFC ml) obtidos nos testes iniciais e após 90 dias de treinamento

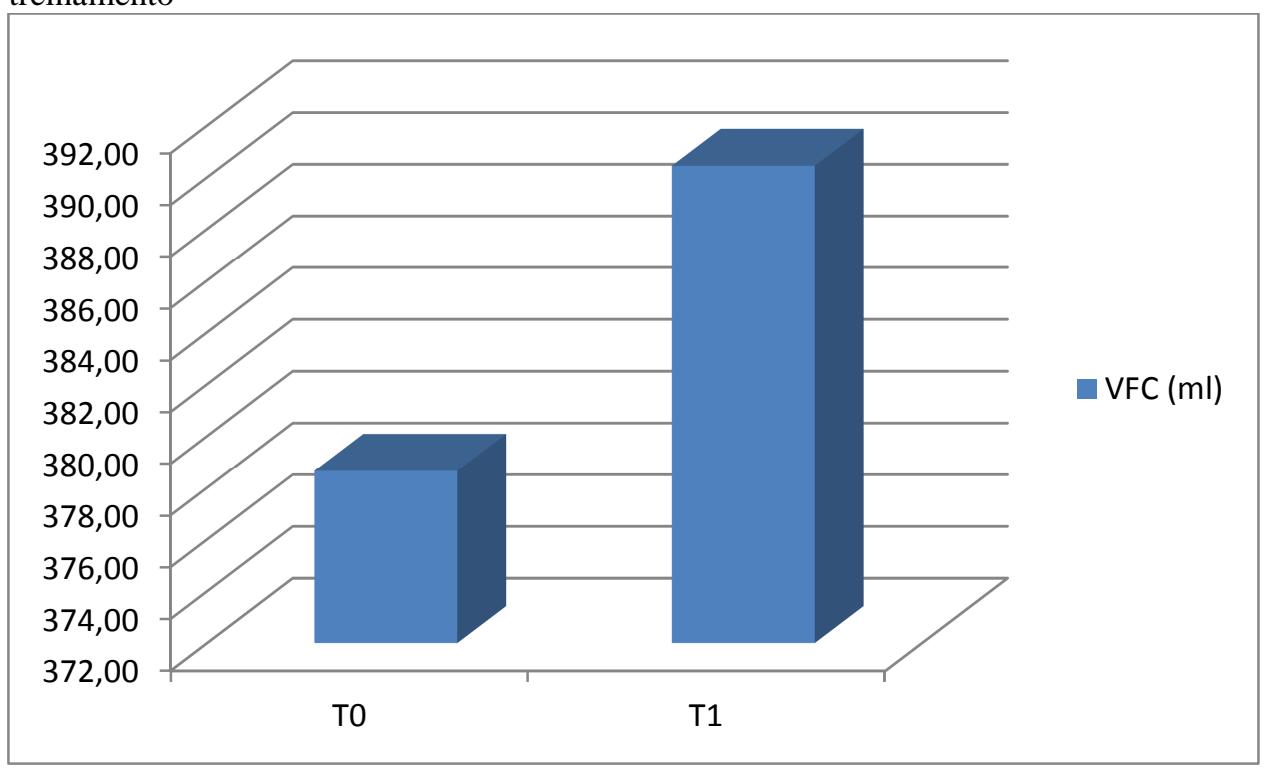


Gráfico 49 - Valores do Débito Cardíaco (DC 1/min) obtidos nos testes iniciais e após 90 dias de treinamento

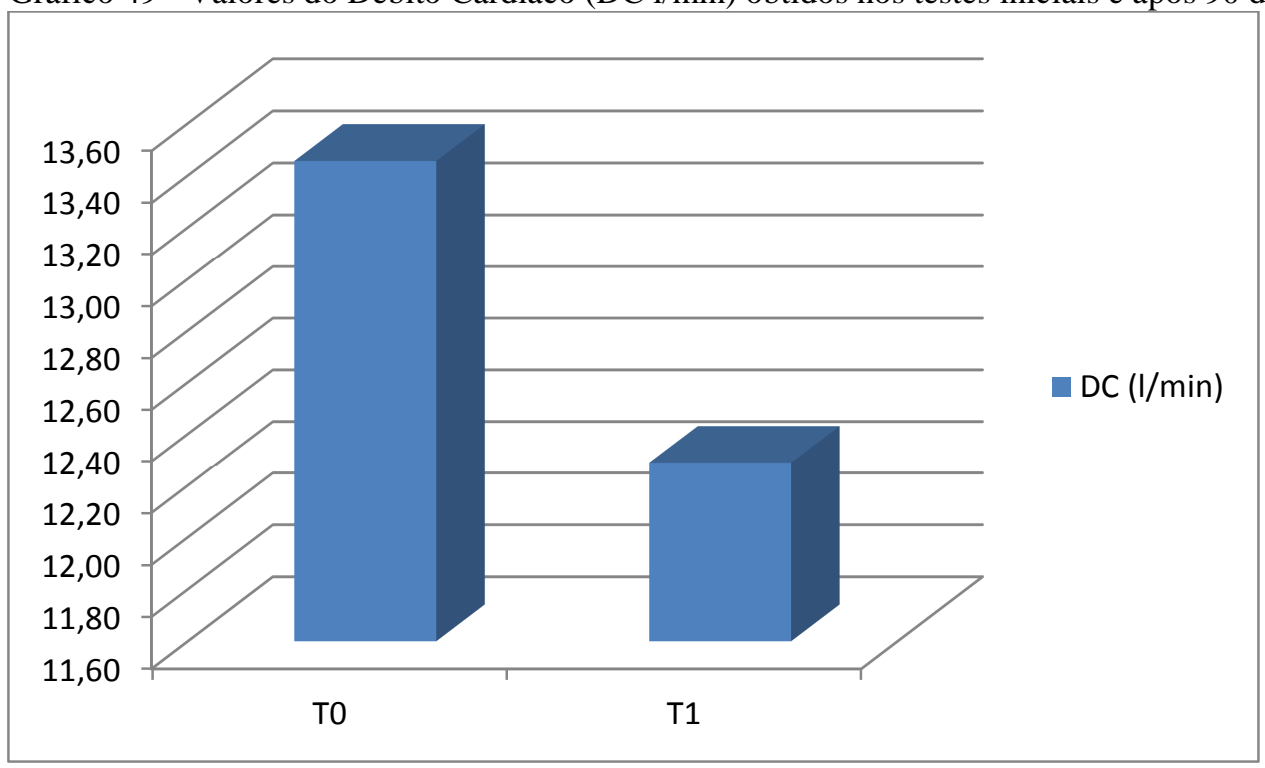

Gráfico 50 - Valores da Fração de Ejeção (FE\%) obtidos nos testes iniciais e após 90 dias de treinamento

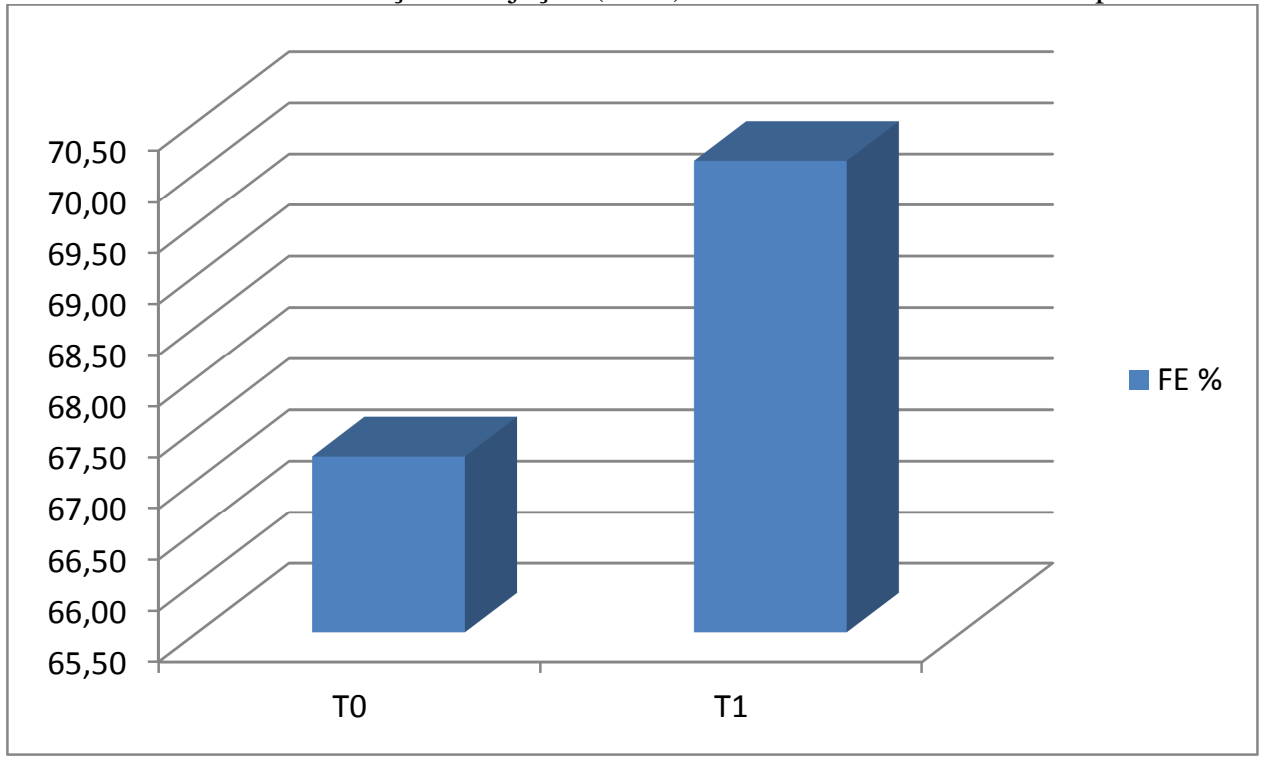


Gráfico 51 - Valores do Diâmetro interno do Átrio Esquerdo (AE) obtidos nos testes iniciais e após 90 dias de treinamento

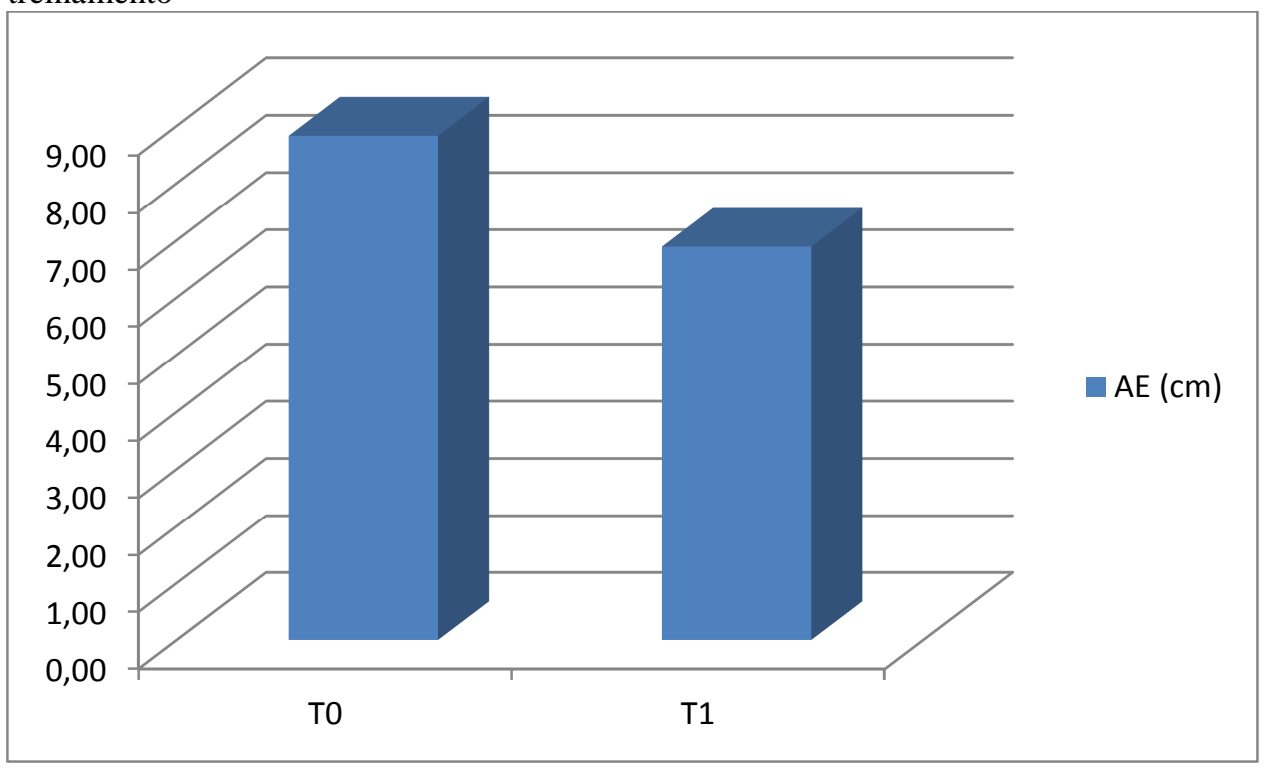

Gráfico 52 - Valores do Diâmetro interno da artéria Aorta (Ao) obtidos nos testes iniciais e após 90 dias de treinamento

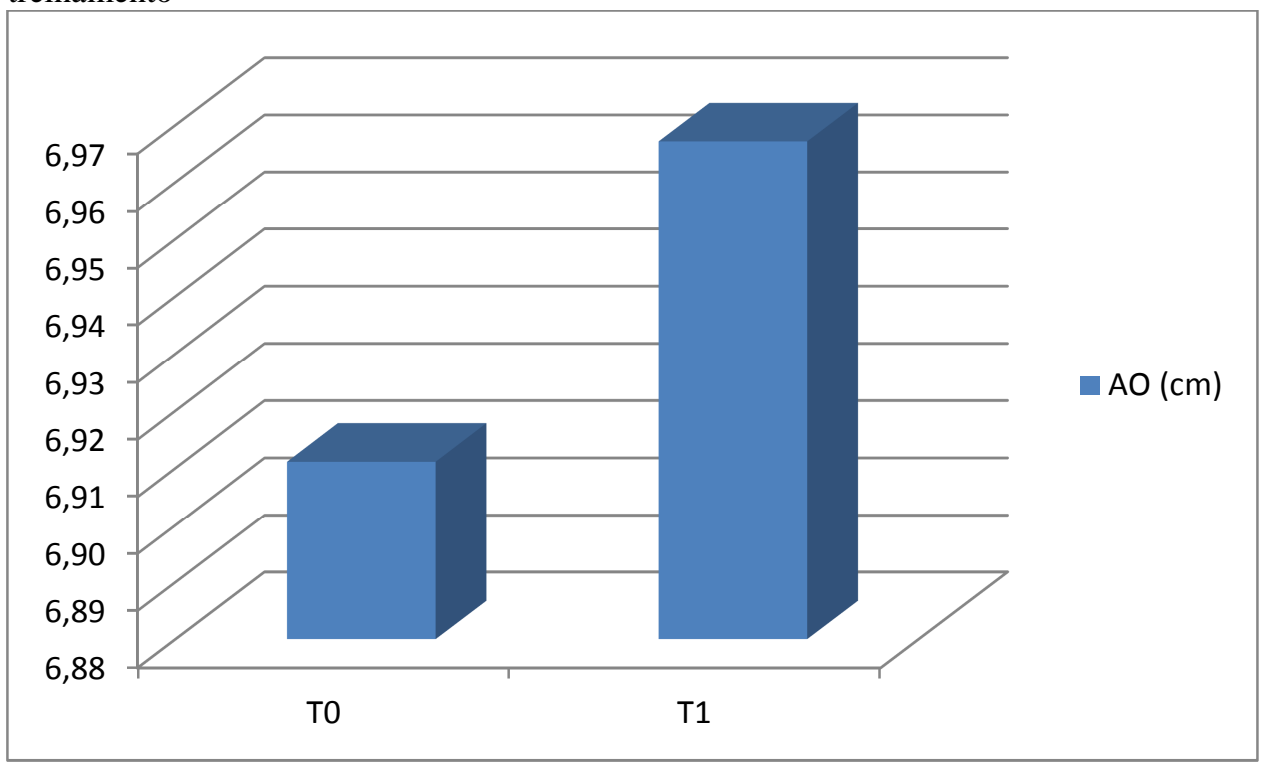


Gráfico 53 - Valores da relação do Diâmetro interno do Átrio Esquerdo (AE) / Diâmetro interno do Átrio Esquerdo (AE) obtidos nos testes iniciais e após 90 dias de treinamento

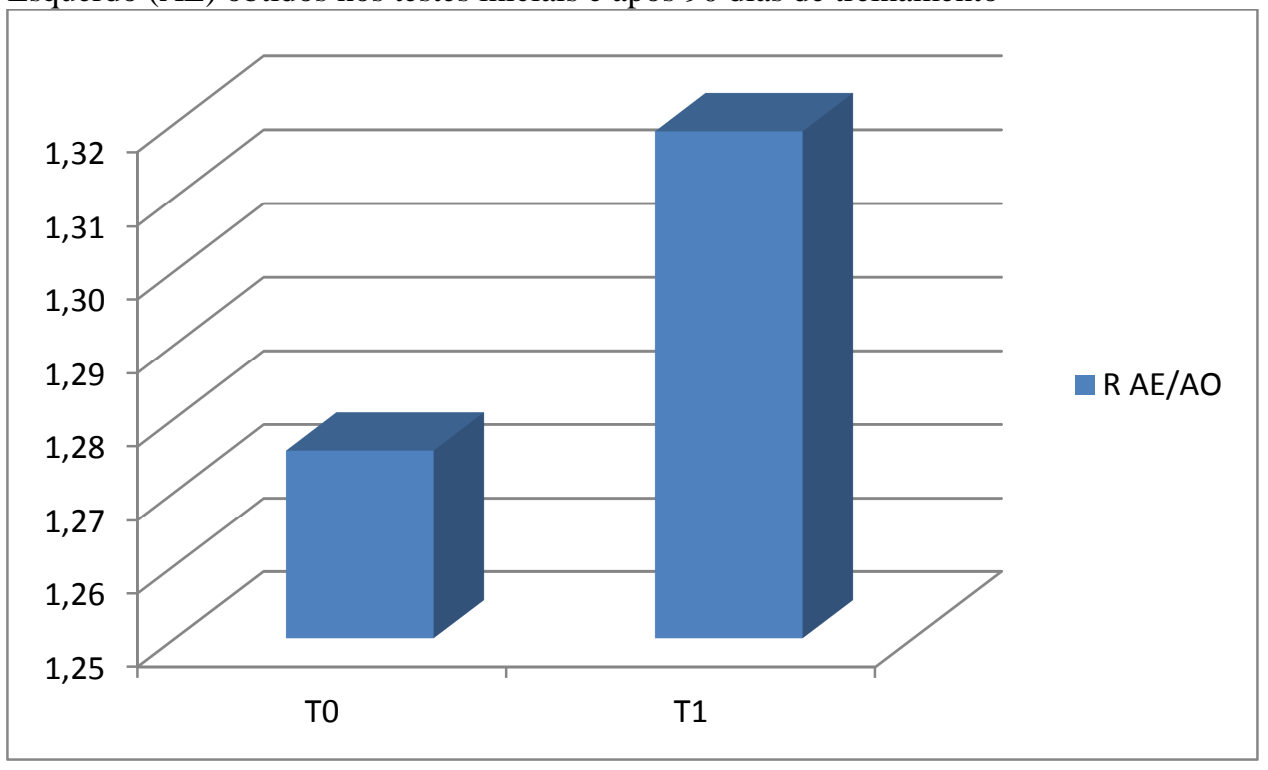

Gráfico 54 - Valores do diâmetro interno de ventrículo direito em diástole (VDd), espessura do septo ventricular em diástole (SIVd), diâmetro interno de ventrículo esquerdo em diástole (DVEd), espessura da parede livre do ventrículo esquerdo em diástole (PLVEd) obtidos nos testes iniciais e após 90 dias de treinamento

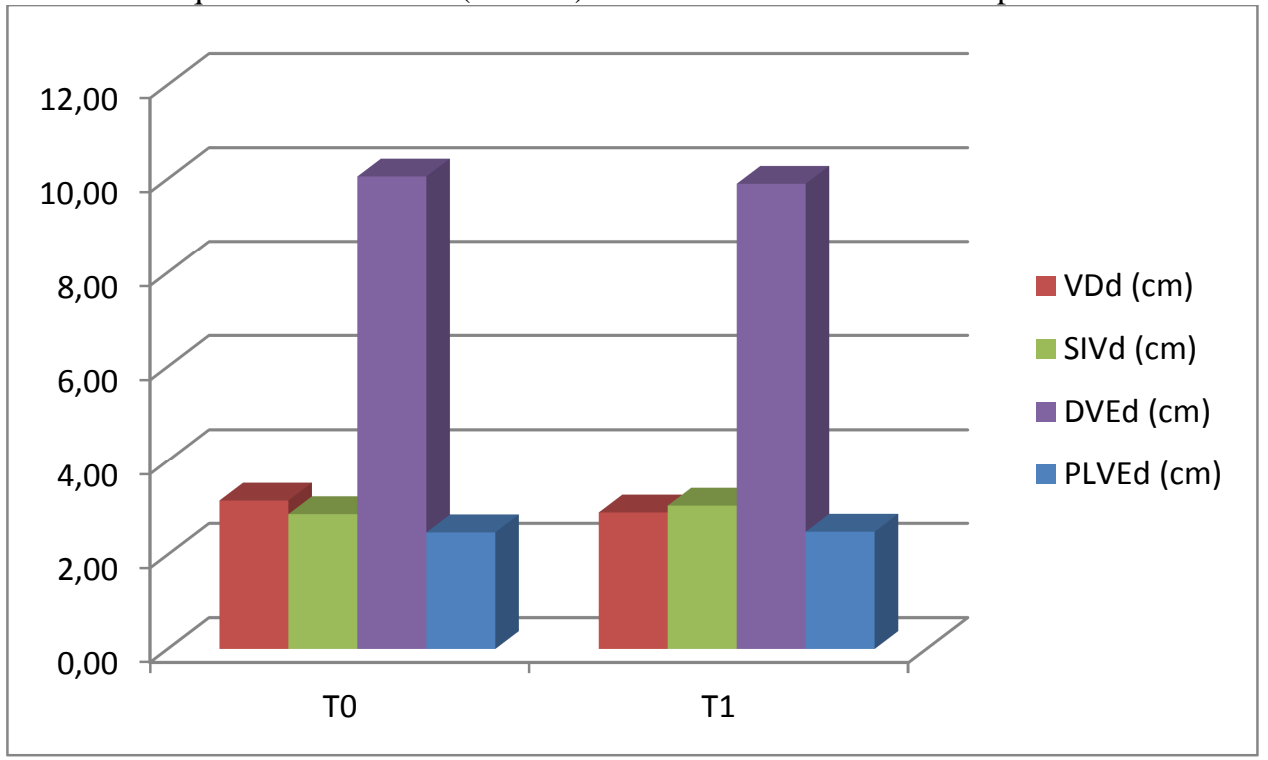


Gráfico 55 - Valores da espessura de septo ventricular em sístole (SIVs), diâmetro interno de ventrículo esquerdo em sístole (DVEs), espessura de parede livre do ventrículo esquerdo em sístole (PLVEs), obtidos nos testes iniciais e após 90 dias de treinamento

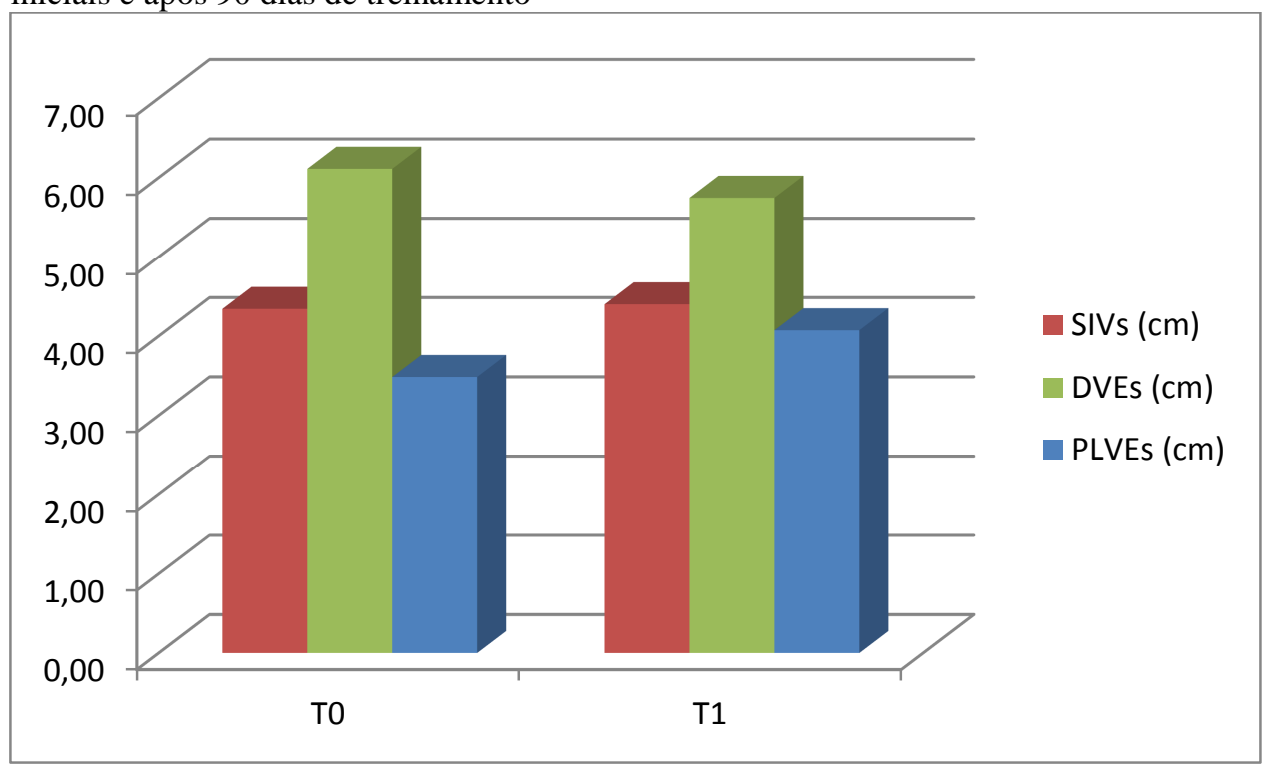

Gráfico 56 - Valores do volume final diastólico do ventrículo esquerdo (VFSVE), volume final sistólico do ventrículo esquerdo (VFDVE), obtidos nos testes iniciais e após 90 dias de treinamento

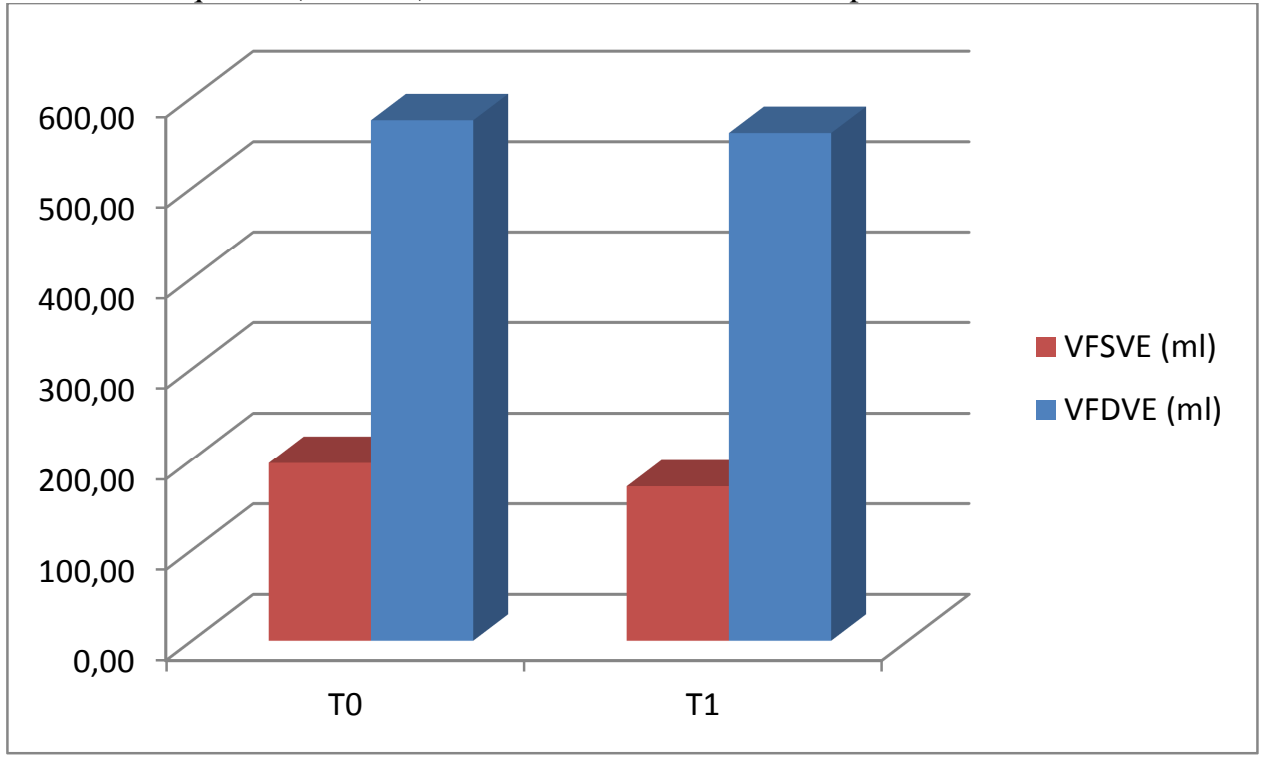


Gráfico 57 - Valores da fração de espessamento do septo ventricular (EFSIV), fração de encurtamento do ventrículo esquerdo (RFDVE) e fração de espessamento da parede livre do ventrículo esquerdo (EFPLVE), obtidos nos testes iniciais e após 90 dias de treinamento

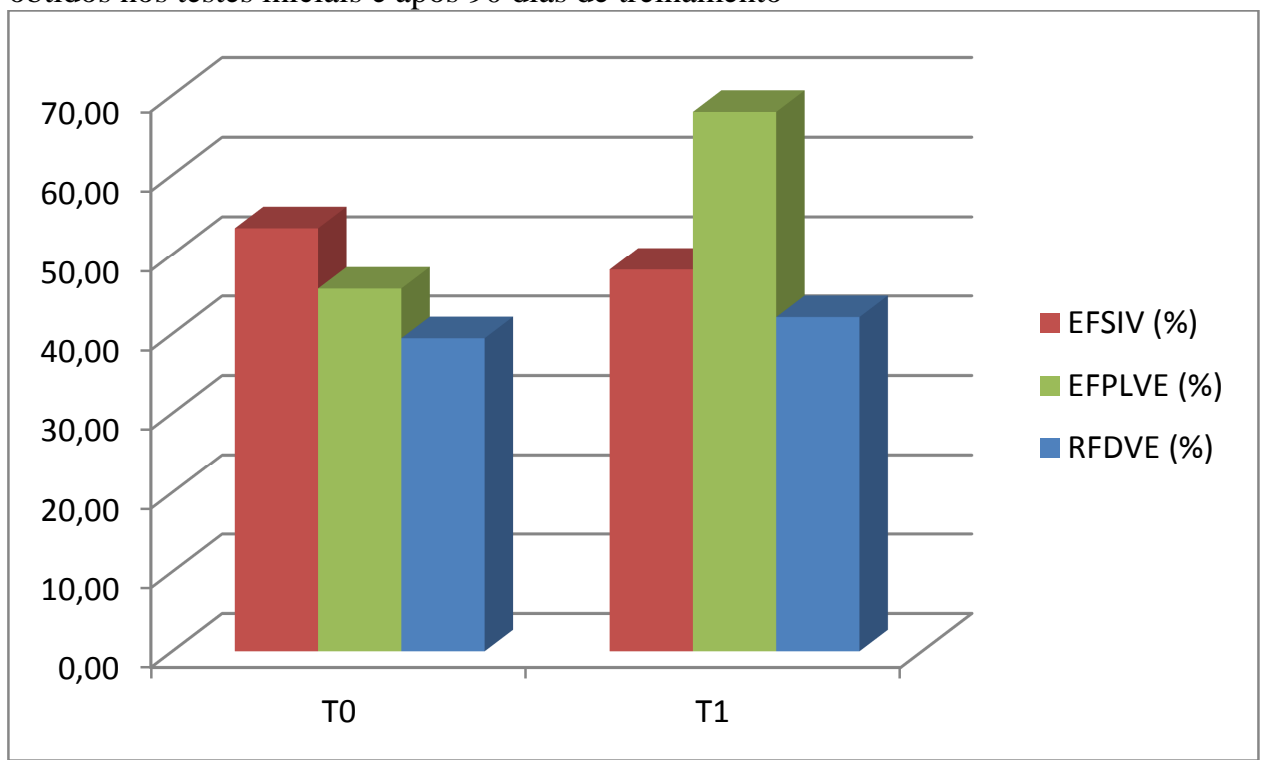

Quando reagrupados em relação ao tipo de treinamento, os resultados estão demonstrados nos gráficos 58 a 68 .

Gráfico 58 - Valores de Frequência Cardíaca (FC) obtidos nos testes iniciais e após 90 dias de treinamento nos grupos treinados a campo e na esteira

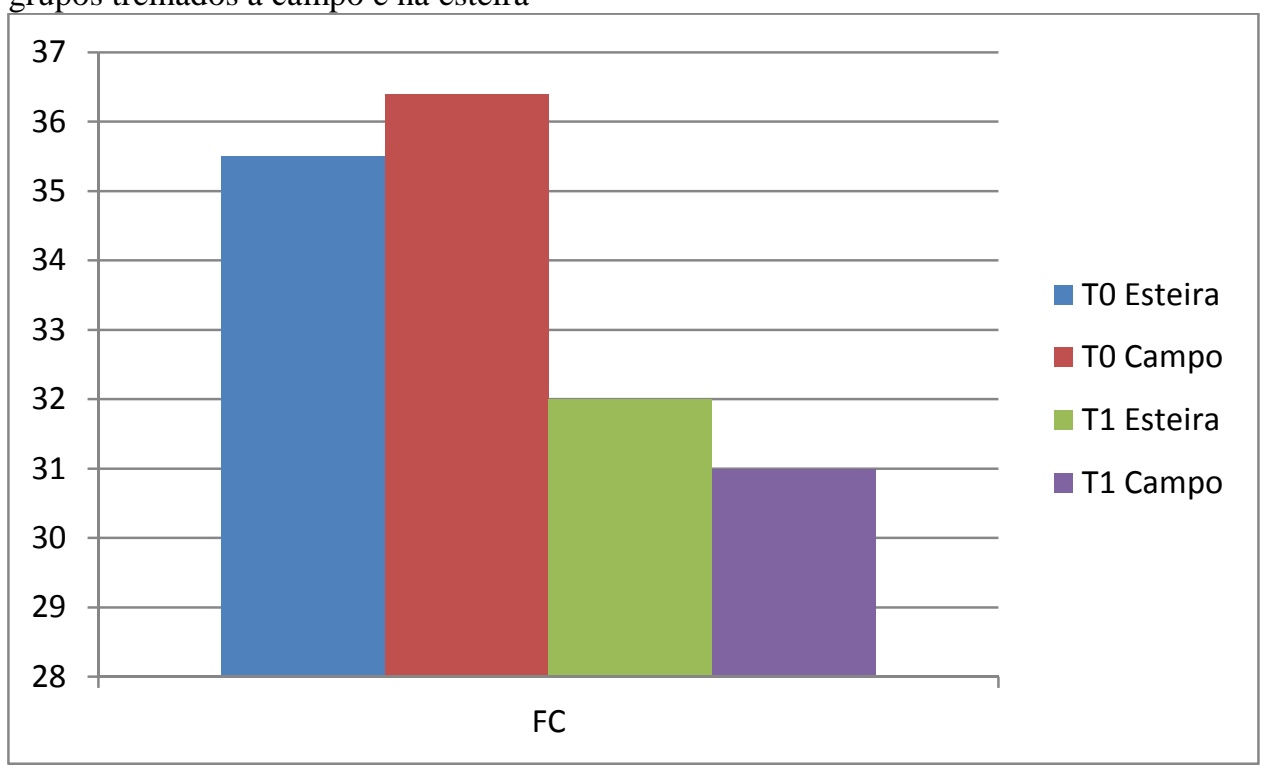


Gráfico 59 - Valores de Volume Final Circulante (VFC ml) obtidos nos testes iniciais e após 90 dias de treinamento nos grupos treinados a campo e na esteira

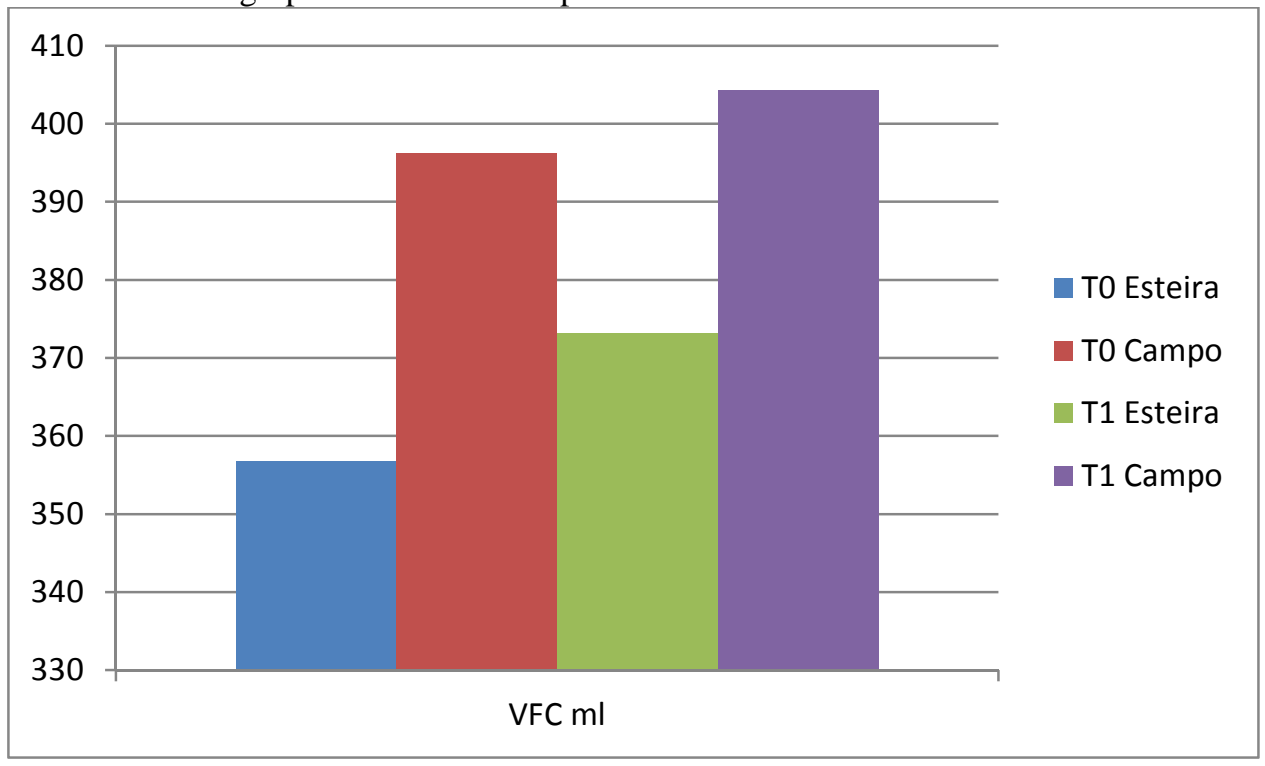

Gráfico 60 - Valores do Débito Cardíaco (DC 1/min) obtidos nos testes iniciais e após 90 dias de treinamento nos grupos treinados a campo e na esteira

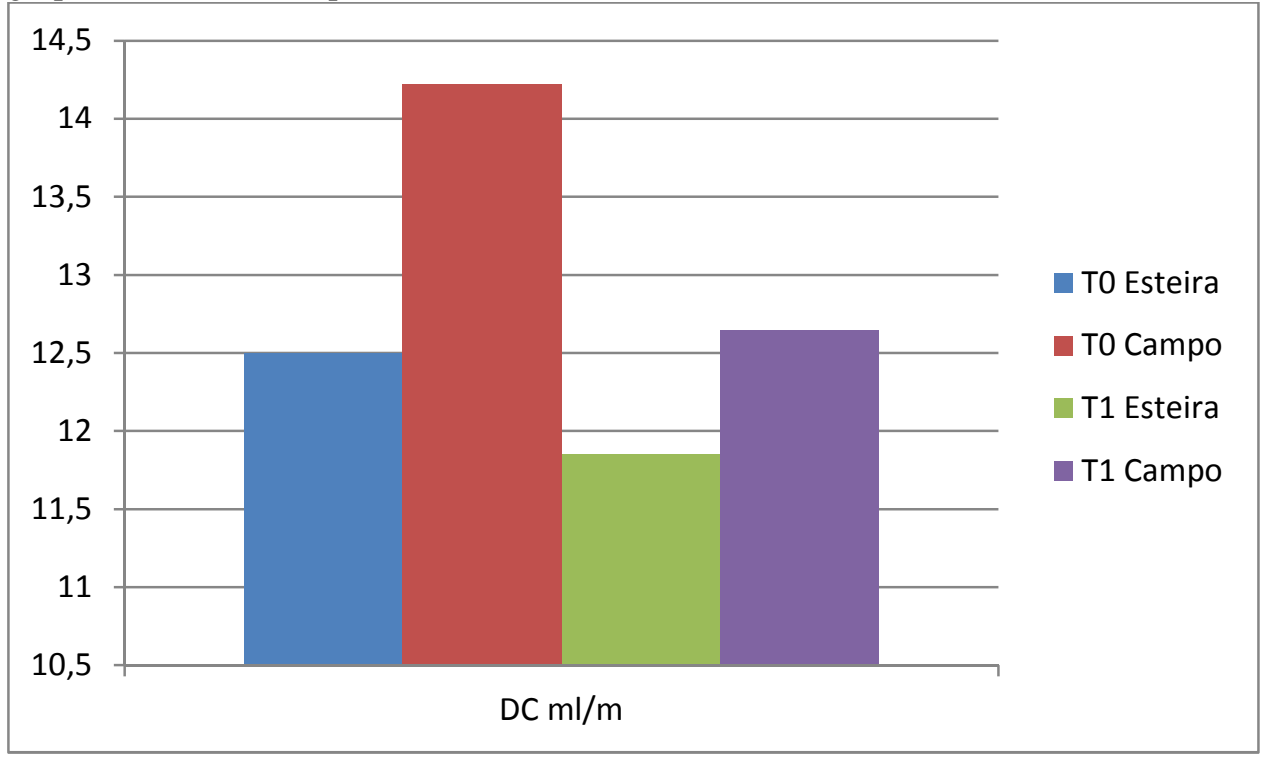


Gráfico 61 - Valores da Fração de Ejeção (FE\%) obtidos nos testes iniciais e após 90 dias de treinamento nos grupos treinados a campo e na esteira

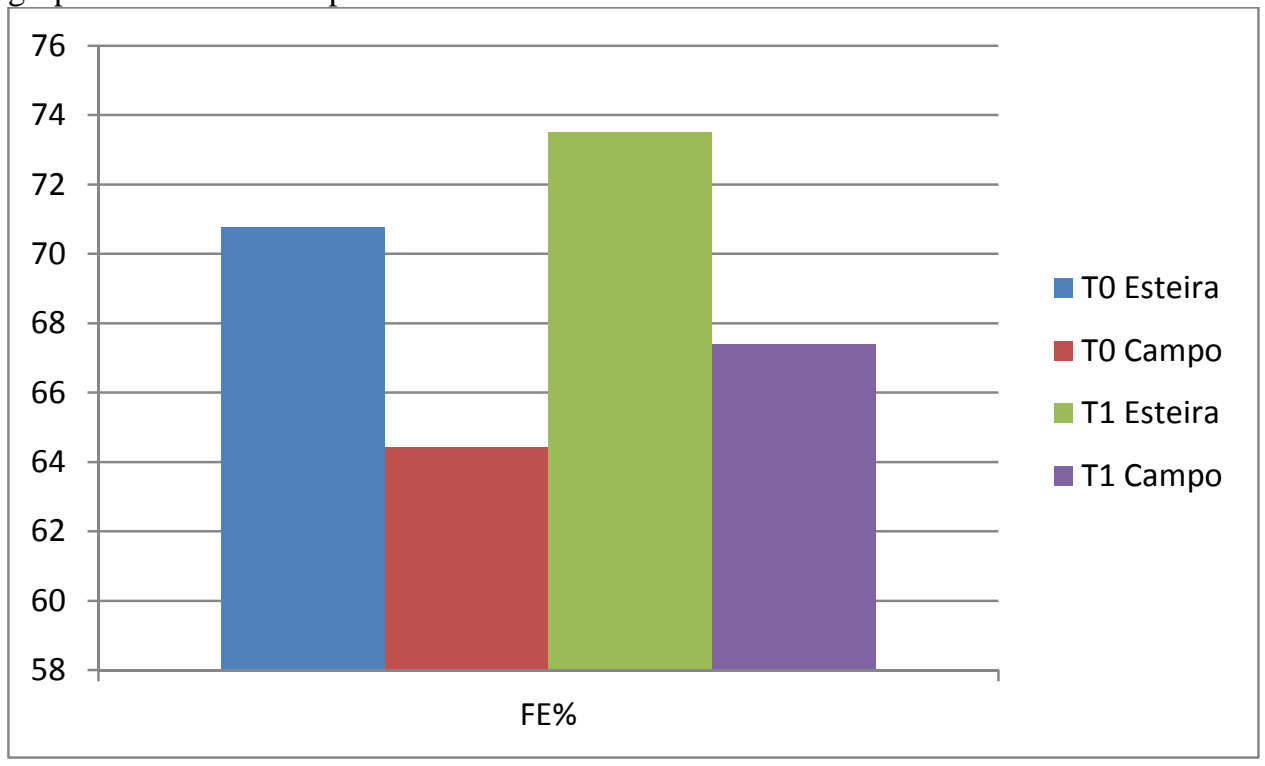

Gráfico 62 - Valores do Diâmetro interno do Átrio Esquerdo (AE) obtidos nos testes iniciais e após 90 dias de treinamento nos grupos treinados a campo e na esteira

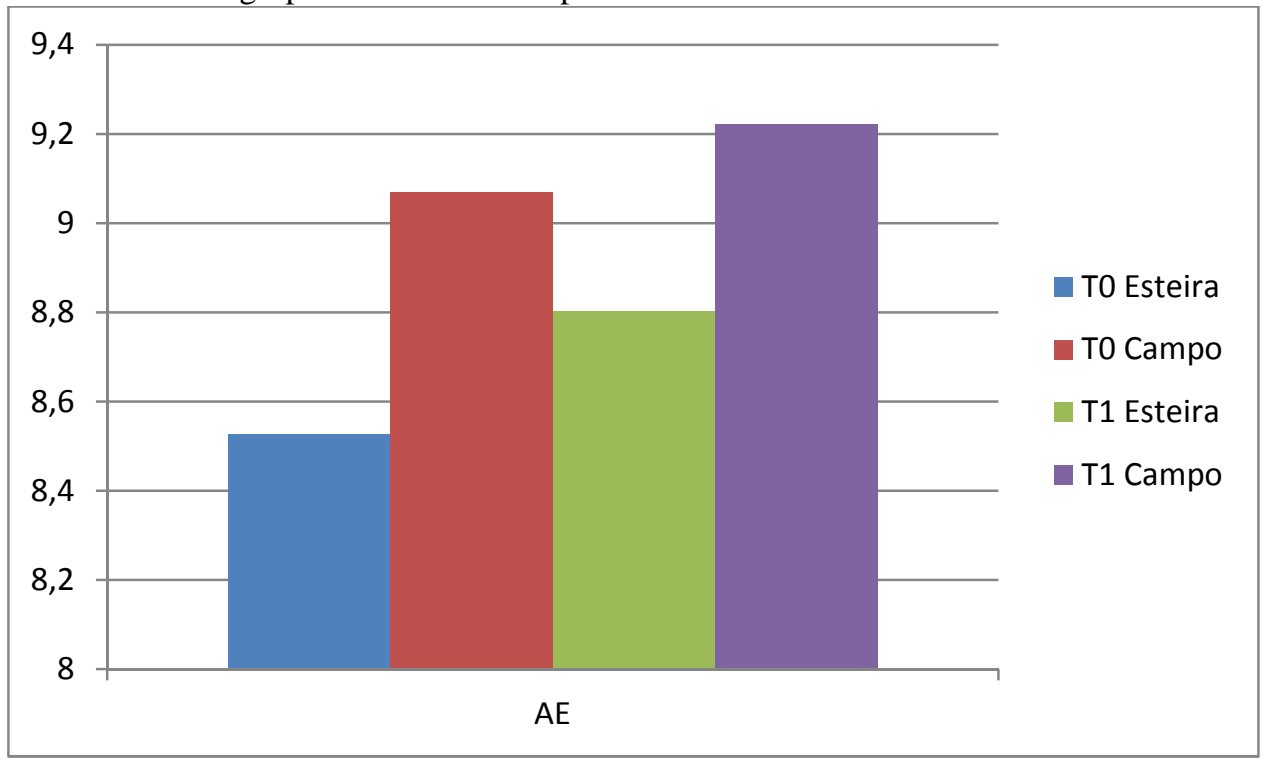


Gráfico 63 - Valores do Diâmetro interno da artéria Aorta (Ao) obtidos nos testes iniciais e após 90 dias de treinamento nos grupos treinados a campo e na esteira

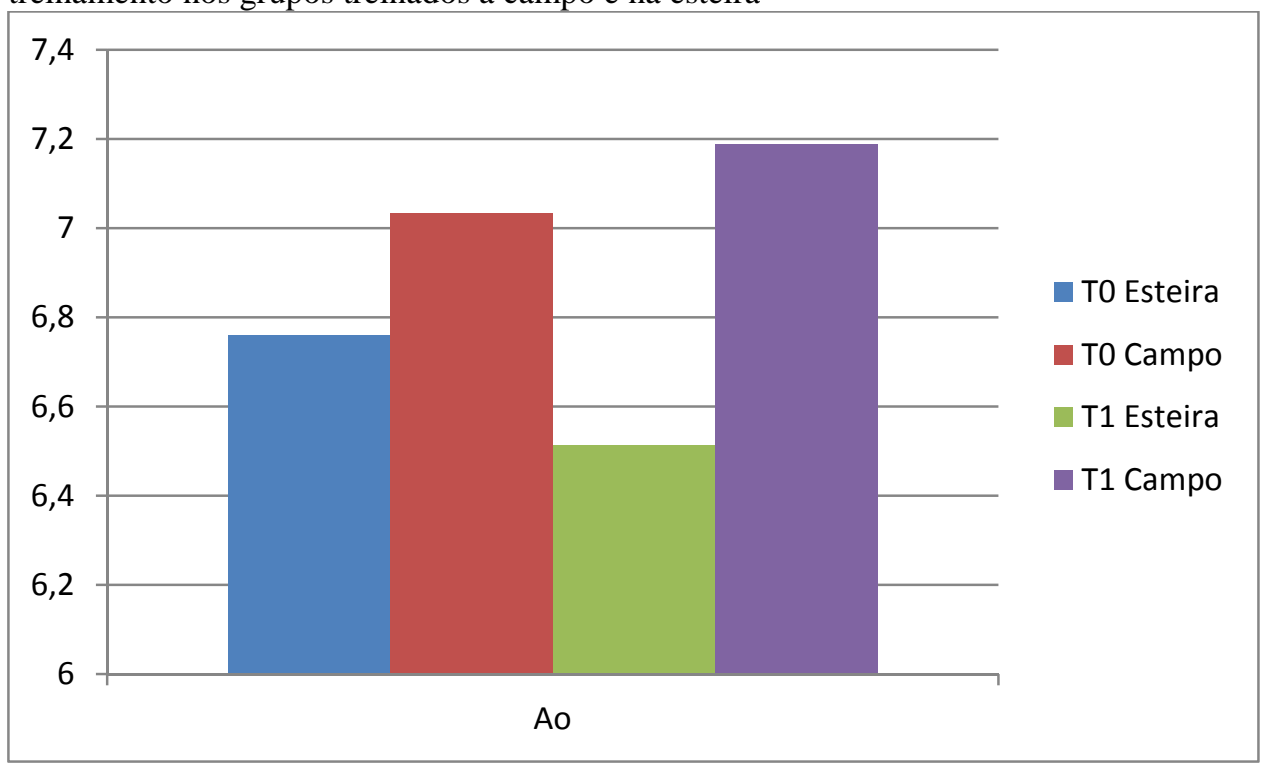

Gráfico 64 - Valores da relação do Diâmetro interno do Átrio Esquerdo (AE) / Diâmetro interno do Átrio Esquerdo (AE) obtidos nos testes iniciais e após 90 dias de treinamento nos grupos treinados a campo e na esteira

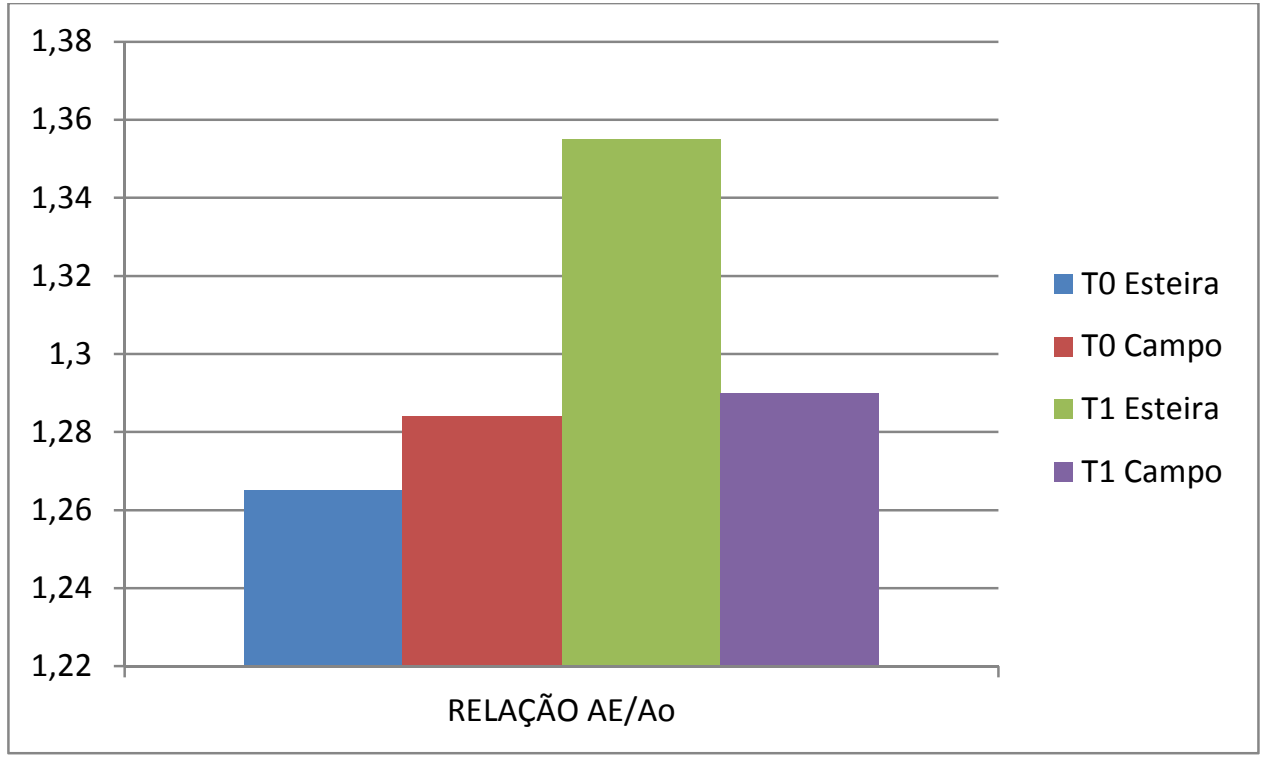


Gráfico 65 - Valores do diâmetro interno de ventrículo direito em diástole (VDd), espessura do septo ventricular em diástole (SIVd), diâmetro interno de ventrículo esquerdo em diástole (DVEd), espessura da parede livre do ventrículo esquerdo em diástole (PLVEd) obtidos nos testes iniciais e após 90 dias de treinamento nos grupos treinados a campo e na esteira

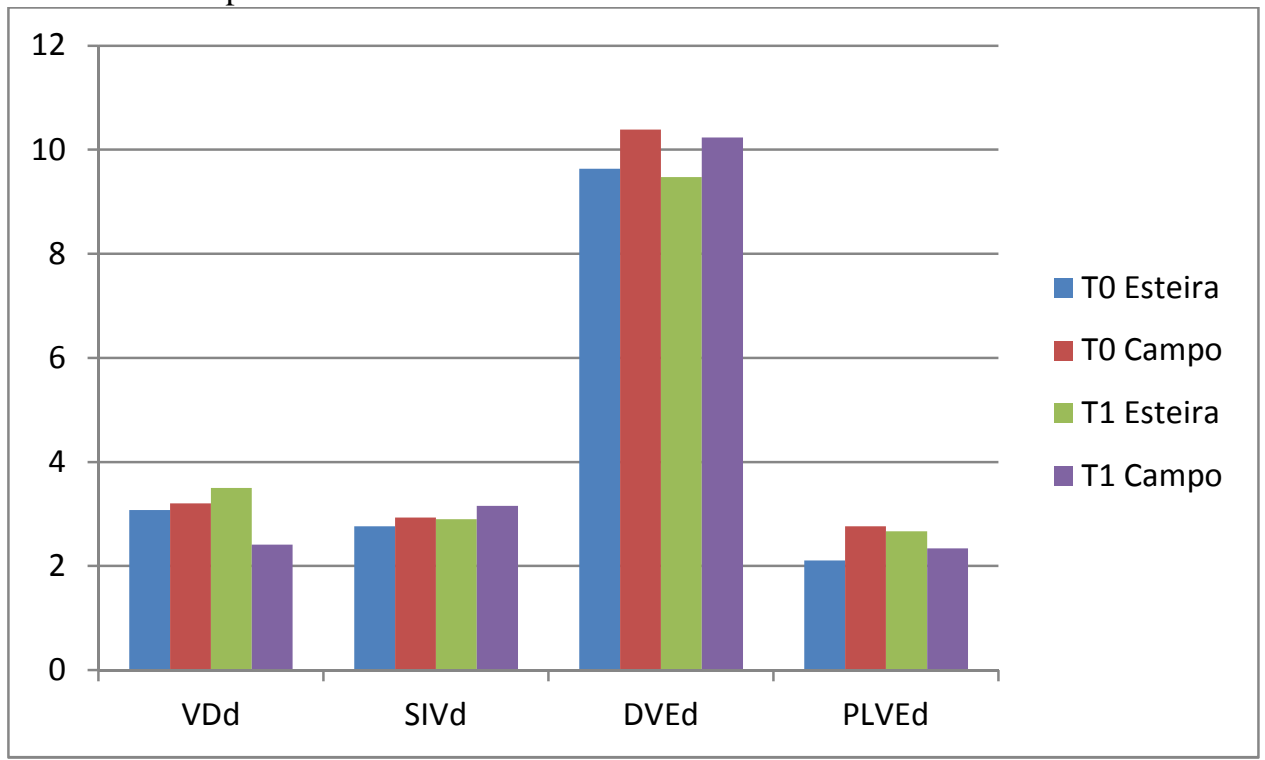

Gráfico 66 - Valores da espessura de septo ventricular em sístole (SIVs), diâmetro interno de ventrículo esquerdo em sístole (DVEs), espessura de parede livre do ventrículo esquerdo em sístole (PLVEs), obtidos nos testes iniciais e após 90 dias de treinamento nos grupos treinados a campo e na esteira

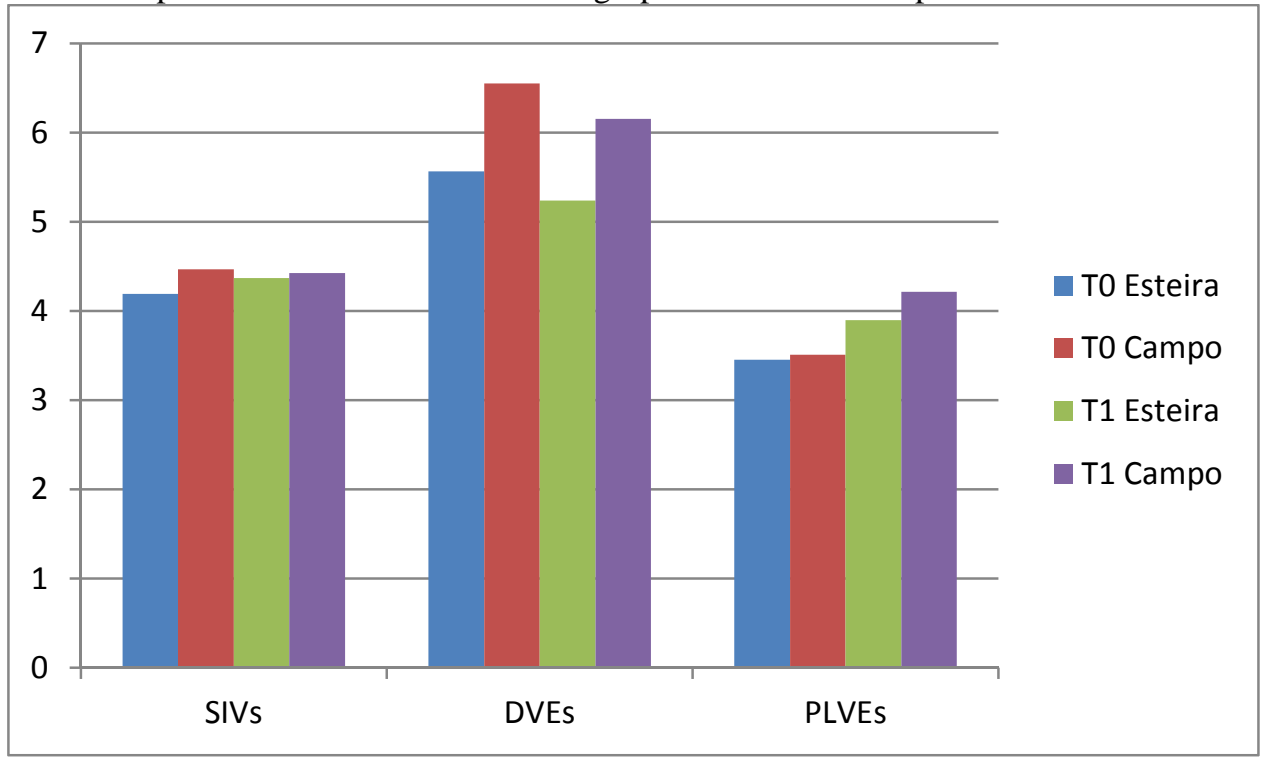


Gráfico 67 - Valores do volume final diastólico do ventrículo esquerdo (VFSVE), volume final sistólico do ventrículo esquerdo (VFDVE), obtidos nos testes iniciais e após 90 dias de treinamento nos grupos treinados a campo e na esteira

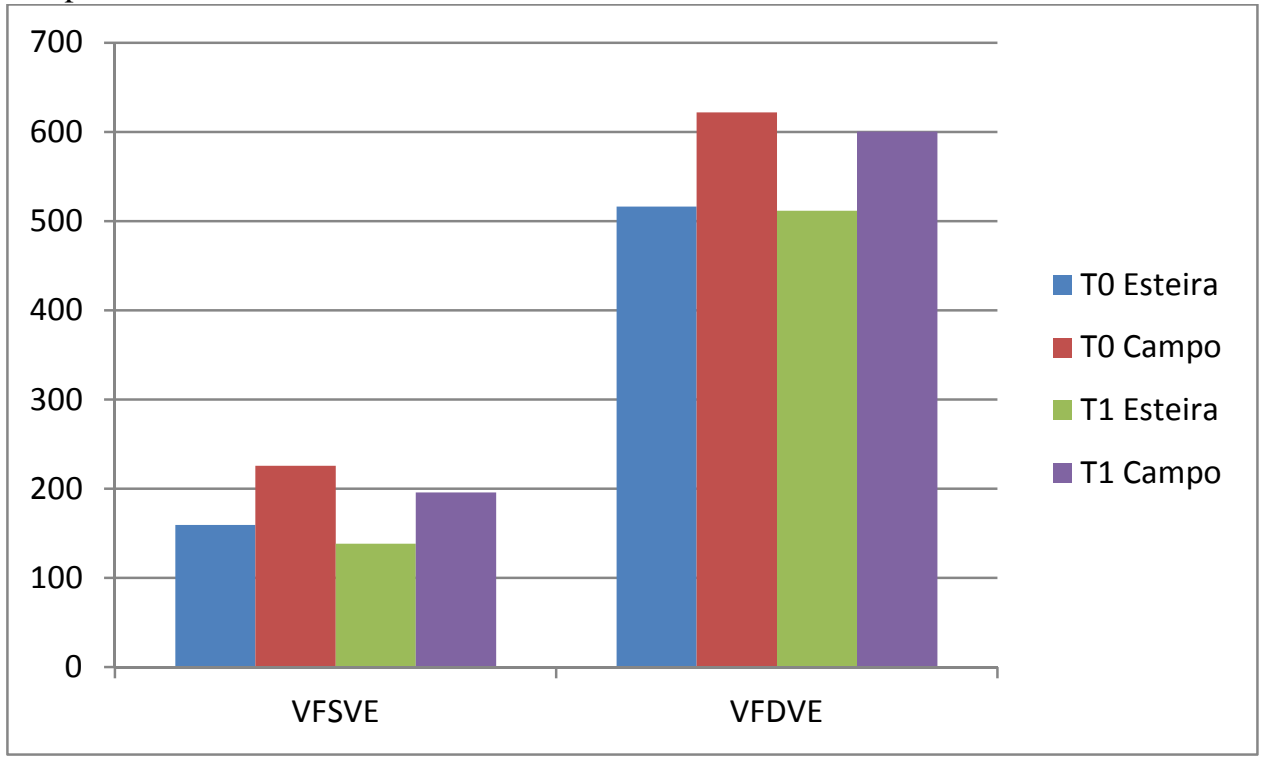

Gráfico 68 - Valores da fração de espessamento do septo ventricular (EFSIV), fração de encurtamento do ventrículo esquerdo (RFDVE) e fração de espessamento da parede livre do ventrículo esquerdo (EFPLVE), obtidos nos testes iniciais e após 90 dias de treinamento nos grupos treinados a campo e na esteira

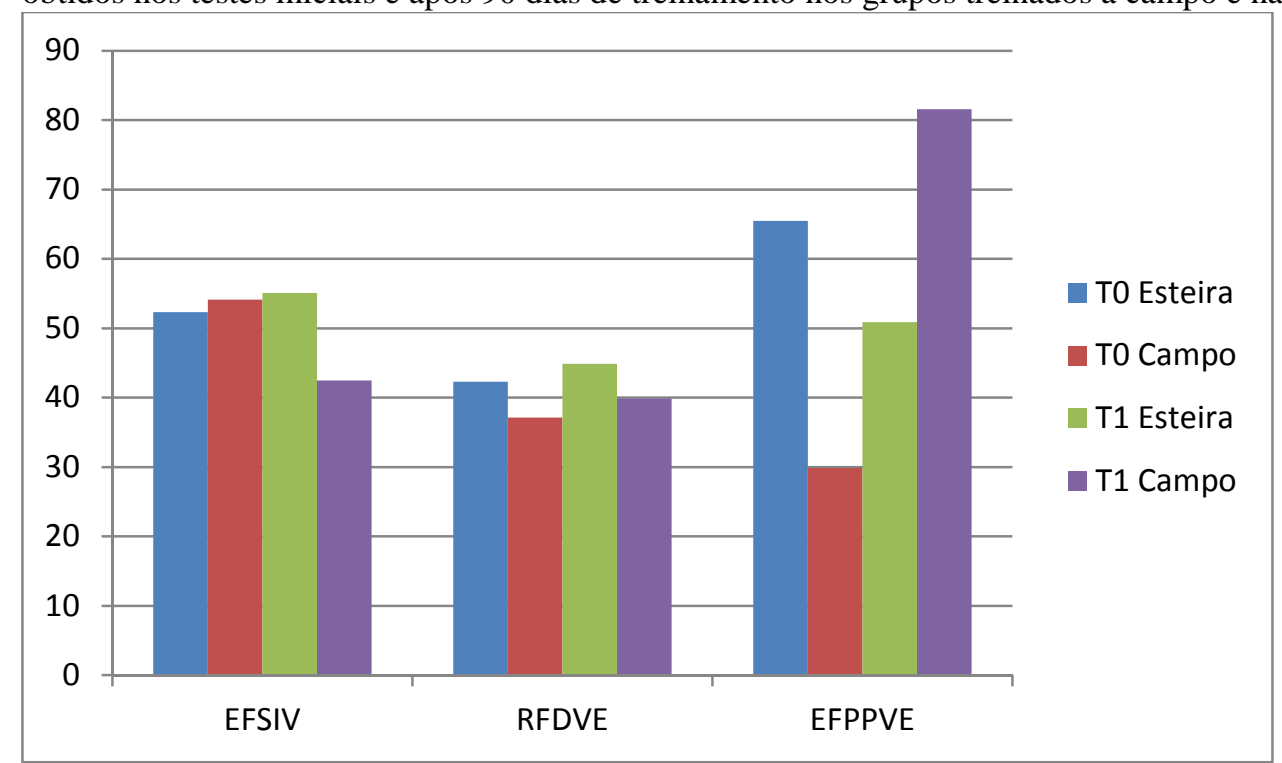




\section{5 - DISCUSSÃO}

Os valores obtidos da resposta da FC nos testes de esforço progressivo foram demonstrados nas tabelas 1 e 2 e gráfico 1, apresentado diferença estatística significante quando comparado os testes $\mathrm{T} 0$ e $\mathrm{T} 1(\mathrm{P}=0,003)$ com todos os animais agrupados.

A elevação da FC durante um teste de esforço é esperada e está diretamente ligada à manutenção do débito cardíaco (DC) durante a prática de atividades físicas, visando manter a oxigenação e a nutrição da musculatura envolvida com o movimento, (GUYTON, 1992; POWERS; HOWLEY, 2000; WASSENRMAN et al., 2005; EVANS, 2007).

Já a atenuação do aumento da frequência cardíaca durante a prática de atividades físicas se dá por uma menor intensificação simpática e menor retirada vagal, alterando a frequência cardíaca intrínseca ou de marca-passo, alterando o seu funcionamento (GAVA et al., 1995)

Essa diferença da resposta da frequência cardíaca em T0 e T1 se deve a melhora da condição cardíaca induzida pelo treinamento aeróbico, uma vez que nas mesmas velocidades, a média das frequências em T1 foi menor que em T0.

A análise do V200 com todos os animais agrupados também demonstra uma melhora na condição cardíaca uma vez que em T0 para se atingir os 200 batimentos cardíacos por minuto foi necessário levar os animais a uma velocidade de $6,63 \mathrm{~m} / \mathrm{s}$ e em T1 para a mesma frequência foi necessário atingir a velocidade de $7,56 \mathrm{~m} / \mathrm{s}$.

Estes fatos indicam que o condicionamento realizado promoveu uma menor exigência do músculo cardíaco para um mesmo grau de esforço, demonstrando uma melhora no condicionamento físico provocado pelo treinamento aeróbico.

Já quando separado os grupos em relação ao tipo de treinamento, nota-se que o grupo de animais treinados a campo finalizou o teste T0 e T1 na mesma velocidade (M7 - 10,0 m/s), apresentando frequências cardíacas muito semelhantes nos momentos de aceleração do protocolo, não sendo observada diferença estatística entre os momentos T0 e T1 (P=0,734). 
Porém mesmo sem diferença estatística significante na evolução da curva da FC, a análise do V200 demonstra uma melhora sendo obtida essa marca em T0 a 6,58 m/s e em T1 a $7,12 \mathrm{~m} / \mathrm{s}$.

O grupo de animais treinados na esteira com um controle mais rígido durante a fase de treino (seja em relação à $\mathrm{FC}$ de treino e mesmo do tempo e velocidade de trote) obteve diferença significativa entre T0 e $\mathrm{T} 1(\mathrm{P}=0,003)$ e conseguindo atingir o esforço máximo em T1 em um estágio amais que em T0. Em T0 o teste foi interrompido no estágio M7 (10 m/s) e em T1 os mesmos cavalos atingiram M8 $(12,5 \mathrm{~m} / \mathrm{s})$.

$\mathrm{Na}$ análise do V200, também nota-se uma melhora muito grande com relação à velocidade em que foi necessária para atingir os 200 batimentos cardíacos. Em T0 foi necessário atingir a velocidade de $6,69 \mathrm{~m} / \mathrm{s}$ e em T1 7,61 m/s sendo esta marca quase $0,5 \mathrm{~m} / \mathrm{s}$ (ou $1,8 \mathrm{~km} / \mathrm{h}$ ) a mais quando comparado com o grupo treinado a campo.

Quando comparado o teste T0 do grupo treinado a campo com o grupo treinado na esteira não se observa diferença estatística significante $(\mathrm{P}=0,410)$ e em T1 também não $(\mathrm{P}=0,410)$, mesmo o grupo dos animais treinados em esteira tendo um indivíduo atingindo M8.

Observou-se diferença estatística entre o T0 e T1 dos animais treinados na esteira, e não se observou diferença estatística entre T0 e T1 dos animais treinados a campo.

Pode-se sugerir que os animais iniciaram o experimento com a condição cardíaca semelhante em T0 e obtiveram resposta semelhante em T1, porém para grupo treinado na esteira essa melhora com relação à FC se demonstrou significante estatisticamente, o que não foi demonstrado no grupo treinado a campo.

Outro parâmetro que apresentou comportamento semelhante ao encontrado na FC foi à pressão arterial sistólica (PAS). Seus valores já foram apresentados nas tabelas 4 e 5 e gráfico 7, e suas curvas apresentaram diferença significativa estatisticamente $(\mathrm{P}=0,005)$ quando analisado todos os animais em conjunto.

A pressão arterial sistólica é o produto do volume sistólico vezes a resistência vascular periférica, que por sua vez depende do diâmetro das arteríolas e também é influenciada pela viscosidade sanguínea. Sua regulação está relacionada a mecanismos cerebrais (comando 
central) e trabalho muscular: diminuição da PO2 e aumento da concentração local de metabólitos levam a modulação central (EVANS, 1994).

Os valores obtidos em $\mathrm{T} 1$ foram significativamente menores que os valores obtidos em T0 e essa diminuição se deve diretamente ao efeito do treino aeróbico como demonstrados em estudos com ratos que foram submetidos a treinamento aeróbico e também em atletas humanos (TIPTON, 1991; ARROL; BEAGLEHOLE, 1992; MARCEAU et al., 1993; VÉRAS-SILVA et al., 1997).

Tais efeitos se devem a possíveis mecanismos relacionados à atividade nervosa simpática como a diminuição da resistência vascular periférica (RVP) e o aumento da sensibilidade barorreflexa (SILVA et al., 1997; BRUM et al., 2000), mas outros pesquisadores relacionam essa diminuição da pressão arterial a diminuição do volume plasmático e do volume sistólico, levando a diminuição do débito cardíaco (URATA; TANABE; KYONAGA, 1987; SEALS; REILING 1991).

Estudos com ratos naturalmente hipertensos demonstraram a queda da pressão sistólica pós-treino influenciada pela diminuição do débito cardíaco ao qual foi associado à bradicardia de repouso (RONDON e BRUM, 2003) e em outro estudo observou-se a expressiva redução do tônus simpático sobre o coração por uma maior sensibilidade do nervo depressor aórtico o que acarretaria na melhora do controle barorreflexo determinando a diminuição da frequência cardíaca de repouso e mesmo durante a prática de atividade fisica (GAVA et al., 1995). O cronotropismo cardíaco negativo em repouso tem grande importância na diminuição do débito cardíaco e consequente diminuição na PAS (KRIEGER; BRUM; NEGRÃO, 1999).

No presente estudo observou-se a diminuição da FC em repouso e durante a prática de atividade física como já discutido anteriormente, o que vem a corroborar a hipótese de que a diminuição da PAS é influenciada pelo cronotropismo negativo e por consequente diminuição do débito cardíaco. Fato este que, mesmo não havendo diferença significativa nos valores achados no ecocardiograma de repouso com relação a variável de débito cardíaco (DC) e FC, sugerem que a mesma hipótese que ocorre em ratos e em atletas também ocorre nos equinos.

Este fato fica mais evidente quando se separar os grupos em relação ao tipo de treinamento submetido. Os animais submetidos ao treino a campo apresentaram diminuição dos valores de PAS durante as fases de incremento de velocidade, porém sem diferença 
estatística significante. $\mathrm{O}$ mesmo ocorrendo para as variáveis analisadas pelo ecocardiograma de repouso (DC e FC).

Os animais submetidos a treinamento controlado na esteira apresentaram valores com diferença significativa estatisticamente de PAS $(\mathrm{P}<0,001)$, e mesmo sem diferença estatística significante, apresentaram tendência a maior diminuição dos valores de DC e FC avaliados pelo ecocardiograma, quando comparados ao grupo treinado a campo e com todos os animais juntos.

Em relação aos testes T0 e T1 quando comparados T0 (campo x esteira) e T1 (campo $x$ esteira) não houve diferença significativa entre os grupos $\mathrm{P}=0,260$ para $\mathrm{T} 0$ e $\mathrm{P}=0,256$ para $\mathrm{T} 1$.

Diferente da PAS, a PAD não apresentou diferença estatística significante entre T0 e $\mathrm{T} 1$ com todos os animais agrupados $(\mathrm{P}=0,124)$ e nem mesmo quando separados pelo tipo de treinamento $(\mathrm{P}=0,209)$. Considerando a PAD um reflexo direto da eficiência do mecanismo vasodilatador local da musculatura em atividade, sendo esse mecanismo diretamente proporcional a maior densidade vascular. Essa vaso dilatação da musculatura esquelética acarreta na diminuição da resistência vascular periférica, que atinge seu ápice quando o exercício atinge ao redor de $75 \%$ do $\mathrm{VO}_{2}$ máximo (PASSARO; GODOY, 1996; BAROS NETO; CÉSAR; TEBEXRENI, 1999; SILVERTHORN, 2003). No presente estudo a não alteração da PAD nos permite sugerir que o possível mecanismo para que ocorra a diminuição da PAS seja mesmo a diminuição do débito cardíaco pela menor influencia vagal e pelo cronotropismo negativo, como discutido anteriormente.

A pressão arterial média (PAM) é calculada a partir da seguinte equação: PAM=1/3 $(\mathrm{PAS})+2 / 3(\mathrm{PAD})$ ou PAM= $[\mathrm{PAD}+1 / 3(\mathrm{PAS}-\mathrm{PAD})]$ sendo uma medida estável em praticamente todo leito vascular e determinada exclusivamente por duas variáveis débito cardíaco e resistência vascular periférica, podendo, a grosso modo, indicar o nível de perfusão tecidual periférica (MAGALHAES, 2002).

No presente estudo os valores de PAM durante os testes de esforço máximo apresentaram diferença estatística significante entre T0 e T1 quando agrupados todos os animais $(\mathrm{P}=0,012)$ e sendo os valores em $\mathrm{T} 1$ menores que os valores obtidos em T0.

O mesmo foi observado em relação ao grupo que treinou na esteira. Este também apresentou diferença estatística significante em relação a T0 e T1 $(\mathrm{P}=0,012)$, porem quando 
comparado T0 esteira x campo e T1 esteira x campo não houve diferença significativa entre eles $(\mathrm{P}=0,389)$.

Este fato também vem a acrescentar mais um fato a favor da possibilidade de que a queda da PAS esteja ligada a diminuição do DC e FC de repouso uma vez que não houve diferença com relação à PAD (relaciona a RVP), mas sim com relação à PAS.

Outras adaptações foram notadas com relação às variáveis analisadas através do ecocardiograma de repouso. Mesmo que nenhuma variável tenha apresentado diferença estatística significante com todos os animais agrupados, podemos observar algumas tendências de melhora com relação ao músculo cardíaco.

A diminuição da FC de repouso como já comentado anteriormente é o principal fator para a diminuição do DC observado, pois se observou um aumento do VFC (volume este que é ejetado do coração em cada sístole - Volume Sistólico).

Outra melhora observada foi em relação a FE\% que demonstrou valores mais altos em T1. Esse parâmetro relaciona em porcentagem a quantidade de sangue que saiu do ventrículo esquerdo no momento da sístole. Essa melhora esta relacionada ao aumento do VFC, e como consequência uma diminuição do VSFVE provocado pelo aumento da PLVEs que acarreta no aumento da EFPLVE\% indicando que o treinamento aeróbico levou a hipertrofia da porção muscular do miocárdio localizado na parede livre o que acarretou num aumento de força de contração, permitindo a ejeção de um volume maior de sangue na sístole.

Essas observações também são validas quando separado os grupos com relação ao tipo de treinamento. Também não foi observada diferença significativa estatisticamente entre T0 e T1 para os diferentes tipos de treino, mas os gráficos mostram diminuição das mesmas variáveis quando analisados todos os animais em conjunto (VFC, VSFVE, PLVEs, EFPLVE\%).

Esse aumento do VS e por consequência o aumento do aporte de nutrientes e oxigênio para a musculatura que esta sendo utilizada permite que a atividade física seja executada por mais tempo em sua fase aeróbica, diminuindo a concentração de lactato durante a prática da atividade e levando a postergação da fadiga muscular.

Quando se analisa os resultados obtidos da concentração de lactato sanguíneo obtidos em T0 e T1 (Gráfico 22) fica evidente essa melhora, uma vez que se observa uma diferença 
estatística significante entre os testes $(\mathrm{P}=0,015)$ com os valores em $\mathrm{T} 1$ comparativamente menores nos mesmos momentos de incremento da velocidade no teste.

Quando reagrupados pelo tipo de treinamento, apenas o grupo treinado na esteira demonstra esse mesmo comportamento. $\mathrm{O}$ grupo treinado na esteira apresentou $\mathrm{P}=0,015$ entre T0 e T1 enquanto o grupo treinado a campo apresentou $\mathrm{P}=0,993$.

Esta melhora reflete também no limiar de lactato que é o momento no qual ocorre uma elevação sistemática e contínua da concentração de lactato sérico com a perda da linearidade da subida, (POWERS; HOWLEY, 2000; WASSERMAN et al., 2005). Quando comparados todos em conjunto em T0 este ponto ocorreu em M4 e em T1 em M5. Já quando separados pelo tipo de treinamento, nos animais treinados a campo não houve mudança desse momento (ambos ocorreram em M4) e nos treinados na esteira em T0 ocorreu em M3 e em T1 em M5.

As variáveis que também avaliam o desempenho atlético dos animais referentes à adaptação pulmonar, com a captação de oxigênio $\left(\mathrm{PO}_{2}\right)$ e na concentração de $\mathrm{O} 2$ diluído no sangue $\left(\mathrm{SO}_{2} \%\right)$ ou no prolongamento da fase aeróbica e consequente fadiga muscular pela produção de gás carbônico $\left(\mathrm{PCO}_{2}\right)$, não se observou diferença estatística significante tanto para todos os animais agrupados como para reagrupados com relação ao tipo de treino.

Quando observado o gráfico 37 da $\mathrm{PCO}_{2}$, observa-se valores menores em T1 quando comparados com T0 com todos os animais agrupados por treinamento. Isto se observa também quando reagrupados os animais. Este achado se deve a melhora da condição cardíaca, uma vez que com o aumento do VS há um melhor aporte de oxigênio e nutrientes para a musculatura, possibilitando a manutenção da atividade física por mais tempo utilizando-se a via aeróbica e com menor fadiga muscular.

$\mathrm{O}$ treino aeróbico apresentou diferença estatística significante $(\mathrm{P}=0,160)$ na acidemia ou alcalemia metabólica. O que se observa nos gráfico 27 do $\mathrm{pH}$ é que com o aumento da velocidade e do esforço, pode ocorrer acidose metabólica (diminuição do $\mathrm{pH}$ ) pelo cúmulo do ácido lático e pelo aumento da formação de ácido carbónico (aumento da $\mathrm{PCO}_{2}$ ) que corresponde ao momento da troca de via energética predominante para a manutenção da atividade (aeróbica ou anaeróbica) e que em T1 esses valores tenderam a ser mais altos na fase anaeróbica do exercício a partir do limiar de lactato como descrito anteriormente. 
A melhora cardíaca também levou a uma melhora da acidemia metabólica apresentando valores mais altos do $\mathrm{pH}$ em $\mathrm{T} 1$ quando comparados a $\mathrm{T} 0$ nos mesmos momentos de incremento de velocidade. 


\section{CONCLUSÃO}

Podemos concluir no presente estudo que o treinamento aeróbico num período de 90 dias já é suficiente para promover adaptação cardíaca com a hipertrofia da parede livre do ventrículo esquerdo e melhora na força de contração cardíaca. Essa melhora na contração permite o aumento do volume ejetado pelo ventrículo esquerdo tendo como consequência um melhor fornecimento de oxigênio e nutrientes para a musculatura que esta sendo utilizada para a atividade física levando a melhora dos parâmetros de desempenho (lactato, limiar de lactato, FC, V200, $\left.\mathrm{PCO}_{2}\right)$.

No mesmo período se observa a diminuição da FC tanto de repouso como durante a prática de atividade física e diminuição do DC, PAS e PAM.

Os resultados sugerem que assim como observado em ratos e em atletas a diminuição da PAS se dá pela diminuição do DC por ação do cronotropismo negativo.

O treinamento em esteira com monitorização e utilizando-se intensidade relativa de treino a 60\% da FC máxima permitiu uma melhora nos índices de desempenho e no tempo de teste, possibilitando que atingissem um estágio a mais no protocolo com o mesmo tempo de treinamento dos animais treinados a campo. 


\section{REFERENCIAS}

ACSM'S. American College of Sports and Medicine. Guidelines for exercise testing and prescription. Philadelphia, Williams \& Wilkins, 2000.

ARROL, B.; BEAGLEHOLE, R. Does physical activity lower blood pressure: a critical review of the clinical trials. J. Clin. Epidemiol., v. 41, p. 439-47, 1992.

BARROS NETO, T. L.; CÉSAR, M. C.; TEBEXRENI, A. S. Fisiologia do exercício. In: GHORAYEB, N.; BARROS, T. L.(Ed.). O exercício: preparação fisiológica, avaliação médica, aspectos especiais e preventivos. São Paulo: Atheneu, 1999. p. 3-13.

BLOMQVIST, G.; SALTIN, B. Cardiovascular adaptations to physical training. Annu. Rer. Physical., v. 45, p. 169-89, 1983.

BRUM, P. C.; SILVA, G. J.; MOREIRA, E. D.; IDA, F.; NEGRÃO, C. E.; KRIEGER, E. M. Exercise training increases baroreceptor gain-sensitivity in normal and hypertensive rats. Hypertension, v. 36, p. 1018-22, 2000.

CECI, R.; HASSMÉN, P. Self-monitored exercise at three different RPE intensities in treadmill vs. field running, Med. Sci. Sports Exerc., v. 23, n. 6, p. 732738, 1991.

CROUTER, S.; FOSTER, C.; ESTEN, P.; BRICE, G.; PORCARI, J. P. Comparison of incremental treadmill exercise and free range running. Med. Sci. Sports Exerc., v. 33 n. 4, p. 644-647, 2001

EVANS, D. L. The cardiovascular system: anatomy, physiology and adaptations to exercise and training. In: HODGSON, D. R.; ROSE, R. J. The athletic horse: principles and practice of equine sports medicine. Philadelphia: W.B. Saunders Company, 1994. p. 129-142.

EVANS, D. L.; Cardiac response to exercise and training. In: MARC, C. Cardiology of the horse. Philadelphia: WB Sounder, 1999. p. 32-43.

EVANS, D. L. Exercise testing in the field. In: HINCHCLIFF, K. W.; KANEPS, A. J.; RAYMOND, J. G. Equine sports medicine and surgery. London: Saunders, 2004. p. $19-31$.

EVANS, D. L. Pruebas de ejercicio a campo. In: HINCHCLIFF, K. W.; KANEPS, A. J.; RAYMOND, J. G. Medicina y cirugia en los equinos de deporte: ciencias básicas 
y clínicas de los equinos de deporte. Buenos Aires: Inter-Médica Editorial, 2007. p. 2237.

FORJAZ, C. L. M.; MATSUDAIRA, Y.; BARRETO, F. R.; NUNES, N.; NEGRÃO C. E. Low intensity exercise reduces post-exercise rate pressure product in humans. Braz. J. Med. Biol. Res., v. 31, p. 1247-55, 1998.

GAVA, N. S.; VÉRAS-SILVA, A. S.; NEGRÃO, C. E.; KRIEGER, E. M. Lowintensity exercise training attenuates cardiac b-adrenergic tone during exercise in spontaneously hypertensive rats. Hypertension v. 26, pt. 2, p. 1129-1133, 1995.

GHORAYEB, N.; BATLOUNI, M.; PINTO, I. M. F.; DIOGUARDI, G. S. Hipertrofia ventricular esquerda do atleta. Resposta adaptativa fisiológica do coração. Arq. Bras. Cardiol., v. 85 n. 3, 2005. Disponível em:

$<$ http://www.scielo.br/scielo.php?script=sci_arttext\&pid=S0066782X2005001600008>. Acesso em: 12 out. 2013.

GUYTON, A. C.; HALL, J. E. Tratado de fisiologia médica. 9. ed. Rio de Janeiro: Guanbara-Kogan, 1998.

HINCHICLIFF, K. W.; GEOR, R. J. Fisiología integral del ejercicio In: HINCHCLIFF, K. W.; KANEPS, A. J.; RAYMOND, J. G. Medicina y cirugia en los equinos de deporte: ciencias básicas y clínicas de los equinos de deporte. Buenos Aires: InterMédica Editorial, 2007. p. 3-9.

KRIEGER, E. M.; BRUM, P. C.; NEGRÃO, C. E. Influence of exercise training on neurogenic control of blood pressure in spontaneously hypertensive rats. Hypertension v. 34, n.4, pt. 2 , p. $720-723,1999$.

MAGALHÃES, L. B. N. C. O significado clínico-epidemiológico da pressão diastólica baixa na elevação da pressão de pulso ou Importância da pressão de pulso no risco cardiovascular. Rev. Bras. Hipertens., v. 9, n. 3, p. 301-303, 2002.

MARCEAU, M.; KOUAMÈ, N.; LACOUCIÈRE, Y.; CLÈROUX, J. Effects of different training intensities on 24-hour blood pressure in hypertensive subjects.

Circulation, v. 88, p. 2803-2811, 1993.

MARQUES, M. S.; FERNANDES, W. R.; COELHO, C. S.; MIRANDOLA, R. Influência do exercício físico sobre os níveis de lactato e de cortisol sérico em cavalos de corida. Hora vet., v. 129, p. 29-32, 2002. 
MARON, B. J. Sudden cardiac death due to hypertrophic cardiomyopathy in young athletes. In: THOMPSON, P. D. (Ed.). Exercise and sports cardiology. New York: McGraw-Hill, 2001. p. 189-210.

MICHIMA, L. E.S. Avaliação das dimensões e índices cardíacos obtidos por ecocardiograma em eqüinos de enduro criados no estado de São Paulo. 2003. 94 p. Dissertação (Mestrado em Clinica Veterinária) - Faculdade de Medicina Veterinária e Zootecnia, Universidade de São Paulo, São Paulo, 2003.

NETO, T. L. B.; CÉSAR, M. C.; TEBEXRENI, A. S. Fisiologia do exercício. In: GHORAYEB, N.; NETO, T. L. B. O Exercicio: preparação fisiológica - avaliação médica - aspectos especiais e preventivos. São Paulo: Editora Atheneu, 1999. p. 3-13.

OLIVEIRA, E.M.; ALVES, G. B.; BRUM, P. C.; KRIEGER, J. E. Aspectos moleculares da hipertrofia dos músculos cardíaco e esquelético após o treino físico. In: NEGRÃO, C. E.; BARRETO, A. C. P. Cardiologia do exercício: do atleta ao cardiopata. 2. ed. Barueri, SP.: Manole, 2006.

PÁSSARO, L. C.; GODOY, M. Reabilitação cardiovascular na hipertensão arterial. Rer. Socesp, v. 6, p. 45-58, 1996.

POWERS, S. K.; HOWLEY, E. T. Metabolismo do exercício. In: POWERS, S. K.; HOWLEY, E. T. Fisiologia do exercício: teoria e aplicação ao condicionamento e ao desempenho. Barueri, SP: Manole, 2000. p. 45-62.

POOL, D. C.; ERICKON, H. H.; Heart and vessels: function during exercise and response to training. In: HINCHCLIFF, K. W.; KANEPS, A. J.; RAYMOND J. G.; Equine sports medicine and surgery. Philadelphia: Saunders, 2004. p. 711-723.

RASKOFF, W. J.; GOLDMAN, S.; COHN, K. The athletic heart: prevalence and physiological significance of left ventricular enlargement in distance runners. JAMA., v. 236, p. 158-62, 1976.

RONDON, M. U. P. B.; BRUM, P. C. Exercício físico como tratamento nãofarmacológico da hipertensão arterial. Rev. Bras. Hipertens., v. 10, p. 134-139, 2003.

SILVERTHORN, D. U. Fisiologia integrada: uma abordagem integrada. 2. ed. Barueri (SP): Manole, 2003.

ROSE, R. J. ; HODGSON, D. R.; Clinical exercise testing In: HODGSON, D. R.; ROSE, R. J. The athletic horse: principles and practice of equine sports medicine. Philadelphia, W.B. Saunders Company, 1994. p. 245- 58. 
SCHEUR, J.; PEHPARGKUL, S.; BHAN, A.; Experimental observations on the effects of physical training upon intrinsic physiology and biochemistry. Am. J. Cardiol., v. 33, p. 744-751, 1974.

SEALS, D. R.; REILING, M. J. Effect of regular exercise on 24 hours arterial pressure in older hypertensive humans. Hypertension, v. 18, p. 583-92, 1991.

SILVA, G. J. J.; BRUM, P. C.; NEGRÃO, C. E.; KRIEGER, E. M. Acute and chronic effects of exercise on baroreflexes in spontaneously hypertensive rats. Hypertension, $\mathrm{V}$. 30, pt. 2, p. 714-719, 1997.

SOCIEDADES BRASILEIRAS DE HIPERTENSÃO CARDIOLOGIA E NEFROLOGIA (SBHCN). In: CONSENSO BRASILEIRO DE HIPERTENSÃO ARTERIAL, 3., 1998, Campos do Jordão. Proceedings... 1998.

TIPTON, C. M. Exercise, training and hypertension: an update. In: HOLLOSZY, J. O. Exercise sports science review. Baltimore: Williams \& Wilkins, 1991.

URATA, H.; TANABE, Y.; KIYONAGA, A.; IKEDA, M.; TANAKA, H. Antihypertensive and volume-depleting effects of mild exercise on essential hypertension. Hypertension, v. 9, p. 245-52, 1987.

VÉRAS-SILVA, A. S.; MATTOS, K. C.; GAVA, N. S.; BRUM, P. C.; NEGRÃO, C. E.; KRIEGER, E. M. Lowintensity exercise training decreases cardiac output and hypertension in spontaneously hypertensive rats. Am J. Physiol.: heart. circ. physiol., v. 273, pt. 2, p. H2627-H2631, 1997.

WASSERMAN, K.; HANSEY, J. E.; SUE, D. Y.; CASABURI, R.; WHIPP, B. J. Fisiologia do exercício. In: WASSERMAN, K.; HANSEY, J. E.; SUE, D. Y.; CASABURI, R.; WHIPP, B. J. Prova de esforço: princípios e interpretação. Rio de Janeiro: Revinter, 2005. p.10-61.

WESTGARD, J. O.; LAHMEYER, B. L.; BIRNBAUM, M. L. Use of the Du Pont "automatic clinical analyzer" in direct determinations of Lactic Acid in plasma stabilized with sodium fluoride. Clin. Chem., n.18, p. 1334-1338, 1972. 